Board of Governors of the Federal Reserve System

International Finance Discussion Papers

Number 1294

July 2020

\title{
What is Certain about Uncertainty?
}

Cascaldi-Garcia, Danilo, Cisil Sarisoy, Juan M. Londono, John Rogers, Deepa Datta, Thiago Ferreira, Olesya Grishchenko, Mohammad R. Jahan-Parvar, Francesca Loria, Sai Ma, Marius Rodriguez, and Ilknur Zer

Please cite this paper as:
Cascaldi-Garcia, Danilo, Cisil Sarisoy, Juan M. Londono, John Rogers, Deepa Datta, Thiago
Ferreira, Olesya Grishchenko, Mohammad R. Jahan-Parvar, Francesca Loria, Sai Ma, Marius
Rodriguez, and Ilknur Zer (2020). "What is Certain about Uncertainty?," International
Finance Discussion Papers 1294. Washington: Board of Governors of the Federal Reserve
System, https://doi.org/10.17016/IFDP.2020.1294.

NOTE: International Finance Discussion Papers (IFDPs) are preliminary materials circulated to stimulate discussion and critical comment. The analysis and conclusions set forth are those of the authors and do not indicate concurrence by other members of the research staff or the Board of Governors. References in publications to the International Finance Discussion Papers Series (other than acknowledgement) should be cleared with the author(s) to protect the tentative character of these papers. Recent IFDPs are available on the Web at www.federalreserve.gov/pubs/ifdp/. This paper can be downloaded without charge from the Social Science Research Network electronic library at www.ssrn.com. 


\title{
What is Certain about Uncertainty?*
}

\author{
Danilo Cascaldi-Garcia Cisil Sarisoy Juan M. Londono \\ John Rogers Deepa Datta Thiago Ferreira \\ Olesya Grishchenko Mohammad R. Jahan-Parvar \\ Francesca Loria Sai Ma Marius Rodriguez Ilknur Zer
}

July 2020

\begin{abstract}
Researchers, policymakers, and market participants have become increasingly focused on the effects of uncertainty and risk on financial market and economic outcomes. This paper provides a comprehensive survey of the many existing measures of risk, uncertainty, and volatility. It summarizes what these measures capture, how they are constructed, and their effects, paying particular attention to large uncertainty spikes, such as those appearing concurrently with the outbreak of COVID-19. The measures are divided into three types: (1) news-based, surveybased, and econometric; (2) asset market based; and (3) Knightian uncertainty. While uncertainty has significant real and financial effects and spills over across countries, the size and persistence of these effects depend crucially on the source of uncertainty.
\end{abstract}

Keywords: global risk, uncertainty, volatility, crises, economic policy, monetary policy, geopolitical risk, trade policy, downside risk.

JEL codes: E6, G1, G15

*The authors are economists at the Board of Governors of the Federal Reserve System, Washington, D.C. 20551 U.S.A. This paper draws from its earlier version "Taxonomy of Global Risk, Uncertainty, and Volatility Measures," academic research internal and external to the Board of Governors of the Federal Reserve System, as well as from ongoing monitoring efforts in the divisions of International Finance, Monetary Affairs, and Research and Statistics. We thank Beth Anne Wilson, Rudi Bachmann, Nick Bloom, Steve Davis, Michiel de Pooter, and Jesús Fernández-Villaverde for their valuable comments and suggestions, Flora Haberkorn for her excellent research assistance, and the following authors from the previous version: Bo Sun, Daniel Beltran, Matteo Iacoviello, and Canlin Li. The views in this paper are solely the responsibility of the authors and should not be interpreted as reflecting the views of the Board of Governors of the Federal Reserve System or of any other person associated with the Federal Reserve System. Corresponding author: Cisil Sarisoy. E-mail: cisil.sarisoy@frb.gov. 


\section{Introduction}

The past decade has highlighted the challenges faced by households and businesses grappling with uncertainty about, among other issues, future economic growth, inflation, and economic policies, as well as the resurgence of global risks from trade and geopolitical tensions and from newer sources of risk, such as global climate and health events. Although it is generally accepted that these uncertainties and risks affect the way households and businesses make decisions, traditional economic models and empirical research have struggled not only to quantify different types of uncertainty but to understand the transmission channels and estimate the effects of such uncertainties. In this paper, we review a broad set of measures that have been proposed recently in the literature to monitor risk, uncertainty, and volatility related to global and country-specific macroeconomic and financial outcomes.

Risk, uncertainty, and volatility measures differ along multiple dimensions, including the method of calculation, the underlying outcome, the horizon at which they are calculated, and whether or not they can be observed/calculated in real time. Figure 1 shows some of the measures widely used in the literature and how they relate to key events. Macroeconomic, financial, and economic policy uncertainty spiked around the 2008 global financial crisis and again concurrently with COVID-19. However, only certain types of uncertainty increase around most other crises. For instance, financial uncertainty seems to be the only measure capturing the dot.com bubble of the late 90's and trade policy uncertainty only surges around the trade tensions between the United States and China from 2018 onward.

To highlight the main differences among risk, uncertainty, and volatility measures, we divide the measures in this survey into three sections. In Section 2, we explore newsbased, survey-based, and econometric measures of uncertainty. In that section, we review the literature on news-based measures of economic, monetary, and trade policy uncertainty; geopolitical risk; and survey-based and econometric measures of macroeconomic uncertainty. In Section 3, we review asset-market-based measures covering equity return volatility, interest rates, oil prices, and inflation. In Section 4, we explore measures 


\section{Figure 1 Alternative Measures of Uncertainty}

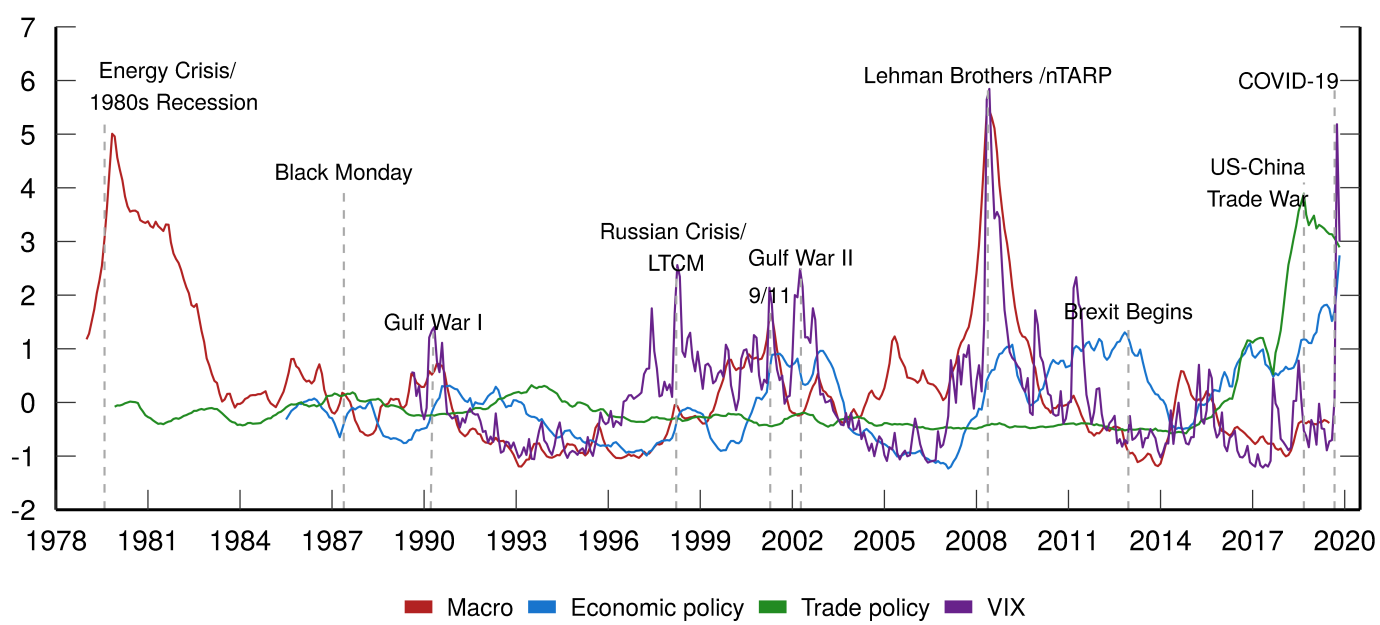

Notes: This figure plots macroeconomic uncertainty calculated by Ludvigson, Ma, and $\mathrm{Ng}$ (2019), economic policy uncertainty calculated by Baker, Bloom, and Davis (2016), trade policy uncertainty calculated by Caldara, Iacoviello, Molligo, Prestipino, and Raffo (2019a) and the CBOE SEP 500 VIX. All variables are normalized for the period Jan/85 to Dec/19. Time series for trade and economic policy uncertainty are 12-month moving averages.

of Knightian uncertainty, which disentangle risk from uncertainty. For each measure, we explain the underlying source of uncertainty captured and provide details on the construction methodology. To understand the transmission channels and effects of uncertainty, we plot the time series of each measure and review the evidence relating each measure to current and future economic and financial conditions. All measures are summarized in Table A.1.

Several broad lessons emerge from our review. First, although most of the literature still speaks in broad brush terms about "uncertainty" or "risk", carefully defining the nature of risk is quite important. This lesson becomes particularly relevant with the emergence of new sources of risk, such as trade and geopolitical tensions, and global health risks, such as the outbreak of the COVID-19 in 2020.

Another lesson is that measures are, by construction, limited to characterize particular types of uncertainty at particular horizons. For instance, although the VIX is a widely used measure of financial uncertainty, it is designed to capture near-term risk assessments related to the U.S. stock market. These limitations could explain the divergence between the low levels of VIX since the 2016 U.S. presidential election and the relatively high 
levels of economic policy uncertainties around the same period.

A third lesson is that uncertainty has first-order effects, and these effects differ depending on the type of uncertainty. Jurado, Ludvigson, and Ng (2015), Caldara, Scotti, and Zhong (2019b) and Cascaldi-Garcia and Galvao (2019), among others, find evidence that different types of uncertainty have sizeable effects on the business cycle. Bloom (2014) explores why uncertainty changes over time and Fernández-Villaverde and GuerrónQuintana (2020) review the mechanisms explaining how uncertainty shocks transmit to the business cycle. Ludvigson et al. (2019), Carriero, Clark, and Marcellino (2018) and Londono, Ma, and Wilson (2019) show that uncertainty has different effects depending on whether it is of macro or of financial origin. Rogers and $\mathrm{Xu}$ (2019) compare the forecasting performance of several uncertainty measures for real and financial outcomes and emphasize the differences between real-time measures of uncertainty and measures that are constructed ex-post. Altig, Barrero, Bloom, Davis, Meyer, and Parker (2020) present a recent example of the first-order effects of uncertainty during the COVID-19 outbreak. According to the Business Uncertainty Survey of the Atlanta FRB, Stanford University, and the University of Chicago, business uncertainty rapidly deteriorated in the first quarter of 2020, and even the very large negative effects on expected sales might be too optimistic.

A final important take-away from our review is that the transmission of risks is substantial, both across sectors and across countries. On the sector level, Bachmann and Bayer (2014) show how uncertainty shocks are important to understand cross-sectional dynamics. On the cross-country level, uncertainty about Brexit and the euro area business cycle increased uncertainty about the U.S. business cycle and weighed on U.S. growth and asset prices, as has uncertainty over COVID-19. Londono and Wilson (2018) and Londono (2013) find evidence of strong correlations in stock market volatility across countries, and Londono et al. (2019) find evidence of spillover effects of macroeconomic uncertainty across countries. All this suggests a sizeable global component to uncertainty. 


\section{News, Survey, and Econometric Indicators}

\subsection{Economic Policy Uncertainty}

One of the most widely used indicators of uncertainty is the economic policy uncertainty (EPU) index developed by Baker et al. (2016). For the United States, the EPU index is constructed from three components: The first quantifies policy-related uncertainty by searching the archives of 10 major U.S. newspapers for articles that contain terms related to EPU. The second component gauges uncertainty regarding the federal tax code, by counting the number of federal tax code provisions set to expire in future years. The third component measures disagreement among economic forecasters as an indicator of uncertainty. EPU indexes are constructed for almost 20 other countries or country aggregates, based on only the first component, newspaper articles regarding policy uncertainty. ${ }^{1}$

For the United States, the news component of the EPU index is constructed by counting the number of articles in 10 leading U.S. newspapers that contain the words "economic" or "economy;" "uncertain" or "uncertainty;" and one or more of "Congress," "deficit," "Federal Reserve," "legislation," "regulation," or "White House." Analogous searches are performed for the other countries.

An obvious difficulty with these raw counts is that the overall volume of articles varies across newspapers and time. Thus, Baker et al. (2016) scale the raw monthly counts for each newspaper by the total number of articles in that newspaper and in that month to produce a monthly EPU series for each newspaper. They scale each newspaper-level series to ensure that each has a unit standard deviation for the 1985 to 2009 period, and then take the average of these 10 monthly series. Finally, they normalize the 10-paper average series to a mean of 100 from 1985 to 2009. The series for all countries are standardized similarly. The indexes are updated regularly on the policyuncertainty.com website.

The first panel in figure 2 shows the monthly time series for the U.S. EPU index constructed based on newspaper coverage since 1985. The index shows clear spikes around

\footnotetext{
${ }^{1} \mathrm{EPU}$ indexes are available for the following countries and country aggregates: the global aggregate, Australia, Brazil, Canada, Chile, China, Colombia, Europe, France, Germany, India, Ireland, Italy, Japan, Korea, Mexico, the Netherlands, Russia, Singapore, Spain, Sweden, and the United Kingdom.
} 
events and developments that may affect uncertainty, such as the Gulf wars, presidential elections, the terrorist attacks on September 11, 2001, the stimulus debate in early 2008, the Lehman Brothers bankruptcy and the subsequent Troubled Asset Relief Program (TARP), legislation in late 2008, the summer 2011 debt ceiling dispute, and the battle over the "fiscal cliff" in late 2012. The EPU indexes for the euro area, United Kingdom, China, and India as well as the global EPU index are also exhibited in figure 2.

Using the Access World News database of over 2,000 U.S. newspapers, Baker et al. (2016) also developed subindexes for policy categories by counting the number of articles that not only meet the criteria for inclusion in the EPU index but also contain terms relevant to the specific category in question. For example, they constructed a health care EPU index by searching for articles that discuss rising EPU as well as terms such as "health care," "Medicaid," "Medicare," "health insurance," "affordable care act," and "medical insurance reform." Similarly, they created a trade policy EPU index by searching for words including "import tariffs," "world trade organization," and "trade policy" in addition to their baseline trio of search terms. ${ }^{2}$

Researchers have used EPU indexes to show that policy uncertainty can affect the economy and asset prices. For example, using firm-level data, researchers have shown that policy uncertainty seems to reduce investment and employment, especially in firms that are more dependent on government spending (Gulen and Ion, 2016; Baker et al., 2016). At the macro level, researchers have shown that higher policy uncertainty can lead to lower investment, output, and employment (Bachmann, Elstner, and Sims, 2013; Baker et al., 2016) as well as reduced monetary policy effectiveness (Aastveit, Natvik, and Sola, 2013). Financial research has also shown that policy uncertainty can increase stock volatility, stock co-movement, and equity premiums (Pástor and Veronesi, 2012, Pástor and Veronesi, 2013; Brogaard and Detzel, 2015) as well as default risk and credit spreads (Manzo, 2013) and financial intermediation costs (Francis, Hasan, and Zhu, 2014). Rogers

\footnotetext{
${ }^{2}$ Other category-specific indexes for the United States include monetary policy, taxes, fiscal policy and government spending, national security, entitlement programs, regulation, financial regulation, and sovereign debt and currency crises. Arbatli, Davis, Ito, Miake, and Saito (2017) developed categoryspecific EPU indexes for Japan covering monetary policy, fiscal policy, trade policy and exchange rate policy. Similarly, Hardouvelis, Karalas, Karanastasis, and Samartzis (2018) created category-specific EPU indices for Greece.
} 
Figure 2 Economic Policy Uncertainty (EPU)

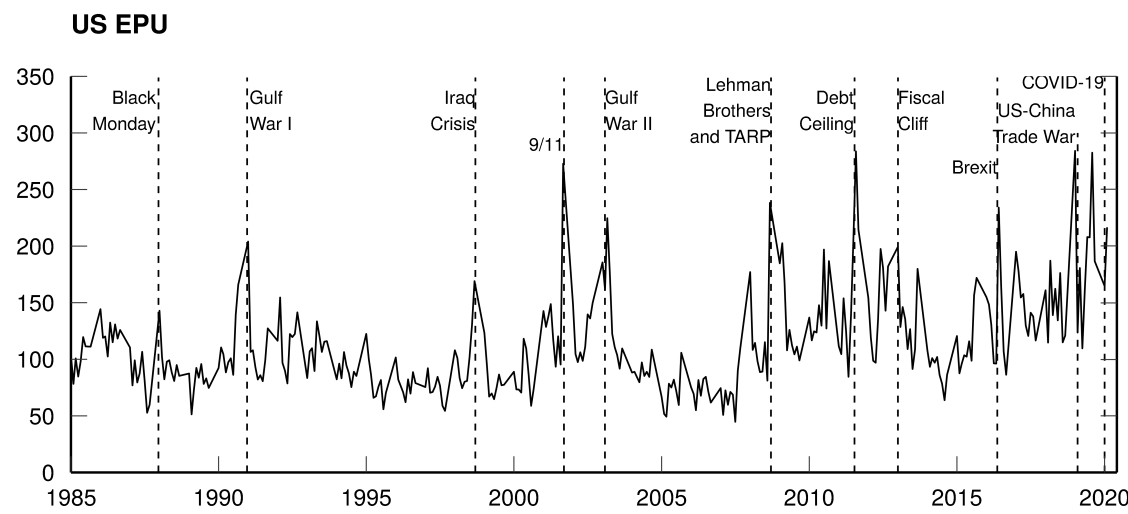

\section{EU EPU}

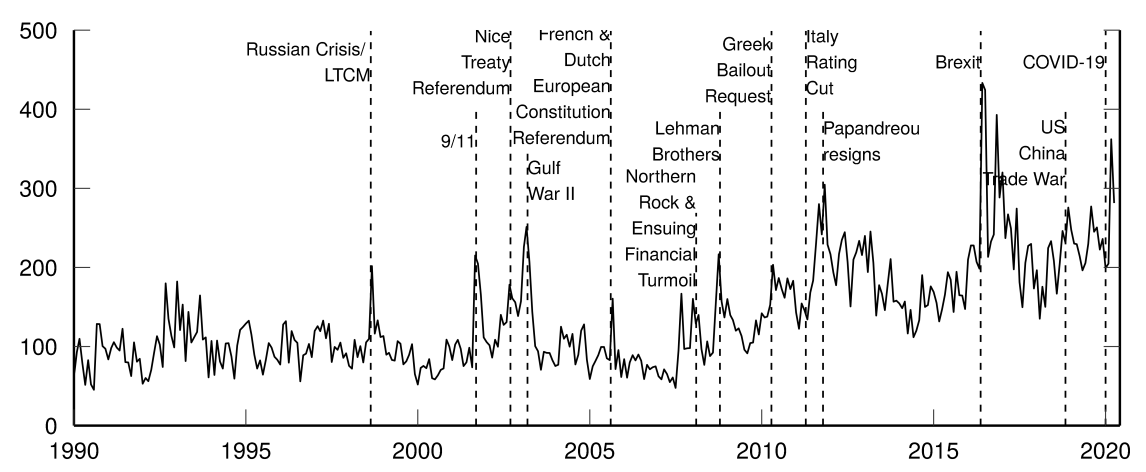

UK EPU

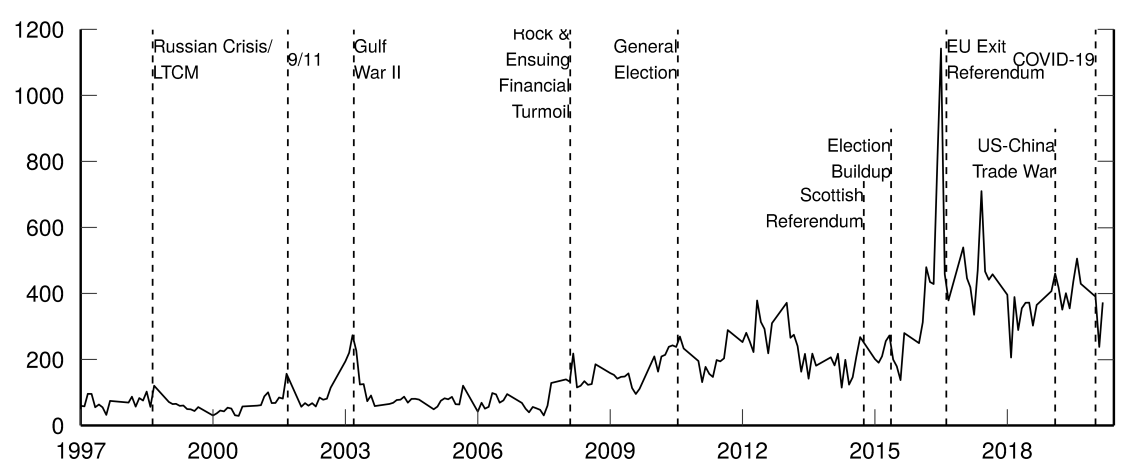

Notes: Panels 1 through 6 depict the EPU index for the following areas: the United States, Europe, the United Kingdom, China, India, and the world, respectively. Each panel shows some of the significant historical events related to EPU increases.

Source: policyuncertainty.com. 
Figure 2 Economic Policy Uncertainty (EPU), continued

China EPU

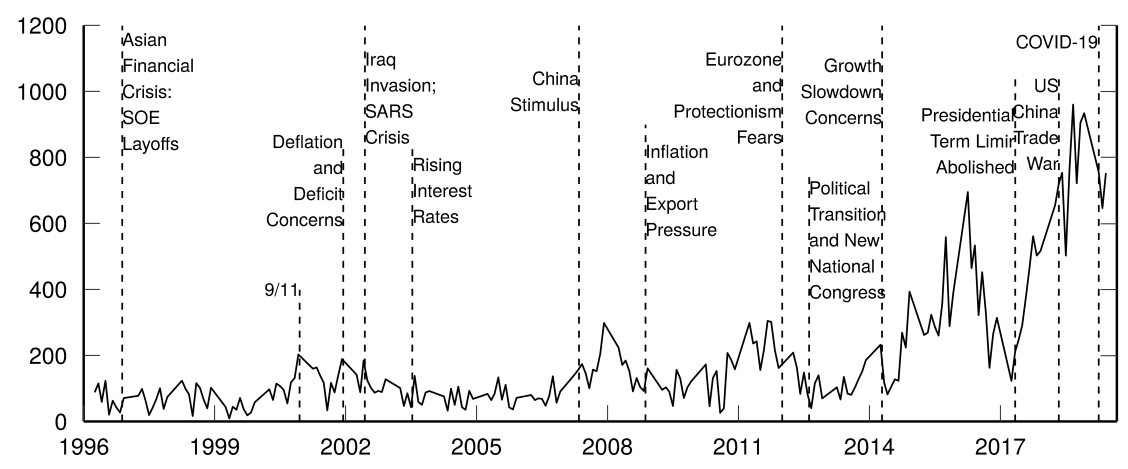

India EPU

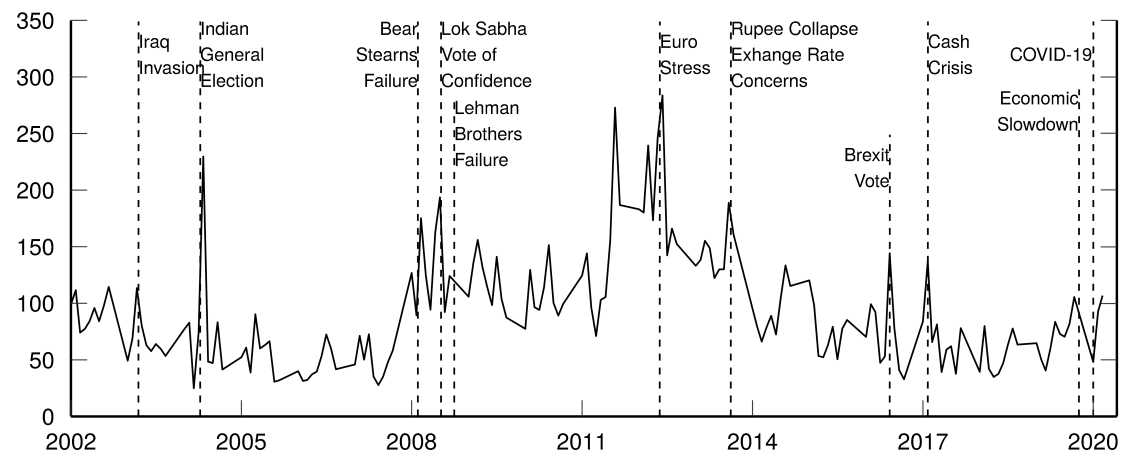

Global EPU

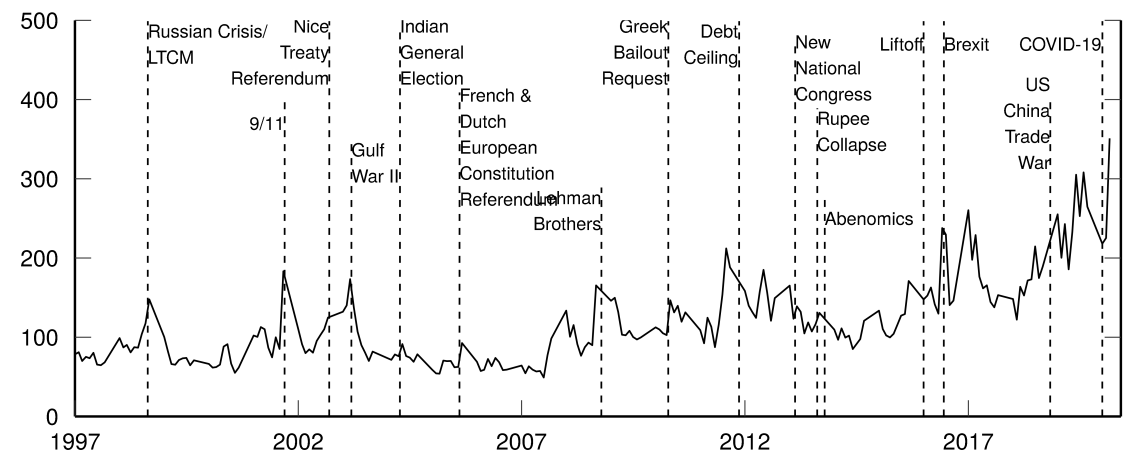


and $\mathrm{Xu}(2019)$ study the forecasting performance of EPU over real and financial outcome variables, along with other measures of uncertainty.

There are two recent streams in the literature on news-based uncertainty that seem highly promising. The first stream links news-based and asset market indicators. Baker, Bloom, Davis, and Kost (2019a) rely on equity market volatility-related articles to construct a newspaper measure that closely tracks the VIX, allowing to parse the forces driving stock market volatility. Baker, Bloom, Davis, and Sammon (2019b) do a narrative identification of the triggers of large daily stock market movements in several countries, by analysing newspaper articles the day after of these jumps. Based on these two methodologies, Baker, Bloom, Davis, Kost, Sammon, and Viratyosin (2020) evaluate the impact of COVID-19 on the U.S. stock market performance. The second stream incorporates machine learning techniques to summarize news coverage into aggregate uncertainty measures. Larsen (2017) uses unsupervised methods to classify news, constructing several uncertainty components for Norway. Kalamara, Turrell, Redl, Kapetanios, and Kapadia (2020) show that U.K. newspaper indicators constructed with machine learning algorithms contain signals of economic sentiment and uncertainty, which can improve economic forecasts.

\subsection{Monetary Policy Uncertainty}

To capture uncertainty related to central bank policies, Husted, Rogers, and Sun (2020) apply the text-based methodology of Baker et al. (2016) to construct an index of monetary policy uncertainty (MPU) by tracking the frequency of newspaper articles related to MPU. For the United States, the MPU index measures the perceived uncertainty surrounding the Federal Reserve Board's policy decisions and their consequences.

Using ProQuest Newsstand and historical archives as a primary source, Husted et al. (2020) construct their index by searching for keywords related to monetary policy from the following three sets: (1) "uncertainty" or "uncertain"; (2) "monetary policy(ies)," "interest rate(s)," "federal fund(s) rate," or "fed fund(s) rate"; and (3) "Federal Reserve," "the Fed," "Federal Open Market Committee," or "FOMC." The index is normalized 
following the methodology of Baker et al. (2016). The narrow word search used for this MPU index gives rise to an index that isolates MPU, relative to the broader word search used for the Baker et al. (2016) EPU index that results in a more-general measure of uncertainty. Husted, Rogers, and Sun (2016) also show that U.S. output and inflation fall and credit costs become tighter following shocks that increase the MPU index.

The first panel in Figure 3 shows the time series for the U.S. MPU index since $1985 .^{3}$ Notably, the MPU index spikes during the taper tantrum in 2013 and right before liftoff of the Fed Funds rate in 2015. The index declines in the immediate aftermath of the FOMC's 100 basis point cut in the Fed Funds rate and quantitative easing measures to support market functioning in the extraordinary meeting of 15 March 2020. The timing of these spikes relative to policy decisions shows the ability of the index to capture the ex post and ex ante uncertainty of different Federal Open Market Committee decisions. Major macroeconomic events with the capacity to affect monetary policy, like the invasion of Iraq in 2003, also move the index. The MPU indexes for the euro area, the United Kingdom, Japan, and Canada are also provided in Figure 3.

\subsection{Trade Policy Uncertainty}

Caldara et al. (2019a) develop two measures of uncertainty related to trade policies (TPU). The first is based on searches of newspaper articles that discuss trade policy uncertainty. To calculate this index, Caldara et al. (2019a) run text searches of the electronic archives of seven U.S. newspapers and select articles that discuss TPU by searching for terms such as "risk," "threat," and "uncertainty," that appear in the same article as a term related to trade policy, such as "tariff," "import duty," "import barrier," and "anti-dumping." The TPU index is the monthly share of articles discussing trade policy uncertainty rescaled to equal 100 for an article share of 1 percent.

The second measure is constructed by aggregating firm-level TPU obtained from automated text searches of the quarterly earnings call transcripts of U.S.-listed corporations. Figure 4 shows that both measures of TPU exhibit similar patterns and reached initial

\footnotetext{
${ }^{3}$ For regular updates of the series, visit https://sites.google.com/site/lucasfhusted.
} 
Figure 3 Monetary Policy Uncertainty (MPU)

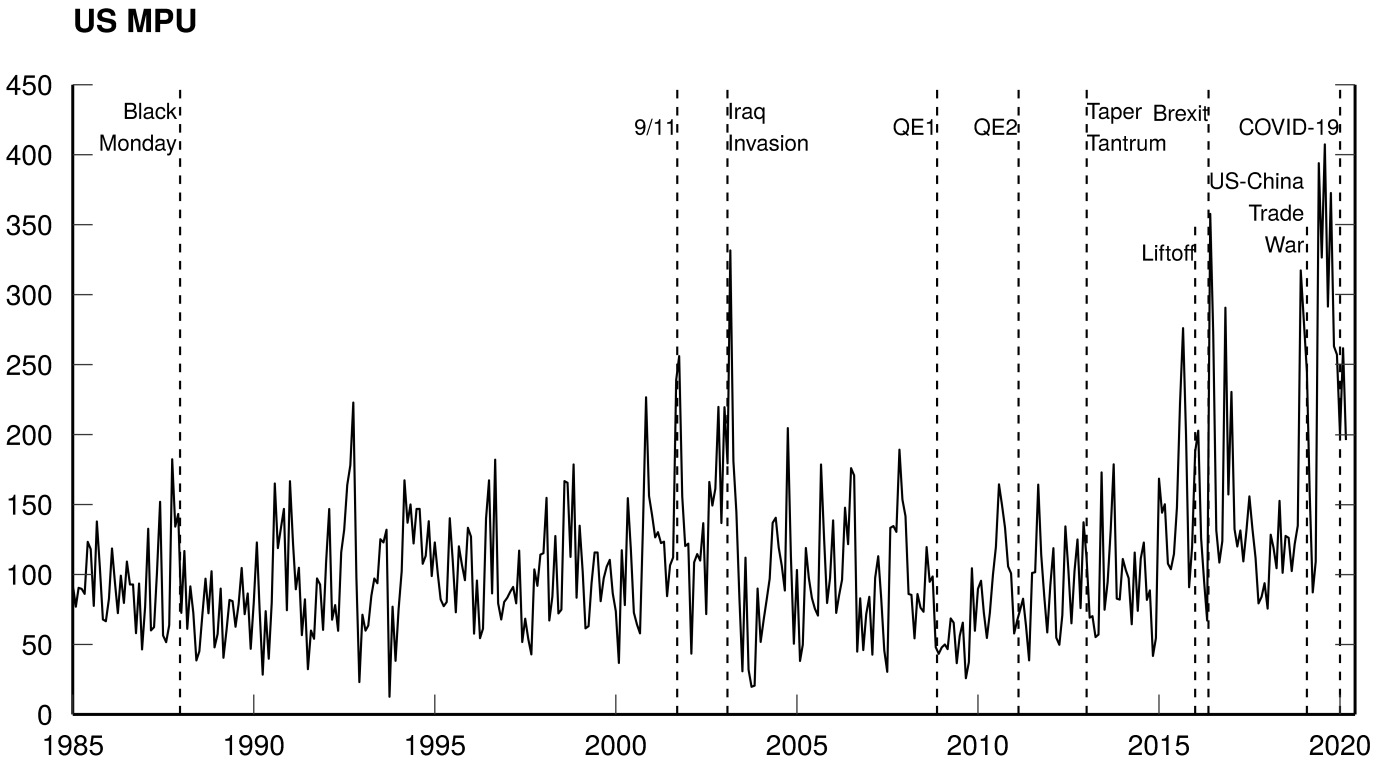

\section{EU MPU}
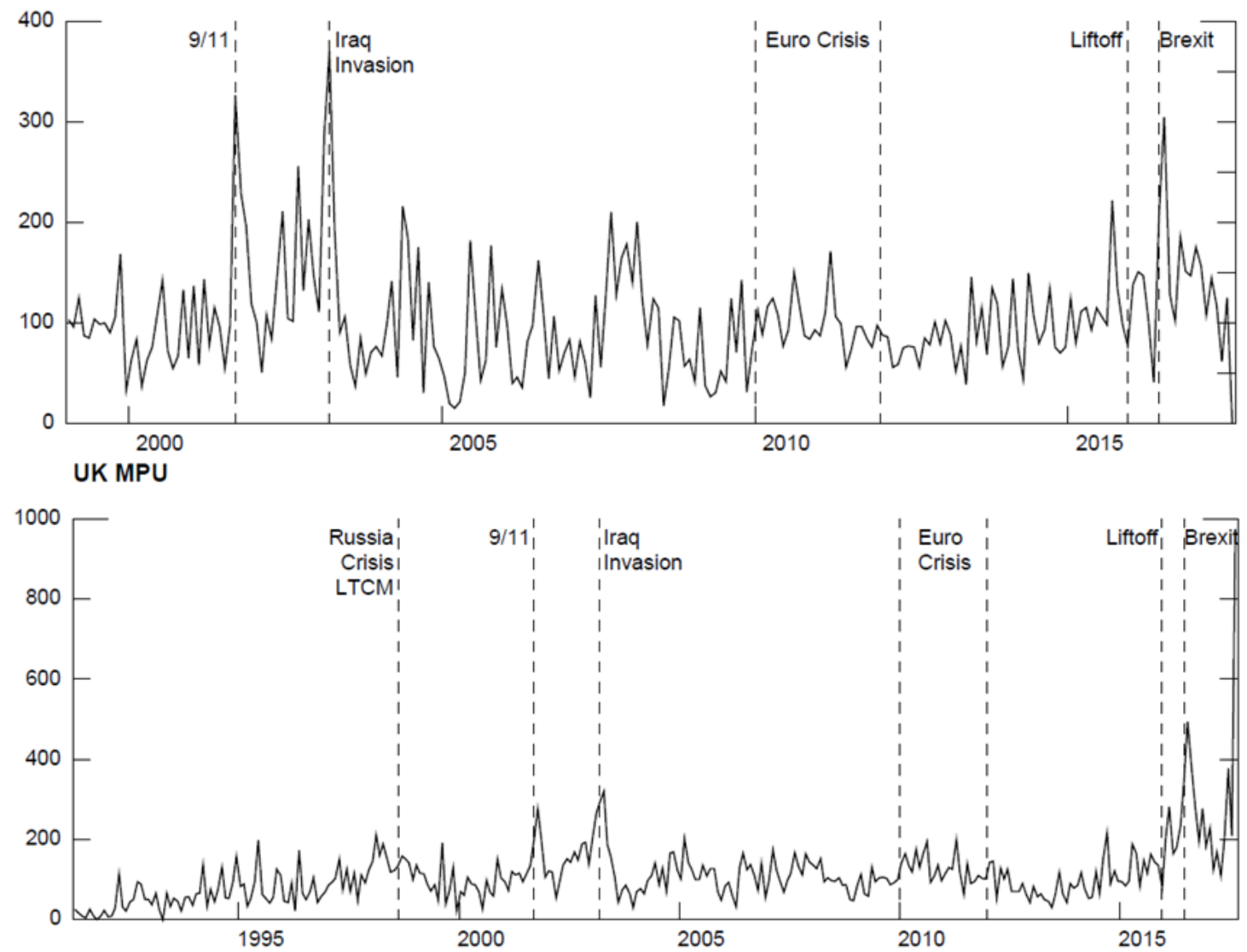

Notes: Panels 1 through 5 depict the MPU index for the following respective areas: the United States, the European Union, the United Kingdom, Japan, and Canada. Each panel shows some of the significant historical events related to MPU increases.

Source: Husted et al. (2016). 
Figure 3 Monetary Policy Uncertainty (MPU), continued

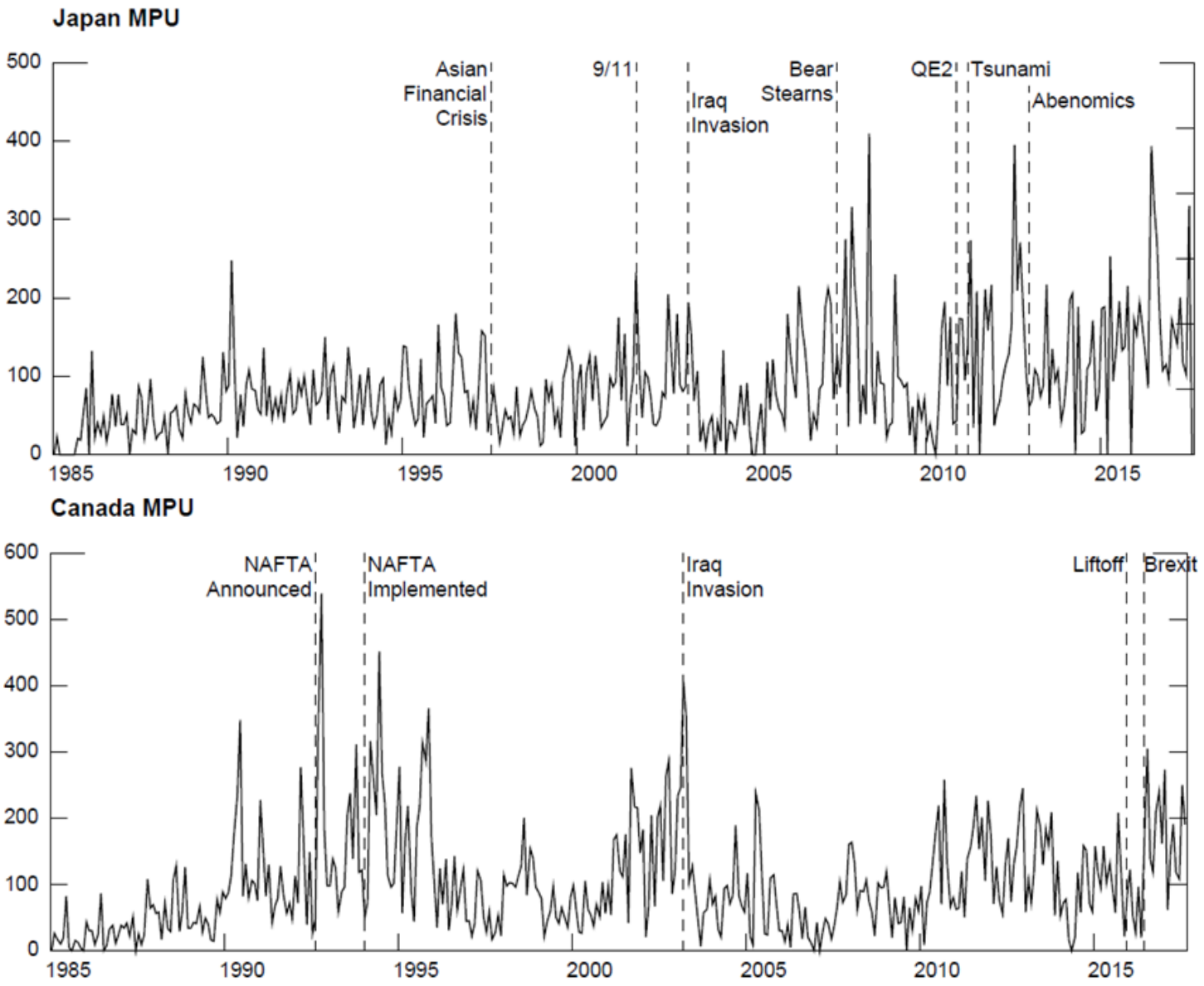


highs in the first half of 2018 and, after subsiding, reached a new peak in the first half of 2019. Using bivariate VAR models, Caldara et al. (2019a) further find that increases in both measures of TPU reduce business investment, which declines between 1 to 2 percent for about a year. This effect is stronger using the news-based measure.

\section{Figure 4 Trade Policy Uncertainty (TPU)}

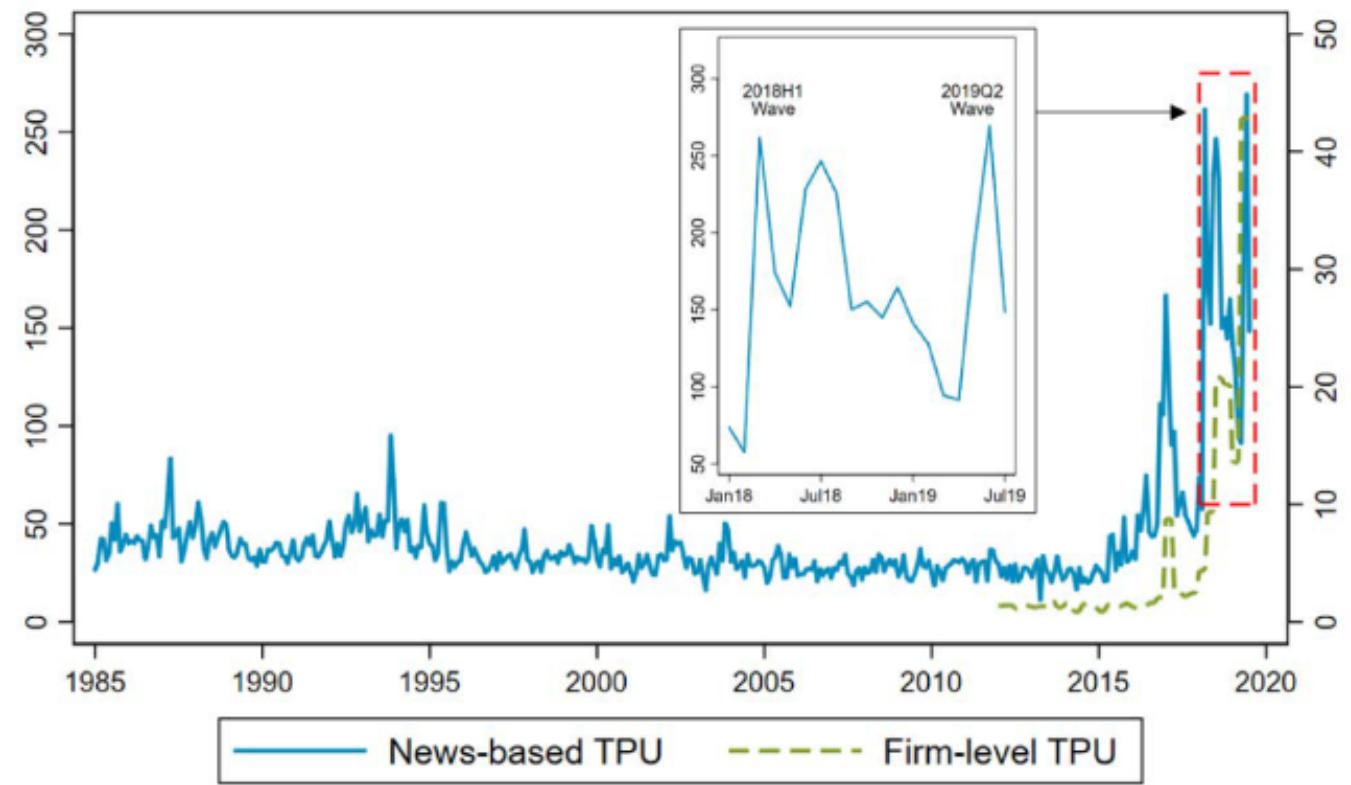

Notes: This figure depicts the News-based and Firm-level TPU. It highlights two waves of high TPU in 2018 and 2019.

Source: Caldara et al. (2019a).

\subsection{World Uncertainty Index}

Ahir, Bloom, and Furceri (2018) construct a panel of uncertainty measures for 143 developed and developing countries based on a word count of "uncertainty" and its variants from Economist Intelligence Unit country reports. These reports cover specific topics related to political and economic developments and have a standardized structure across countries. More importantly, because these reports are all produced by the same source, the possibility of ideological bias between countries is mitigated. The World Uncertainty Index (WUI) is a GDP-weighted average of country-level uncertainty indexes, and is calculated using quarterly data spanning from 1996. The index is designed to capture global uncertainty co-movement, as heightened local uncertainty may spread across bor- 
ders through economic and financial linkages.

Figure 5 World Uncertainty Index (WUI)

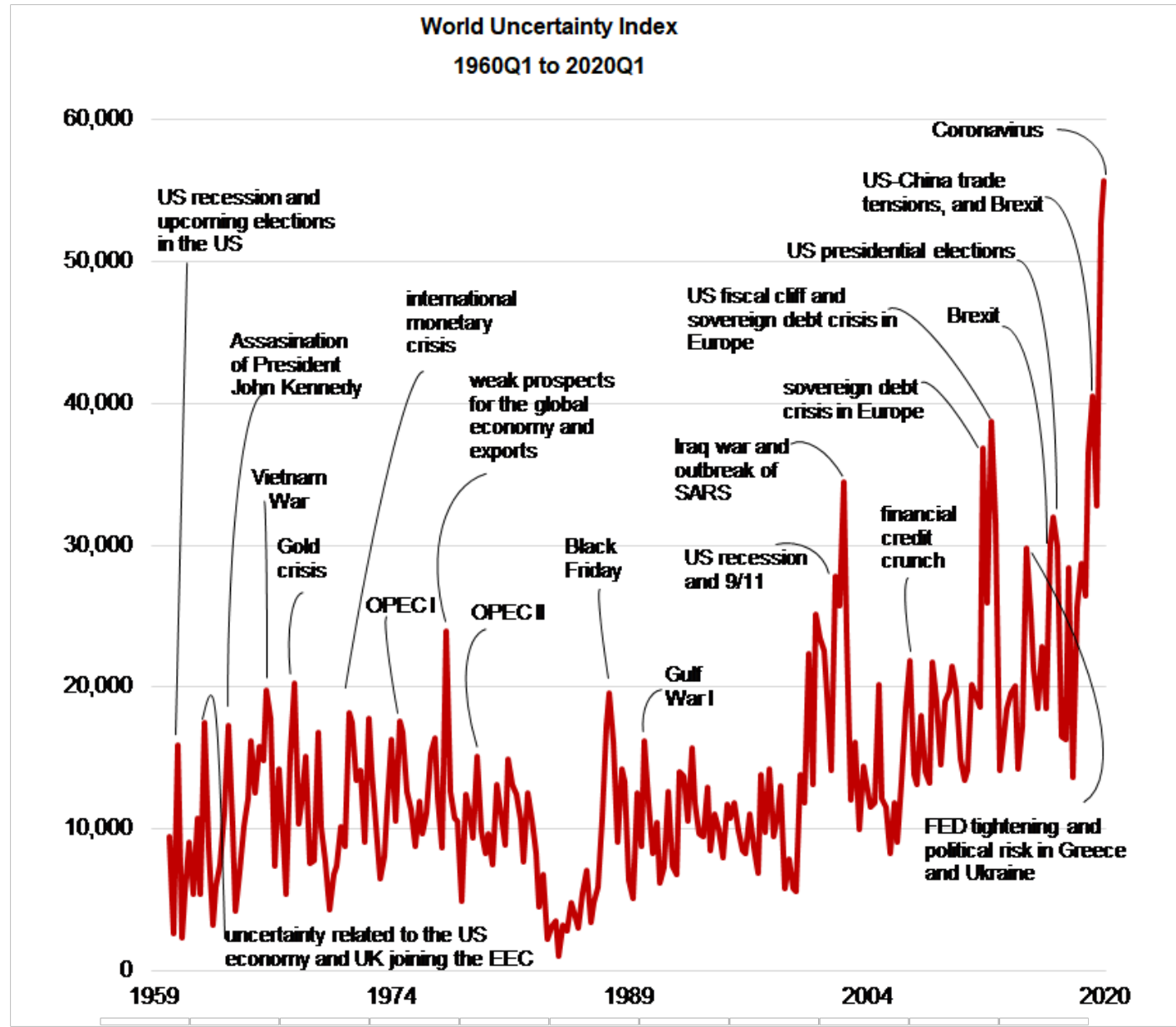

Notes: This figure shows the World Uncertainty Index calculated by Ahir et al. (2018). The index is normalized by the total number of words and aggregated as a GDP weighted average. The figure shows some of the main significant historical events that triggered global uncertainty.

Source: policyuncertainty.com.

Figure 5 shows the WUI index time series. As seen in the figure, global uncertainty seems to have increased substantially in recent years. Uncertainty spiked in high-profile episodes such as the 9/11 attacks, the Iraq war, the sovereign debt crisis in Europe, Brexit, and several U.S trade policy developments. Interestingly, the dynamics of the index around the global financial crisis is more muted. At the country level, Ahir et al. (2018) discuss several stylized facts of uncertainty. In particular, (i) uncertainty is, on average, higher in developing economies, (ii) uncertainty is more synchronized among advanced economies, and (iii) there is significant heterogeneity across countries driven by countryspecific events. The U.K., for example, displays a notable spike in uncertainty related 
to the Brexit referendum that is not necessarily reflected in other countries' uncertainty. A quantitative analysis of a panel of 46 countries shows that global uncertainty has real effects. In particular, a one-standard deviation increase in the WUI index generates a statistically significant decrease in output, which peaks at around 1.4 percent 10 quarters after the shock.

\subsection{Geopolitical Risk}

Caldara and Iacoviello (2018) construct an index that measures geopolitical risk (GPR) based on a tally of newspaper stories that contain a fairly broad set of terms related to geopolitical tensions. The GPR index measures the risk associated with geopolitical events, such as wars, political tensions, and terrorist acts, that affect the normal course of domestic politics and international relations. Caldara and Iacoviello (2018) also propose two indexes that distinguish between geopolitical acts and geopolitical threats. Countryspecific GPR indexes are also available for the following countries: the United States, Argentina, Brazil, China, Colombia, India, Indonesia, Israel, Korea, Malaysia, Mexico, the Philippines, Russia, Saudi Arabia, South Africa, Thailand, Turkey, and Venezuela.

The GPR index is constructed by counting the occurrence of words related to geopolitical tensions in leading international newspapers. In particular, the GPR index reflects automated text searches in the electronic archives of 11 national and international newspapers for articles that contain several keywords, including "risk of war," "terrorist threats," and "geopolitical tensions."

Figure 6 shows the GPR index since 1990. The GPR index spikes during the Gulf War, the 2003 invasion of Iraq, and on 9/11, as well as in periods of increased bilateral tensions. Moreover, the index has remained heightened since the beginning of 2017, a sign of mounting tensions between the new U.S. administration and their global partners as well as growing instability in the Levant. Caldara and Iacoviello (2018) show that increased geopolitical risk leads to declines in real activity and is associated with increases in the VIX, lower oil prices, and higher corporate credit spreads. 


\section{Figure 6 Geopolitical Risk Index (GPR)}

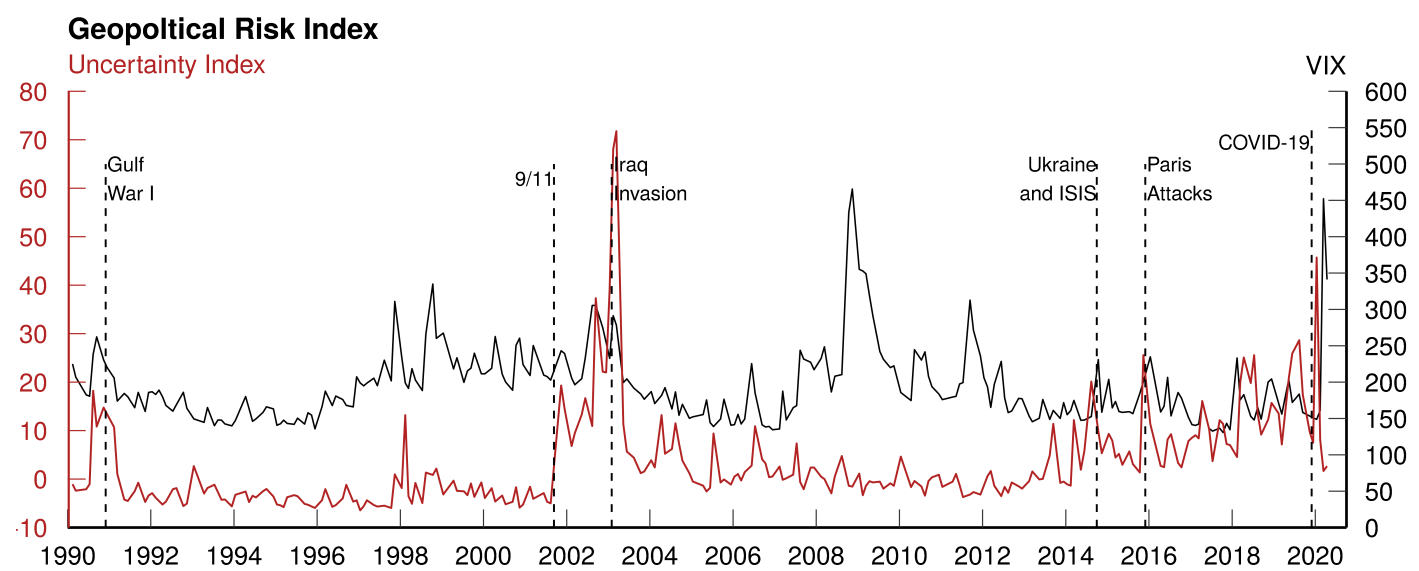

Notes: This figure depicts the GPR index (the black line) plotted against the VIX (the red dashed line). It shows some of the significant historical events that could have increased GPR. Source: Caldara and Iacoviello (2018).

\subsection{Survey-Based Macroeconomic and Inflation Uncertainty}

Economic surveys provide useful information about survey participants' probabilistic assessments of future economic outcomes. These surveys typically ask each individual respondent about point predictions (that is, mean or mode expectation) of future events, such as a inflation rate or a GDP growth for the next year. Aggregating these individual responses allows for the estimation of a measure of the dispersion across respondents regarding the point prediction. However, this aggregation across individuals does not provide meaningful information regarding the uncertainty that each individual may attach to his or her point forecast. Therefore, some surveys also ask individual respondents about the uncertainty surrounding their point forecasts. Such surveys allow for the estimation of both the dispersion across individuals and the uncertainty of each individual regarding his or her own forecast. ${ }^{4}$ For example, the Survey of Professional Forecasters, a quarterly publication, asks respondents to provide both point estimates and probabilistic assessments of the outlook for U.S. inflation and 10-year interest rates, from which aggregate proxies for both dispersion and uncertainty can be constructed.

\footnotetext{
${ }^{4}$ Both the dispersion across individuals and the uncertainty that each individual perceives are relevant for studying market surprises and the effects of realized future events. For a detailed discussion of this issue, see the speech by the Federal Reserve Board's Vice Chairman Stanley Fischer on April 17, 2017, "Monetary Policy Expectations and Surprises," delivered at the Columbia University School of International and Public Affairs, https://www.federalreserve.gov/newsevents/speech/fischer20170417a.htm.
} 
Scotti (2016) uses macroeconomic news and survey forecasts to construct an ex post realized measure of uncertainty about the state of the economy. The macroeconomic uncertainty index proposed by Scotti (2016) is calculated based on weighted averages of the square of economic data surprises, which are measured by examining deviations of recent economic data releases from consensus expectations from Bloomberg forecasts an hour before the data release. A dynamic factor model is employed to estimate monthly business condition indexes and compute the weights representing the contribution of the economic indicators to these business condition indexes. Those weights are then used to average the squared surprises to construct the uncertainty index. Figure 7 shows Scotti's uncertainty index since 1990. The index closely follows the VIX leading up to and after the global financial crisis of 2008 and Brexit. Scotti (2016) shows that a higher uncertainty index is associated with lower real activity.

Other papers that study survey-based macroeconomic uncertainty and ex-post forecast errors include Giordani and Söderlind (2003), Bachmann et al. (2013), Arslan, Atabek, Hulagu, and Şahinöz (2015), Rossi and Sekhposyan (2015), Masayuki (2016), Binder (2017), Bachmann, Carstensen, Lautenbacher, and Schneider (2018), Jo and Sekkel (2019), and Dahlhaus and Sekhposyan (2020). Bachmann, Elstner, and Hristov (2017) show how surveys that combine expectation with outcome data can be used to refine uncertainty measurement.

Grishchenko, Mouabbi, and Renne (2019) use a range of inflation forecasts in the surveys of professional forecasters to construct an inflation uncertainty measure. To that end, they propose a term structure model with stochastic volatility estimated using information from various surveys of professional forecasters and define inflation uncertainty as the fitted second moment of the probability distribution of various inflation outcomes. Inflation uncertainty for different horizons is available in closed form thanks to the affine properties of the model.

Figure 8 displays the time series and the term structure of inflation uncertainty - modelimplied conditional variance of inflation forecasts for the United States and the euro area. The top charts of the figure show that 5-year inflation uncertainty spiked around the 2008 


\section{Figure 7 Scotti's Uncertainty Index}

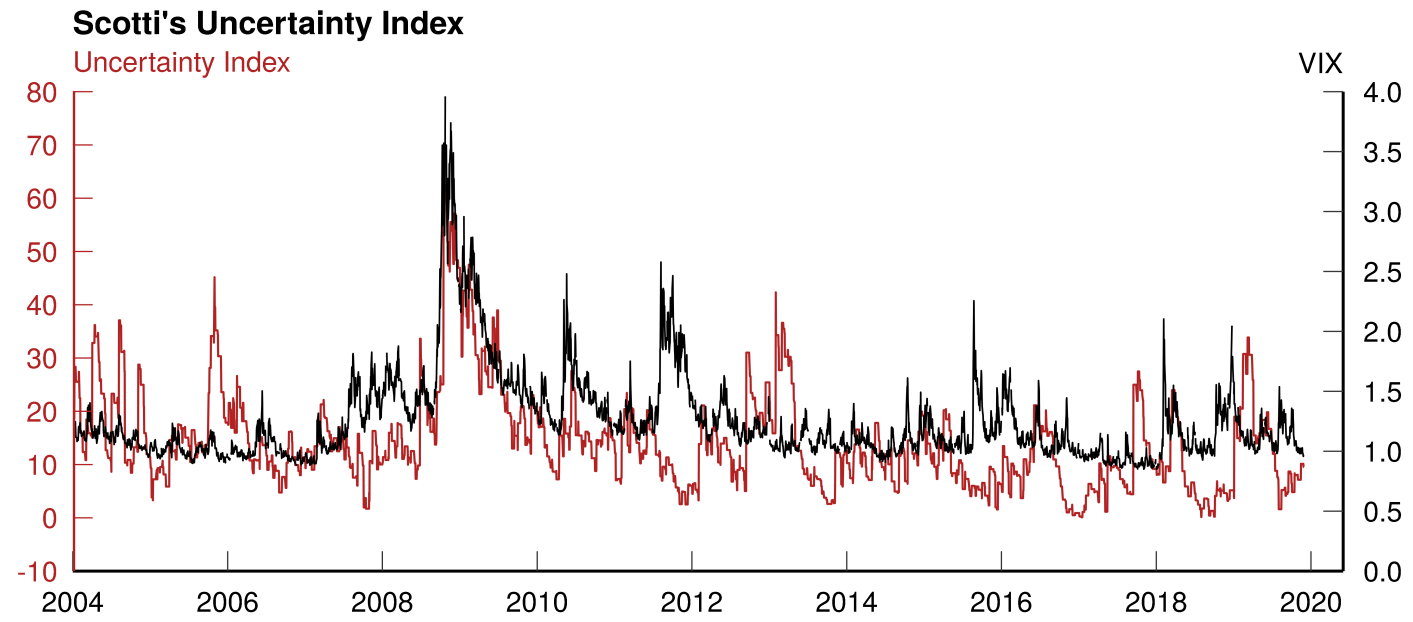

Notes: This figure depicts Scotti's uncertainty index (the black line) plotted against the VIX (the red dashed line). It shows some of the significant historical events that could have increased economic uncertainty.

Source: Scotti (2016).

global financial crisis, with a more pronounced spike for the United States. Since then, inflation uncertainty in the United States gradually declined to pre-crisis levels, but surged again following the COVID-19 pandemic outbreak. Inflation uncertainty in the euro area remained high following a dramatic increase during the 2008 global financial crisis and climbed up further during the COVID-19 period, in line with the increase in inflation uncertainty in the United States. The bottom charts of the figure show the term structures of inflation uncertainties up to 10 years for two dates: January 2008 and April 2020. The term structure of inflation uncertainty in the United States became downward-sloping lately relative to the periods of upward-sloping or flat term structure of inflation uncertainty a decade earlier as forecasters appeared more uncertain about near-term inflation outlook than inflation further out. Such a difference in uncertainty about near-term vs long-term is likely driven by the Federal Reserve explicit statement of its longer-term inflation target in January 2012. The term structure of inflation uncertainty in the euro area was flat on both selected months. ${ }^{5}$

\footnotetext{
${ }^{5}$ Regular updates of inflation uncertainty measures of Grishchenko et al. (2019) can be found at https://jrenne.shinyapps.io/ShinyGMR/.
} 
Figure 8 Inflation Uncertainty in the United States and the Euro Area
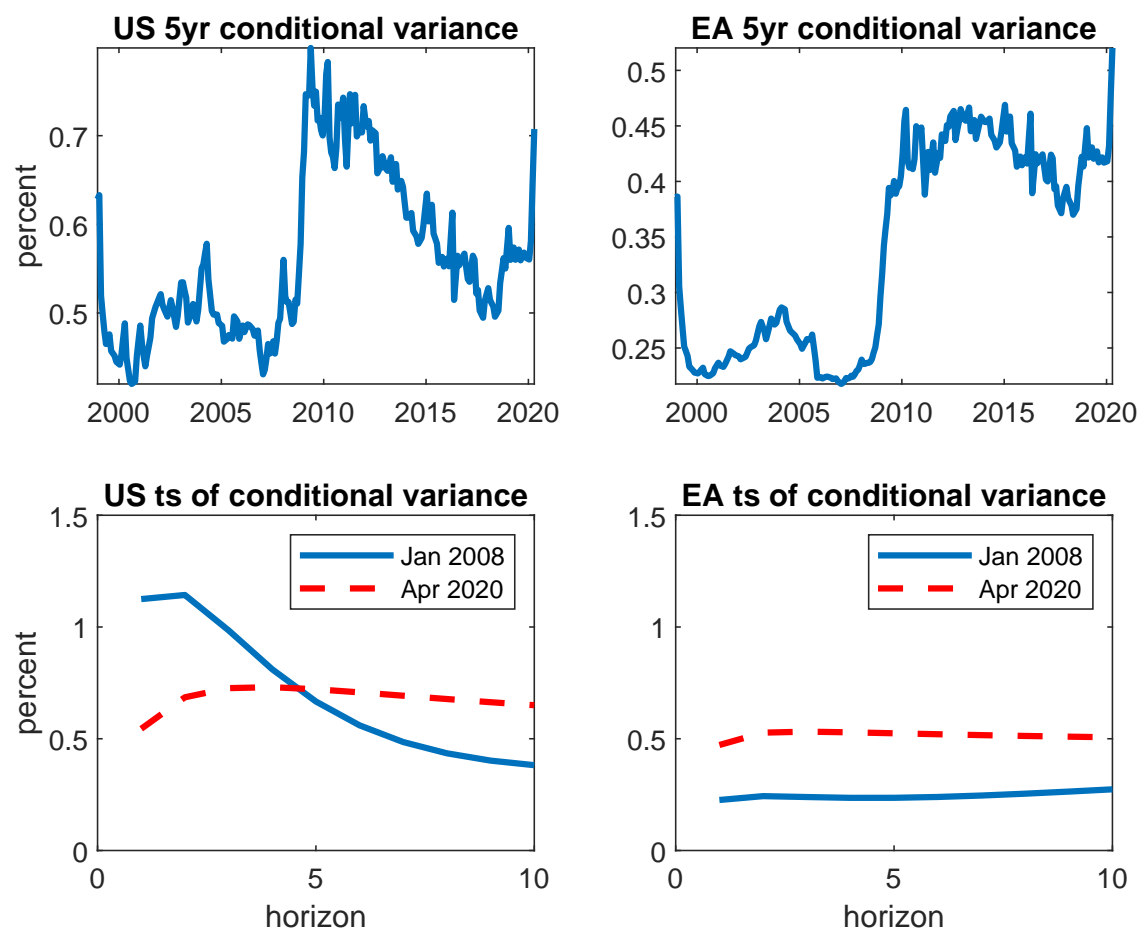

Notes: This figure displays the time series of the conditional variance of the annualized expected 5-year inflation rate (top charts) and the term structure of model-implied conditional variance (bottom charts) up to a horizon of 10 years. Figures to the left show uncertainty in the United States and those to the right for the euro area. In the bottom charts, the blue lines show term structures for January 2008 and the red dashed lines show the term structure for April 2020.

Source: Grishchenko et al. (2019) and jrenne.shinyapps.io/ShinyGMR/.

\subsection{Econometric Measures of Macroeconomic Uncertainty}

Jurado et al. (2015) construct an index of macroeconomic uncertainty as an aggregate of the volatility of statistical forecasts for hundreds of economic series. ${ }^{6}$ This measure is an objective econometric-based uncertainty, rather than sentiment-based as reflected in news or in analysts' forecasts. To calculate their measure, Jurado et al. (2015) use a monthly dataset comprising information from hundreds of macroeconomic indicators, and construct direct econometric estimates of uncertainty for each indicator. Formally, Jurado et al. (2015) define the $h$-period ahead uncertainty in a single variable as the conditional volatility of the unforecastable component of the future value of the variable;

\footnotetext{
${ }^{6}$ Jurado et al. (2015) use a similar methodology to construct a measure of financial uncertainty. The financial uncertainty measure is explored further in Ludvigson et al. (2019).
} 
Figure 9 JLN Macroeconomic Uncertainty Index

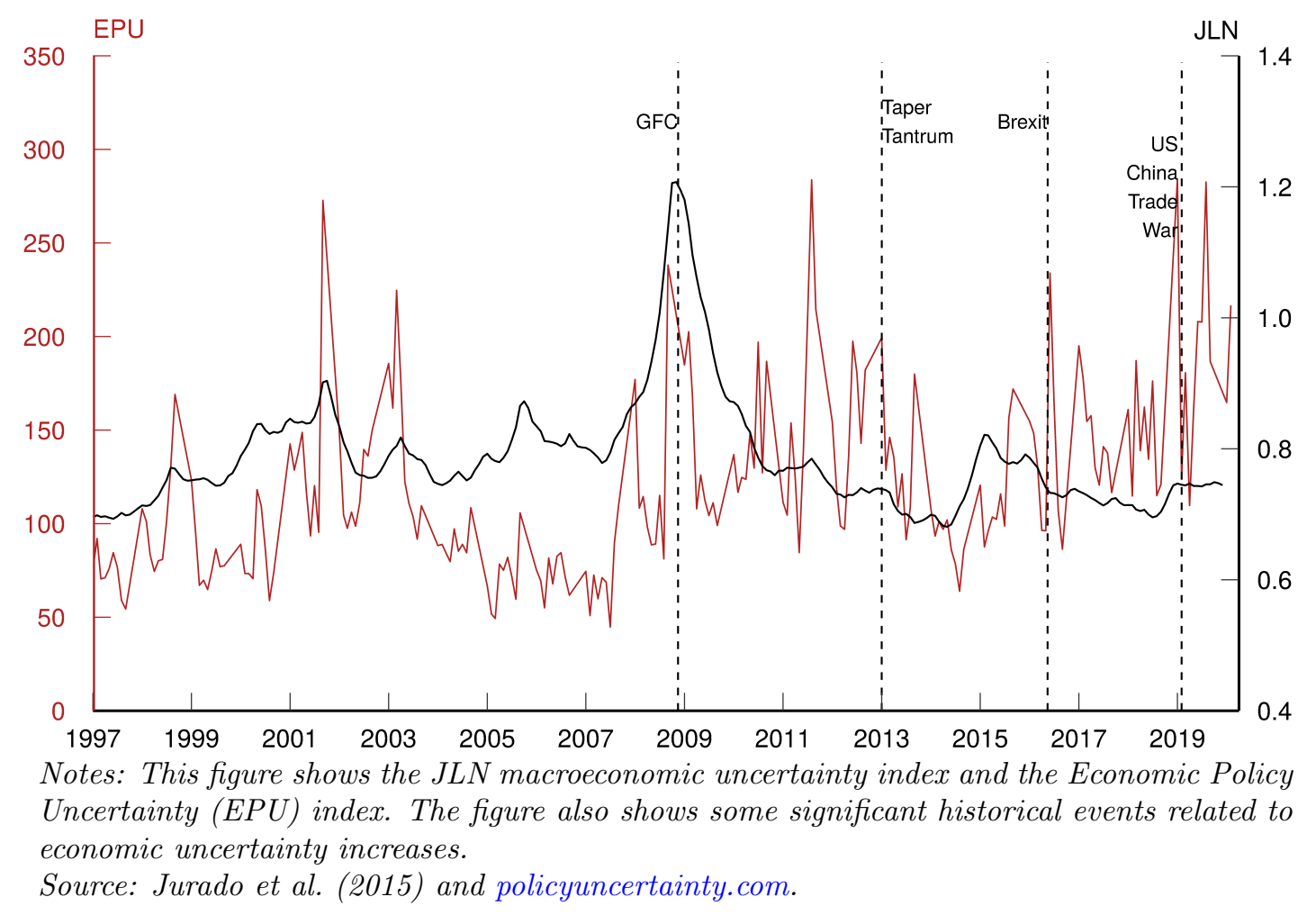

that is, the difference between the future value of the variable and its expectation based on the information available at time $t$. The aggregate uncertainty at the macro level is the average of the uncertainty measures across all macro variables.

The macroeconomic uncertainty index in Jurado et al. (2015) (henceforth referred to as the JLN index) differentiates uncertainty from traditionally used measures of volatility, such as conditional volatility. Conditional volatility (see stock volatility in section 3.1) does not necessarily remove the forecastable component of a time series, while the JLN index does so by incorporating a large number of indicators into the forecasting model for each individual time series.

Figure 9 compares the JLN index with the EPU index discussed in section 2.1. As can be seen from the figure, the JLN index is more persistent and exhibits fewer spikes than the EPU index. Jurado et al. (2015) explore the effects of macroeconomic uncertainty and find that increases in the JLN index are associated with large declines in U.S. real economic activity.

As pointed out by Rogers and Xu (2019), real-time considerations are very important 
in the calculation of the JLN index and for the quantification of its real effects. Figure 10 compares the original JLN index with the Rogers-Xu real-time recalculation of that series. Both are scaled such that the index equals 1.0 in January 2000. Notice that real-time macro uncertainty fell between 2000 and 2008, while the original, ex-post uncertainty series rose. Furthermore, in JLN's original series, uncertainty peaks at a level nearly $80 \%$ above the starting point, but with the real-time series that rise is greatly attenuated, only about $40 \%$ above starting point. Rogers and $\mathrm{Xu}$ (2019) show that the forecasting performance of the real-time index is notably worse than the original measure.

\section{Figure 10 Real-Time v.s. Ex-Post Macroeconomic Uncertainty}

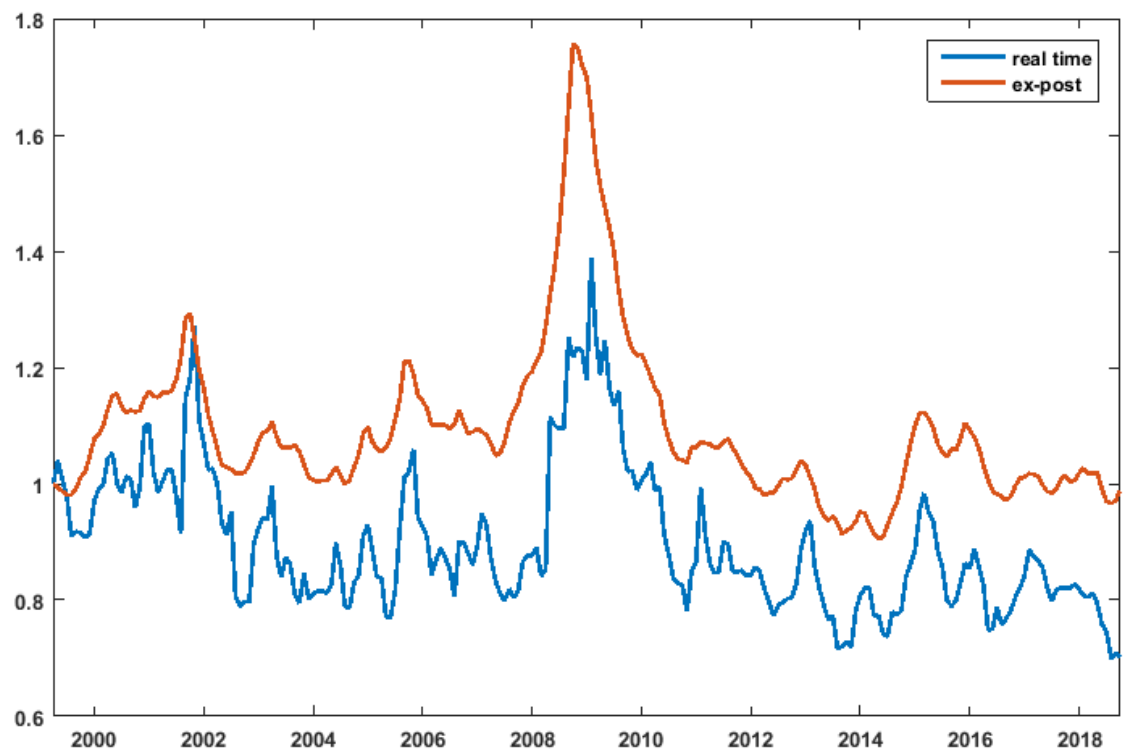

Notes: This figure shows the real-time (blue) and ex-post (orange) JLN macroeconomic uncertainty index.

Source: Rogers and Xu (2019).

Based on the JLN methodology, Londono et al. (2019) construct foreign real economic uncertainty (REU) indexes for the G-7 economies and Switzerland. They also calculate an aggregate non-U.S. measure as the GDP-weighted average across all countries but the United States. Figure 11 shows that uncertainty about the real economy in the United States and foreign countries tends to increase around U.S. recessions and around the time of the euro-area crisis and Japanese earthquake in 2011, when U.S. REU was relatively subdued. Londono et al. (2019) document that an increase in foreign REU imparts a drag to U.S. industrial production after one year. Redl (2018) constructs macro uncertainty 
indexes for 11 advanced countries based on the JLN framework and finds that macro uncertainty shocks matter for the vast majority of countries and that the real effects of macro uncertainty shocks are generally larger conditioning on close elections.

\section{Figure 11 Foreign Real Economic Uncertainty Index}

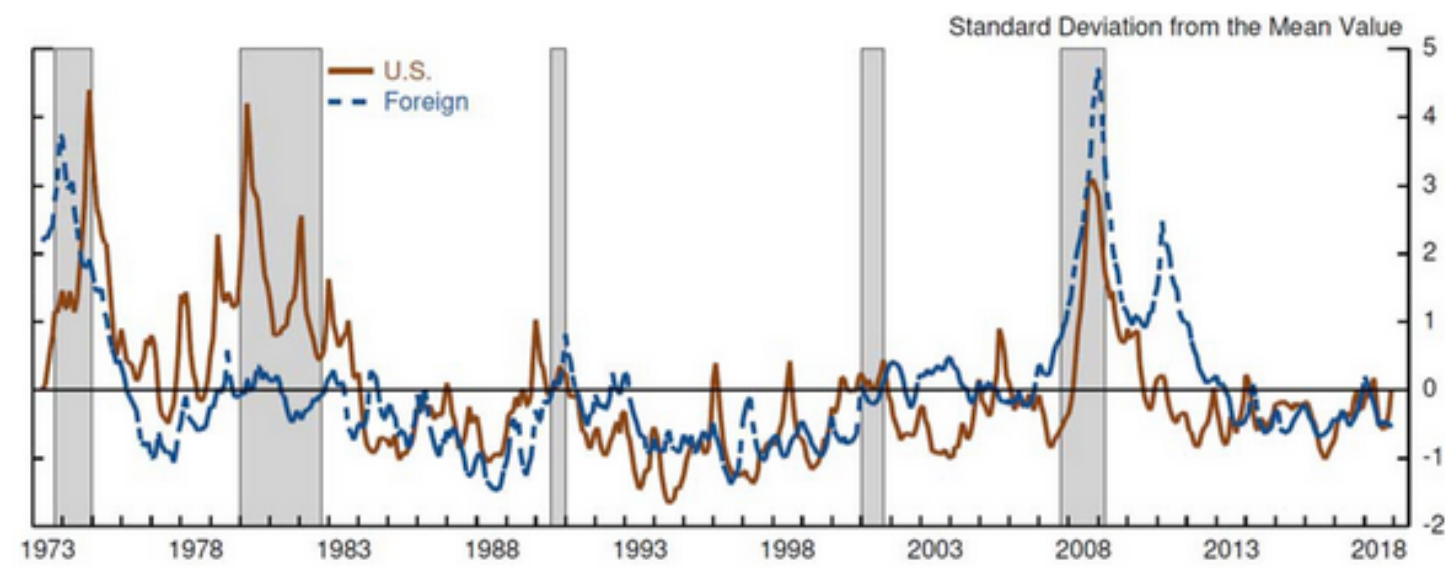

Notes: This figure depicts the U.S. and foreign real economic uncertainty indexes. Shaded areas represent NBER recessions.

Source: Londono et al. (2019).

Macroeconomic and financial uncertainty can also be obtained using econometric techniques from the estimated latent stochastic volatility process of macroeconomic and financial variables. This approach is used, for example, for interest rate uncertainty (Fernández-Villaverde, Guerrón-Quintana, Rubio-Ramírez, and Uribe, 2011), financial uncertainty (Alessandri and Mumtaz, 2014 and Shin and Zhong, 2018), uncertainty about fiscal policy (Fernández-Villaverde, Guerrón-Quintana, Kuester, and Rubio-Ramírez, 2015), inflation uncertainty (Chan, 2017) and regional-specific uncertainty (Mumtaz and Musso, 2019). Carriero et al. (2018) propose a model in which the common factors of the stochastic volatilities of macro and financial variables are allowed to interact. Following a similar setup, Cascaldi-Garcia (2019) constructs quarterly macro and financial uncertainties for the United States. These measures are shown in figure 12. Some periods are characterized by high macro and financial uncertainties, such as the global financial crisis, but some are characterized mostly by macro uncertainty (as in the the Great Moderation, mid-1980s) or by financial uncertainty (as in the dot-com crisis, 1999-2001). Cascaldi-Garcia (2019) also shows that macro and financial uncertainties endogenously react to expected future changes in the technological level of the economy. 
Figure 12 Macroeconomic and Financial Uncertainties from Stochastic Volatility

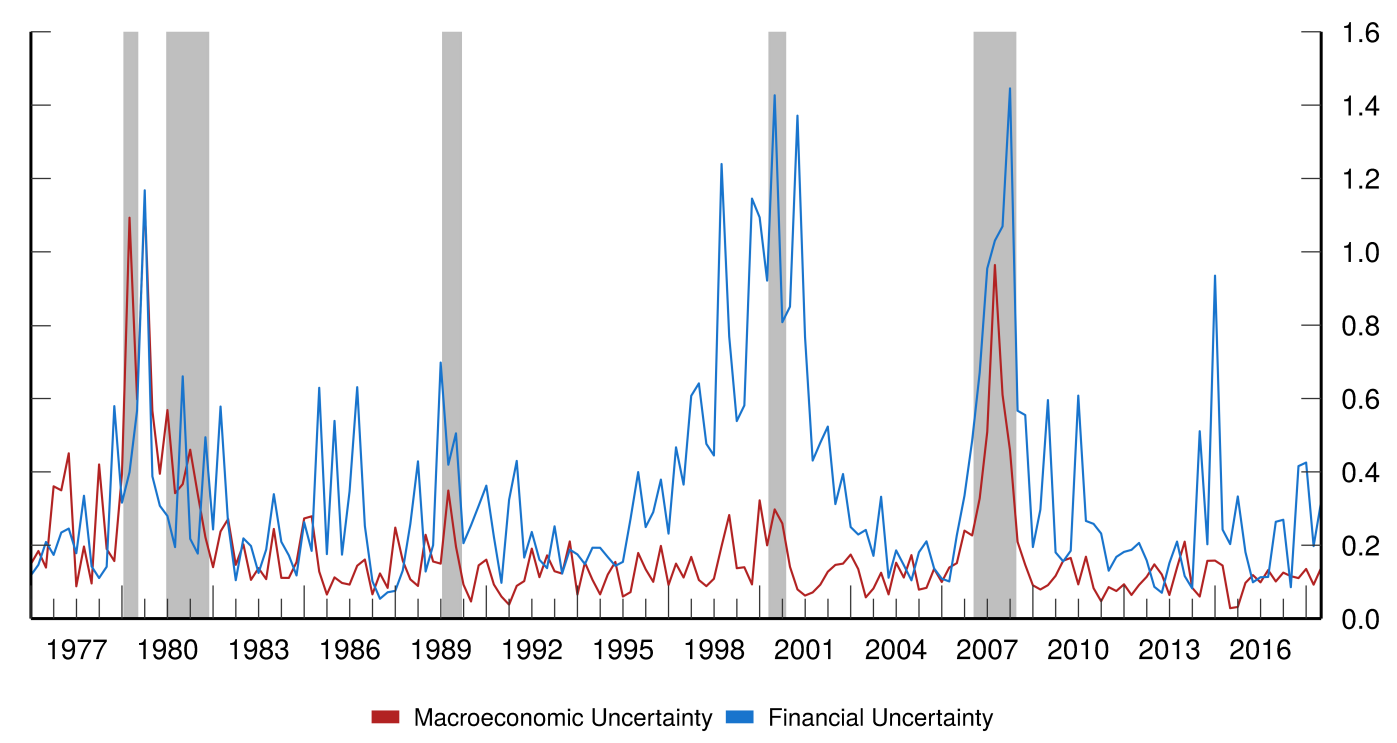

Notes: Macroeconomic and financial uncertainties measured as the common factor on macroeconomic and financial volatilities, respectively. Shaded areas represent NBER recessions. Source: Cascaldi-Garcia (2019).

\subsection{Quantile-Regression Risk Measures in Real-Time}

The value-at-risk (VaR) is defined in the finance literature as a threshold such that the probability of a specific outcome not exceeding this threshold is equal to a desired level. This threshold is equivalent to the corresponding quantile of the desired level. The VaR has recently been used to construct measures of risk to U.S. macroeconomic aggregates drawing from quantile regressions. Unlike standard OLS regressions, quantile regressions look beyond the conditional mean and allow the study of the conditional quantiles of a given variable. Thus, this technique makes it possible to analyze how economic conditions influence not only the modal outlook but also the tail dynamics of economic time series.

Using the VaR methodology, Adrian, Boyarchenko, and Giannone (2019) compute the downside risk to the annualized average growth rate of U.S. GDP over the next quarter/year by constructing a conditional distribution using quantile regressions. Their conditioning variables are macroeconomic activity, as summarized by GDP growth, and financial conditions, characterized by the National Financial Conditions Index (NFCI) 
constructed by the Chicago Fed. Adrian et al. (2019) find that, while the relationship between average future GDP growth and economic conditions is fairly symmetric across quantiles, financial conditions have explanatory power for the left tail (e.g., its 10th quantile) of GDP growth but no information content for its right tail (e.g., its 90th quantile). In this sense, the downside vulnerability of GDP growth seems to be informed by financial health and/or by amplification mechanisms in the financial sector. ${ }^{7}$

Real-Time Growth-at-Risk. Caldara, Cascaldi-Garcia, Cuba-Borda, and Loria (2020) extend these results by employing new monthly measures of macroeconomic and financial factors, together with a monthly version of U.S. GDP growth that tracks fluctuations within the quarter in real-time. As in Adrian et al. (2019), at each point in time, the authors fit a skewed- $t$ density (a flexible distribution which accommodates departures from normality) on the estimated conditional quantiles of average GDP growth over the next 12 months. This a useful tool to quantify and visualize risks to the future outlook, and particularly in times of economic downturn, such as the COVID-19 pandemic. For instance, figure 13 presents the conditional distributions of average U.S. GDP growth over the next 12 months from Caldara et al. (2020), as of December 2019 (before the pandemic) and as of March 2020 (at the onset of the pandemic). Compared to December, the distribution in March features a lower mean and a higher variance, due to the weak economic activity and tight financial conditions. The March distribution also exhibits more pronounced skewness to the left, which contributes to heightened downside risk.

The time evolution of the conditional quantiles of average future GDP growth is reported in figure 14. The chart puts the current vulnerability of GDP growth into historical context and reveals that the risks to the outlook in March at the onset of the COVID-19 pandemic are comparable to the risks around the global financial crisis. Further, it reveals that the distribution has changed over time as downside risks to GDP growth, as captured by the $10^{\text {th }}$ quantile, increased around recessions while upside risks remained more stable.

\footnotetext{
${ }^{7}$ Adrian, Grinberg, Liang, and Malik (2018) find similar results in an international context by looking at a panel of 11 advanced and 11 emerging market economies.
} 
Figure 13 Conditional Densities of Average U.S. GDP Growth over the Next 12 Months - The COVID-19 Pandemic

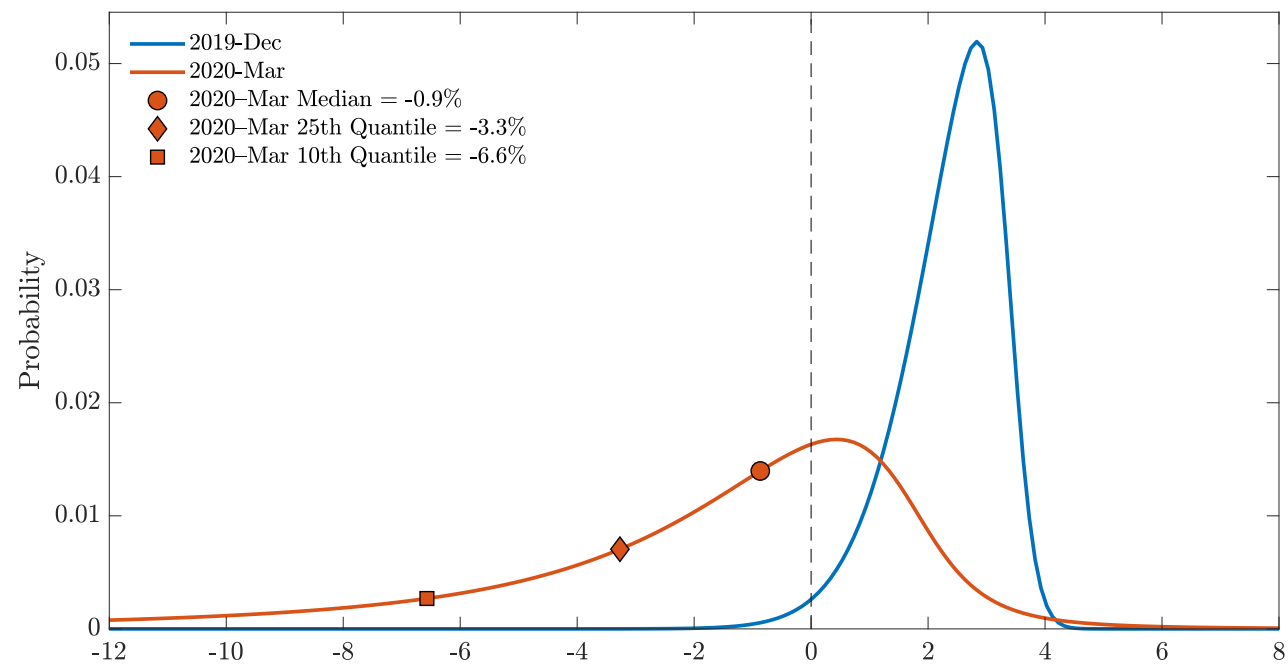

Notes: Estimated conditional densities of average twelve-month ahead GDP growth. The reference period for the '2020-Mar' predictive distribution is average GDP growth between April 2020 and March 2021. Following the same convention, the reference period for the '2019-Dec' predictive distribution is average GDP growth between January 2020 and December 2020.

Source: Caldara et al. (2020).

Figure 14 Conditional Quantiles of Average U.S. GDP Growth over the Next 12 Months

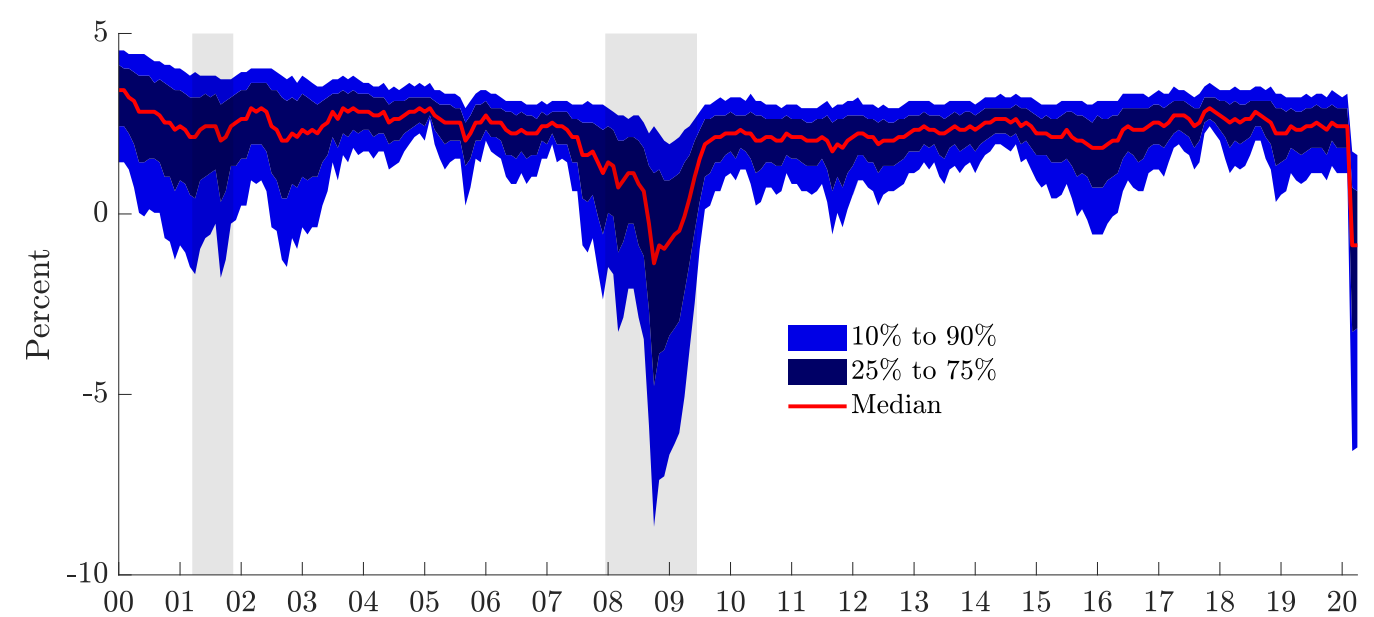

Notes: The figure displays the time evolution of the conditional quantiles of U.S. GDP growth estimated from the quantile regressions. Shaded areas represent NBER recessions.

Source: Caldara et al. (2020).

Real-Time Inflation-at-Risk. Also using the quantile regression methodology, LopezSalido and Loria (2019) study the risks to the inflation outlook. They frame the effects of different risk factors on the annualized inflation rate of average core CPI over the next year within an augmented quantile Phillips curve model. This setup relates inflation risks 
to variations in the unemployment rate, inflation persistence, (long-run) expectations, relative import prices, and financial conditions (approximated by credit spreads). Figure 15 shows the conditional densities of average core CPI inflation over the next 12 months obtained from the monthly specification of the Lopez-Salido and Loria (2019) model. In line with the results for GDP growth, as of March 2020, the inflation distribution features a lower mean, a higher variance, and a more pronounced skewness to the left - all features that make the downside risks to the inflation outlook more severe. This is a direct result of tighter financial conditions, which, as shown by Lopez-Salido and Loria (2019), are key drivers of the asymmetry in the predictive inflation distribution. Figure 16 shows the evolution of the conditional quantiles and suggests that these downside risk estimates are comparable to those observed around the global financial crisis.

\section{Figure 15 Conditional Densities of Average Core CPI Inflation over the Next 12 Months - The COVID-19 Pandemic}

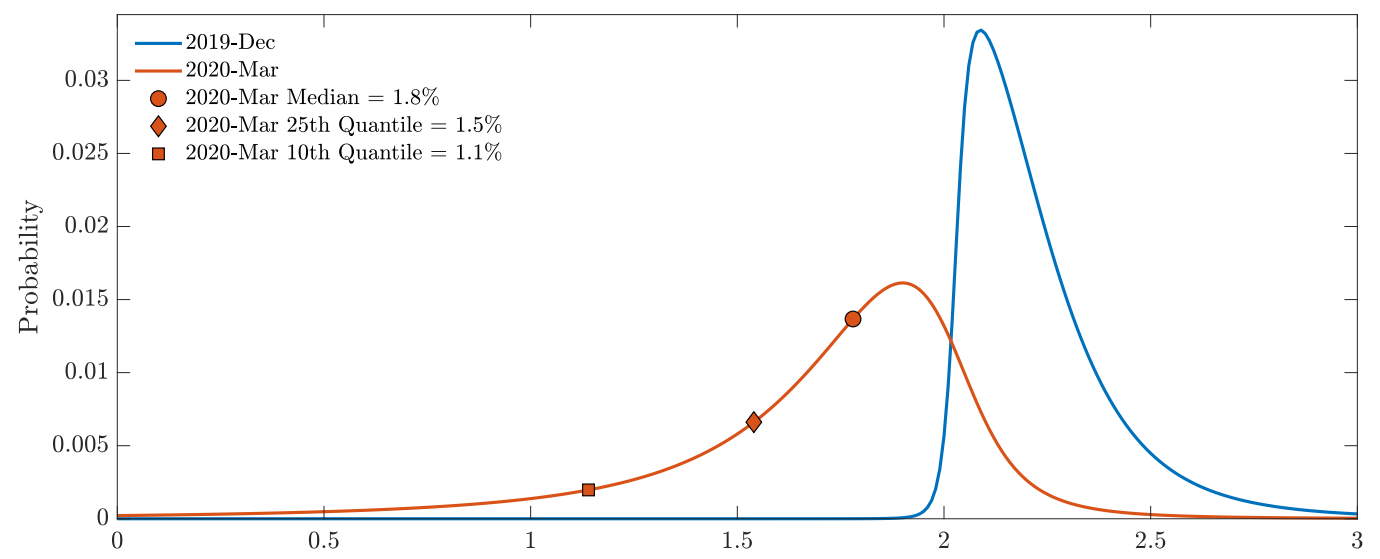

Notes: Estimated conditional densities of average four-quarter ahead euro area core CPI inflation. The reference period for the '2020-Mar' predictive distribution is average core CPI inflation between April 2020 and March 2021. Following the same convention, the reference period for the '2019-Dec' predictive distribution are average core CPI inflation rates between January 2020 and December 2020.

Source: Lopez-Salido and Loria (2019). 


\section{Figure 16 Conditional Quantiles of Average Core CPI Inflation over the Next} 12 Months

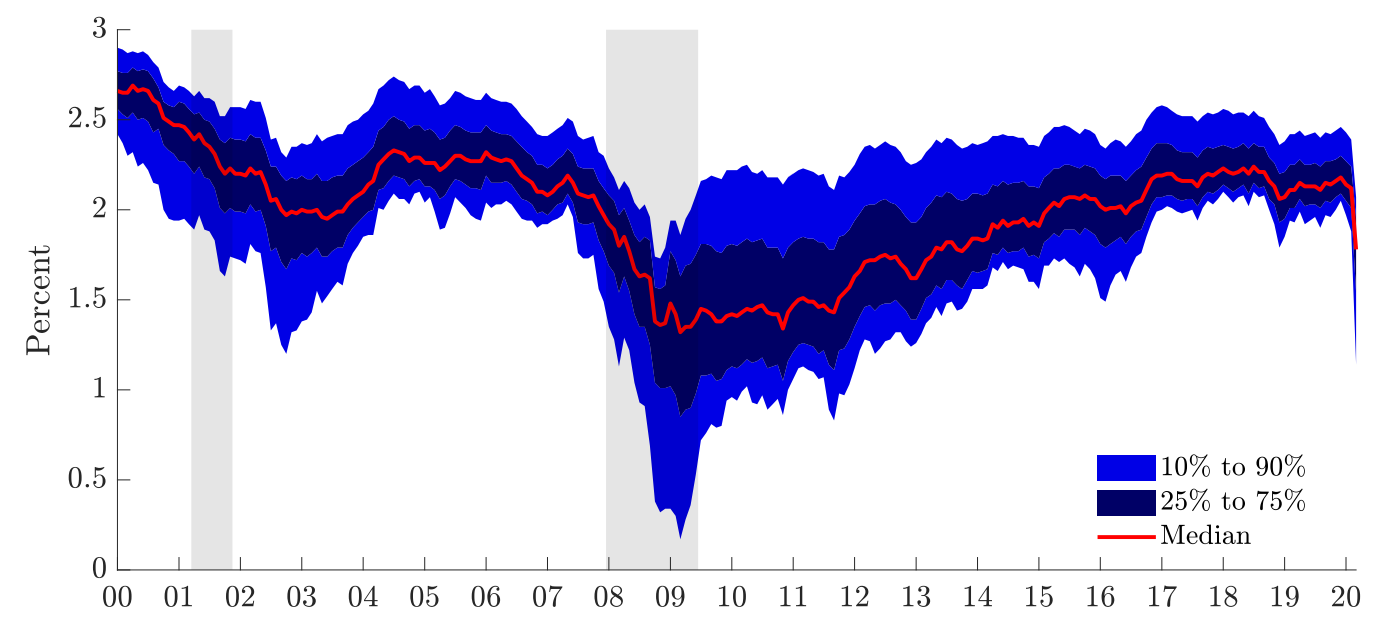

Notes: The figure displays the time evolution of the conditional quantiles of U.S. core CPI estimated from the quantile regressions. Shaded areas represent NBER recessions.

Source: Lopez-Salido and Loria (2019).

\section{Asset-market Indicators}

\subsection{Realized Volatility}

Before 2000, equity return volatility was largely modeled using parametric methods, such as generalized autoregressive conditional heteroskedasticity (GARCH) or stochastic volatility (SV) methods. ${ }^{8}$ Although these methods are extensively used to model financial and even macroeconomic time series, they have several limitations. For example, GARCH-based models generally fail to capture the magnitude of sudden volatility increases, such as the increase that occurred on October 19, 1987. These models are also relatively hard to extend to and implement in multivariate settings, such as for multiple assets of countries.

Pioneered by Andersen, Bollerslev, Diebold, and Labys (2001, 2003), realized volatility (RV)-defined as the scaled sum of squared daily returns-offers a nonparametric alternative to traditional parametric volatility measures. RV estimators are feasible in multivariate applications, flexible, and easy to implement.

The properties of RV-style estimators are well documented in the literature, and they are routinely used for forecasting volatility (Alizadeh, Brandt, and Diebold, 2002;

\footnotetext{
${ }^{8}$ For a comprehensive review of GARCH and related models refer to Poon and Granger (2003).
} 
Corsi, 2009; Patton and Sheppard, 2015; among many others) and for predicting returns (Bollerslev and Zhou, 2006; among many others). However, while RV-style measures have proved successful in predicting future volatility, their ability to predict financial returns is somewhat limited.

Figure 17 shows the time series of RV for headline equity indexes for the United States, Germany, Japan, the United Kingdom, and the euro area. These RV measures are based on daily returns (as opposed to intradaily data), and seem to be particularly high around episodes of market uncertainty, which are usually associated with unexpected news or events. Not surprisingly, the most notable volatility spikes in this sample occurred around the collapse of Lehman Brothers in 2008 and in March 2020 during the COVID-19 pandemic, when RV reached values over 92 percent. These measures also spiked in July and August of 2011 at the peak of the euro-area crisis and between the second quarter of 2015 and the third quarter of 2016, when Chinese equity markets experienced substantial losses and the U.K. referendum took place. RV measures also spiked moderately during the two episodes of market turmoil in early and late 2018 in response to trade uncertainty.

\section{Figure 17 Realized Volatility (RV)}

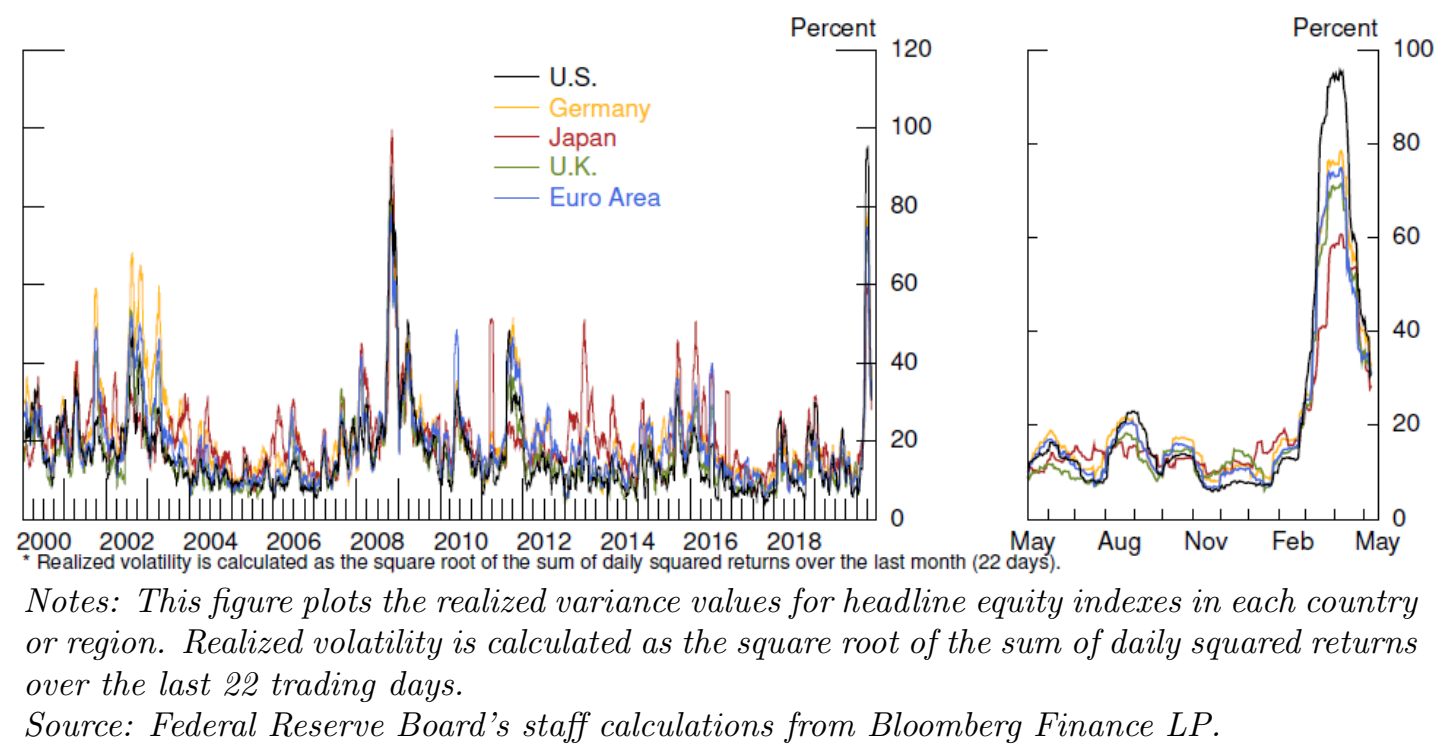




\subsection{Low Volatility}

Since the global financial crisis in 2008, policymakers have been searching for tools and indicators that can help them predict vulnerabilities that may lead to future crises. Danielsson, Valenzuela, and Zer (2018) argue that financial market volatility - although being one of the commonly used market indicators - is not a useful predictor of crises. However, prolonged periods of low volatility have strong in- and out-of-sample predictive power for the incidence of banking crises and can be used as a reliable crisis indicator.

The main idea in Danielsson et al. (2018) combines the insights of both Keynes (1936) and Minsky (1977). Keynes (1936) argues that perceptions of risk, especially when it deviates from what economic agents expect, affect risk-taking behavior. These notions are made more formal by Minsky (1977) in what the author refers to as the instability hypothesis, where economic agents that observe stable economic environments are induced to take on more risk, which ultimately leads to a higher probability of a crisis.

To estimate "unusually" low annual volatility, Danielsson et al. (2018) first calculate realized volatility as the standard deviation of 12 monthly real returns for 60 countries, spanning from 1800 to 2010 (see Section 3.1). Volatility differs considerably across countries, and even throughout the history for a given country. Hence, a particular measurement of volatility could be seen as high or low, depending on the country or year. To obtain a threshold for each country indicating the usual/expected value of volatility, the authors use the long-run historical trend, calculated via the one-sided Hodrick and Prescott (1997) filter. Low volatility is then defined as the deviation of realized stock market volatility below its historical trend.

Danielsson et al. (2018) find that prolonged periods of low volatility (that is, if volatility stays low for at least 1 year) increases both banking sector leverage and aggregate credit, which they interpret as increased risk appetite and risk taking. The economic impact of low volatility is highest if the economy stays in the low volatility environment for five years: a 1 percent decrease in volatility below its trend translates to a 1.01 percent increase in the probability of a crisis.

Figure 18 shows volatility and trend estimates for the United States. Low volatility 
episodes are those where volatility is below the trend. Episodes of high volatility usually correspond to recessions and crises. The highest volatilities are observed during the Great Depression and the late 1930s recession, followed by the 1850s recession, the early 1970s recession, the 1987 crash, and the 2008 global financial crisis.

Figure 19 shows the low volatility along with key stress events in world economic history. Low volatility seems to presage stress events; for example, in the late 1920s before the Great Depression, in the mid-1990s before the Asian crisis, and the mid-2000s before the 2008 crisis.

Figure 18 Volatility and Trend

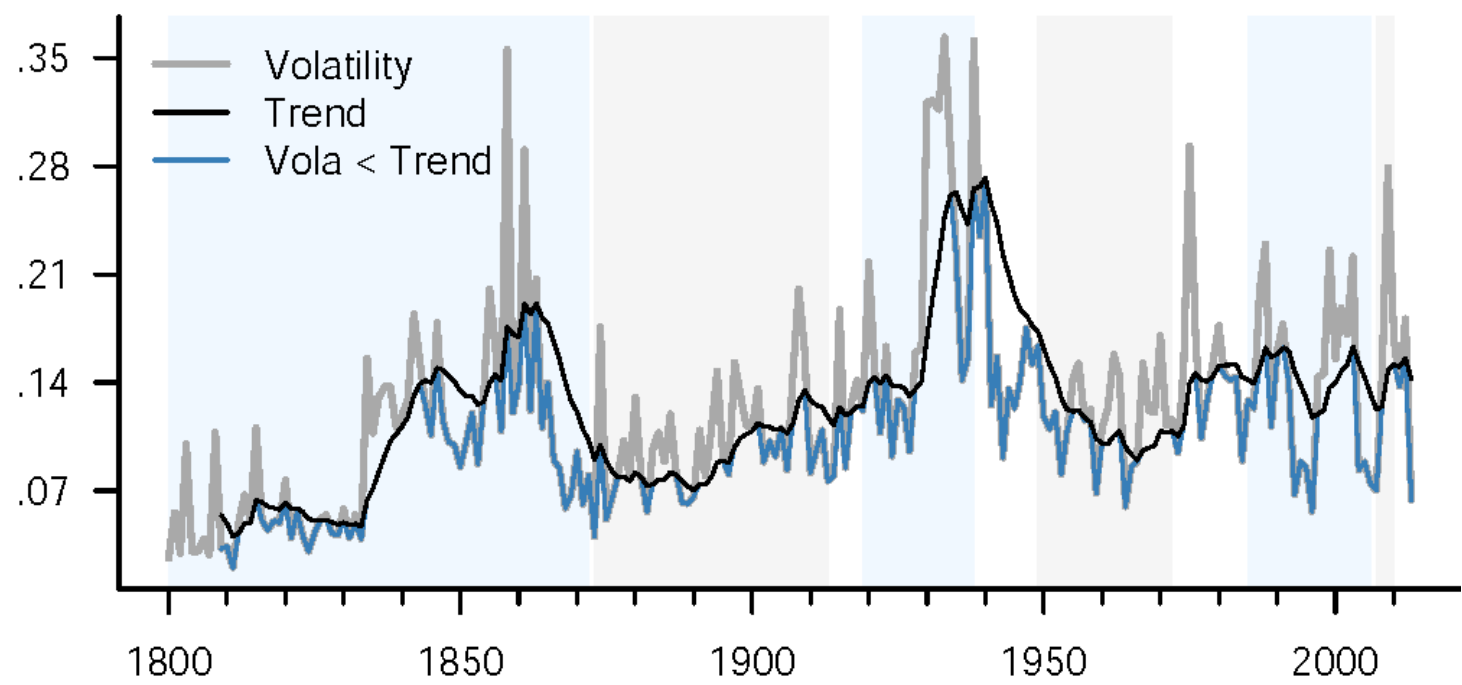

Notes: The figure shows volatility and trend estimates for the United States. Volatility is the realized annual volatility, calculated as the standard deviation of 12 monthly stock returns. The one-sided Hodrick and Prescott (1997) filter with smoothing parameter 5000 is applied to decompose volatility into trend and deviations from the trend. Low volatility is the volatility below the historical trend.

Source: Global Financial Data, Inc., GFDatabase.

\subsection{Cross-Sectional Distribution of Stock Market Returns}

The RV measures in section 3.1 are calculated using time series of data on the aggregate stock market. Additional measures of volatility can be computed by exploiting the distribution of stock returns across firms at each point in time (for example, all stocks in the S\&P 500 index). For instance, Bloom (2009) and Christiano, Motto, and Rostagno (2014) use the variance across individual stock returns at each point in time as a mea- 


\section{Figure 19 Low Volatility and Key Events}

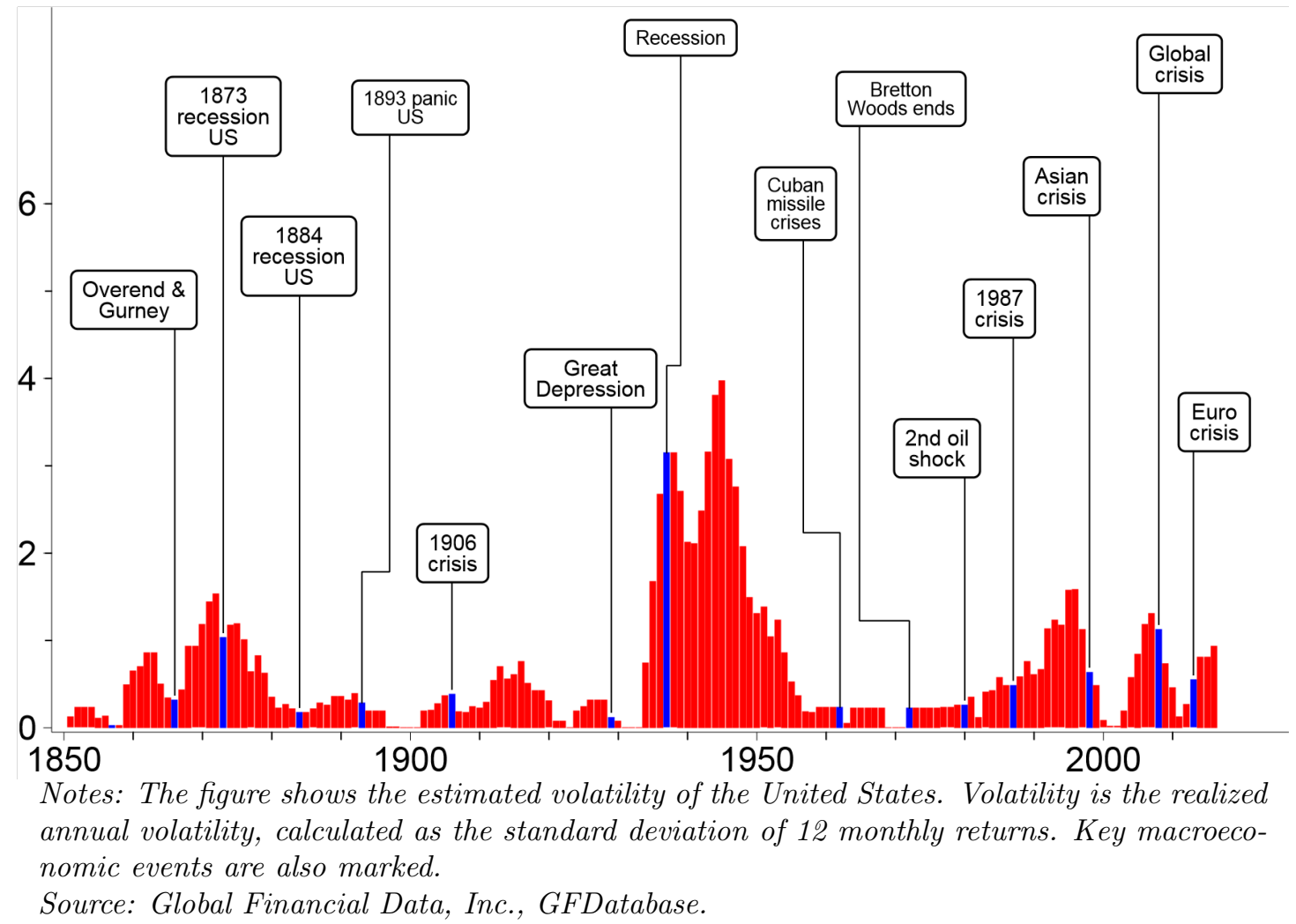

sure of cross-sectional uncertainty and show that exogenous shocks to these measures are important sources of business cycle fluctuations.

Higher-order moments of the cross-sectional distribution of stock returns can also provide useful information about the economic cycle. In particular, Ferreira (2018) focuses on the skewness of the distribution of log returns across firms and assesses the balance between upside and downside risks. Ferreira (2018) shows that cross-sectional stock return skewness (financial skewness) not only closely tracks the business cycle but predicts economic activity better than several well-known bond spreads (for example, the term spread and the spread in Gilchrist and Zakrajsek, 2012) and other cross-sectional moments.

Figure 20 sheds light on the relationship between cross-sectional stock return skewness (financial skewness) and the business cycle since 1926. The figure shows that sharp decreases in financial skewness; that is, when the left tail of the distribution becomes larger than the right tail, coincide with slowing GDP growth and recessions, especially over the past two decades. Financial skewness was at its lowest during the recent global 
financial crisis, the recession following the savings and loan crisis of the 1990s, and the Great Depression. During the global financial crisis, the measure of financial skewness started to plummet well before the drop in economic activity. Ferreira (2018) estimates that shocks to financial skewness have sizable effects on economic activity, credit growth, and corporate credit spreads. ${ }^{9}$

Figure 20 Financial Skewness and Economic Activity

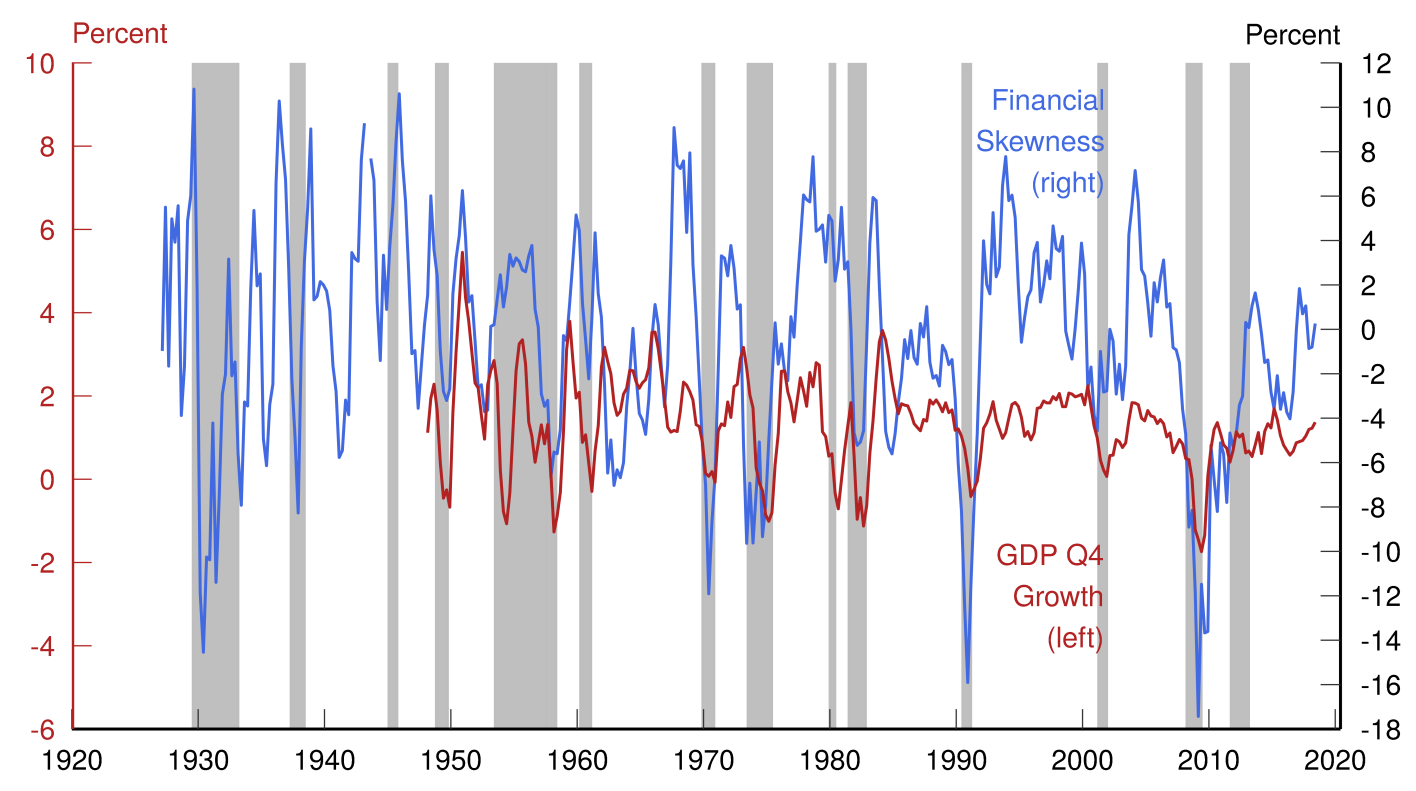

Notes: The financial skewness refers to skewness of the distribution of log returns across firms and is shown as a four-quarter moving average. Shaded areas represent NBER recessions. Source: Ferreira (2018).

\subsection{Derivative-Implied Risk and Uncertainty Measures}

Derivative prices reflect investor preferences as well as investor beliefs about the likelihood of future realizations of the underlying asset's price. For instance, buying a put option, which provides a positive payoff if the price of the underlying equity drops below the strike price of the option, is a profitable strategy only if the price of the underlying asset falls below a certain threshold - the strike price of the option. The price of a put option will increase with the probability an investor assigns to an outcome in which the price of

\footnotetext{
${ }^{9}$ The literature finds that high-order moments of the cross-sectional distribution of other economic variables also co-move with the economic cycle, such as nonfinancial firm sales, profit, and employment (Salgado, Guvenen, and Bloom, 2019); household income (Guvenen, Ozkan, and Song, 2014); and price changes (Luo and Vallenas, 2017).
} 
the asset will drop below its strike price, and will also increase with the value an investor places on a positive return in the event of a price drop. Thus, at any point in time, the prices of derivatives at different strikes contain commingled information about the probabilities assigned to each possible market outcome as well as investor preferences.

Derivative-implied distributions allow us to calculate derivative-implied moments, such as the derivative-implied volatility or skewness, as well as the cost of insurance against any potential outcome (for example, a price drop of a certain magnitude). The derivative-implied distribution used to generate these moments is often referred to as the risk-neutral distribution because, by construction, this is the probability measure that makes the expected return on a risky investment equal to the risk-free rate. It is not called a risk-neutral measure because we assume that agents are risk neutral, but rather because, under this measure, probabilities are calculated as though agents only cared about the mean return. Because investors are not risk neutral in most cases, derivative-implied distributions contain information about risk premiums.

Risk-neutral or derivative-implied probabilities are different from actual (usually referred to as physical) probabilities. Typically, the actual or physical distribution cannot be known. However, if we assume that the process is stationary (that is, tomorrow's draw will come from the same distribution as historical draws), then the physical distribution can be estimated from historical realizations. Comparing the estimated physical distribution with the derivative-implied distribution can provide some information about investors' risk preferences - that is, about investors' outcome-specific preferences, such as their preference for having positive returns in one state of the economy (for example, a large drop in asset prices) versus another. For example, if the risk-neutral distribution systematically has wider tails than the physical distribution (that is, more probability assigned to extreme market outcomes), we can infer that either investors systematically overestimate the probability of tail events or that their estimations are correct but they particularly value positive returns in those tail events. 


\subsubsection{Market-based Measures of Monetary Policy Uncertainty}

Market participants naturally follow and gauge central bank communications with respect to monetary policy because the stance of monetary policy is a key input for a wide variety of financial decisions. To that end, several papers derive measures of uncertainty about the path of monetary policy from policy-sensitive interest rates derivatives. Swanson (2006) developed a measure of monetary policy uncertainty based on the width of the probability distribution of the federal funds rate one-year ahead, as implied by market prices on interest rate derivatives. Figure 21 shows the $90 \%$-confidence interval of the market-implied distribution for the effective federal funds rate at the one-year horizon, computed from at-the-money eurodollar futures options and adjusted for the level difference in volatility between the federal funds rate and eurodollar rates. According to this measure, U.S. monetary policy uncertainty fluctuated notably in the early 1990s, declined in the 2000s, reached a trough during the zero lower bound (ZLB) period, and moved up again in recent years after the FOMC began to lift interest rates away from the ZLB. More recently, this measure declined drastically as the Federal Reserve slashed interest rates again to the ZLB following the COVID-19 pandemic outbreak.

Several papers in the literature study the effect of the monetary policy uncertainty (Market-MPU) on various market prices. For example, Swanson (2006) uses the derivativebased measure from eurodollar futures and options, similar to the one shown on figure 21, to find that increased transparency in Federal Reserve communications, that is naturally associated with decline in monetary policy uncertainty, has led to improved private sector interest rates forecasts. Using the same Market-MPU measure, De Pooter, M. and Favara, G. and Modugno, M. and Wu, J. (2020) document that the level of the MarketMPU matters for the reaction of medium- and long-term yields on the nominal and real U.S. Treasury securities to monetary policy surprises. Bauer, Lakdawala, and Mueller (2019) use a similar Market-MPU measure based on the eurodollar futures and options - a standard deviation of conditional risk-neutral distribution of changes in the shortterm interest rate at different horizons — to study the effect of the Market-MPU on the financial markets. They show that changes in uncertainty have pronounced effects on 
asset prices, distinct from the effects of changes in expected policy rates. In particular, they document that when uncertainty is low, monetary policy surprises have stronger effects on asset prices. Lastly, Tillmann (2020) uses three measures of monetary policy uncertainty to assess its effect on the term structure of interest rates. The first is the news-based MPU measure by Husted et al. (2020) that we discuss in Section 2.2; the second is the interquartile range of the 12-month ahead forecasts about 3-month Treasury bills from the Survey of Professional Forecasters; and the third is a disagreement in 12-month ahead forecasts about 10-year yields from Consensus Economics introduced by Istrefi and Mouabbi (2018). In line with De Pooter, M. and Favara, G. and Modugno, M. and Wu, J. (2020), Tillmann (2020) also finds that the level of the monetary policy uncertainty is important for the reaction of the term structure of interest rates to monetary policy surprises. Bundick, Herriford, and Smith (2017) provide a model for the relationship of the term premium, interest rate uncertainty and correlation of bond yields with consumption, in a representative agent endowment economy.

Figure 21 Market-based Measure of Monetary Policy Uncertainty

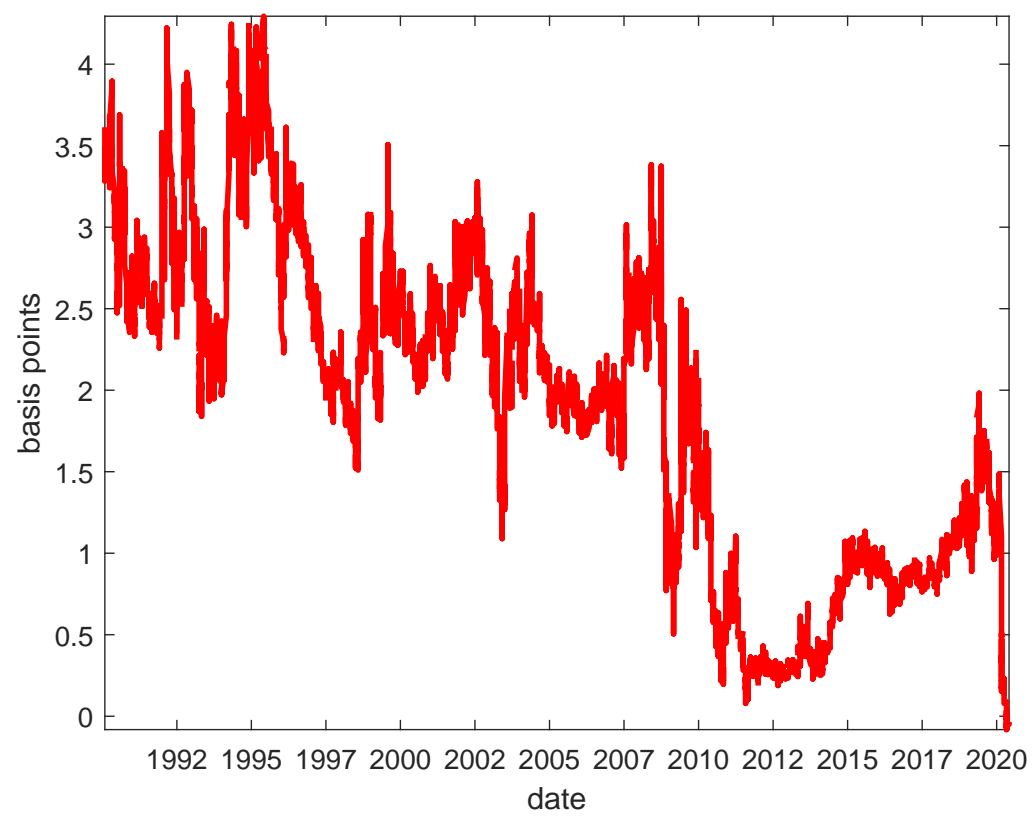

Notes: This figure shows the level of monetary policy uncertainty, measured as the 90\% width of the market-implied distribution for the effective federal funds rate at the one-year horizon, computed from at-the-money eurodollar futures options and adjusted for the level difference in volatility between the federal funds rate and eurodollar rates.

Source: CME Group; Federal Reserve Board calculations. 


\subsubsection{Option-Implied Volatilities for Equity Indexes}

Option-implied volatilities for headline equity indexes are calculated using the methodology first introduced by Britten-Jones and Neuberger (2000). For each underlying index, implied volatility is calculated as a weighted average of the price of put and call options that expire in more than 23 days but less than 37 days. The weight assigned to each option depends on its strike and its maturity, and is intended to generate a portfolio of options that isolates the expected volatility of the underlying equity index at the 30-day horizon (see Britten-Jones and Neuberger, 2000). ${ }^{10}$ Therefore, option-implied volatility is formally defined as the risk-neutral expectation of the volatility of the equity index over the next 30 days.

To the best of our knowledge, option-implied volatilities calculated with this methodology are only available for headline equity indexes of the following countries: the United States (S\&P 500), Germany (DAX 30), Japan (Nikkei 225), the United Kingdom (FTSE 100), Switzerland (SMI), the Netherlands (AEX 25), and France (CAC 100). Impliedvolatility is also available for the euro area (Euro Stoxx 50). The U.S. option-implied volatility, the VIX, is perhaps the most popular derivative-implied risk measure and is frequently used by researchers and market participants to gauge fear or uncertainty with respect to the U.S. equity market and even with respect to global equity markets. Although there has been extensive research on the usefulness of the VIX as a tool to monitor equity and other financial asset markets, its informational content is often misunderstood and abused.

Figure 22 shows the time series for the VIX (the black line) between January 2000 and May 2020. Also shown are the equivalent option-implied volatility measures for the headline equity indexes of Germany, Japan, the United Kingdom, and the euro area. The VIX seems to be particularly high around episodes of high market uncertainty, usually associated with unexpected news or events, which is why the VIX is commonly known as the "investor fear gauge" (Whaley, 2000). Not surprisingly, the most notorious VIX

\footnotetext{
${ }^{10}$ Option-implied volatilities are also available at horizons other than 30 days. For example, the S\&P 500 VIX Short-Term Futures Exchange Traded Notes (ticker: VXX) is similar to the VIX, the S\&P 500 option-implied volatility, but with a 9-day horizon.
} 
spikes in this sample occurred around the collapse of Lehman Brothers in 2008 and in March 2020 during the COVID-19 pandemic, when the VIX reached almost 90 percent. The VIX was also particularly high in July and August 2011, at the peak of the euro-area crisis. Other recent episodes of relatively high VIX realizations occurred in August 2015 and February 2016, two times when the Chinese equity market experienced substantial losses, and June 2016, with the unexpected results of the U.K. referendum campaign. Interestingly, between 2016 presidential election and January 2018, the VIX remained at near-historical lows. With the increased uncertainty about the U.S. trade policy starting in January 2018, this index spiked afterward. The figure also suggests that optionimplied indexes are highly correlated across countries and tend to spike simultaneously (see Londono, 2013).

Figure 22 Option-Implied Volatilities for Headline Equity Indexes

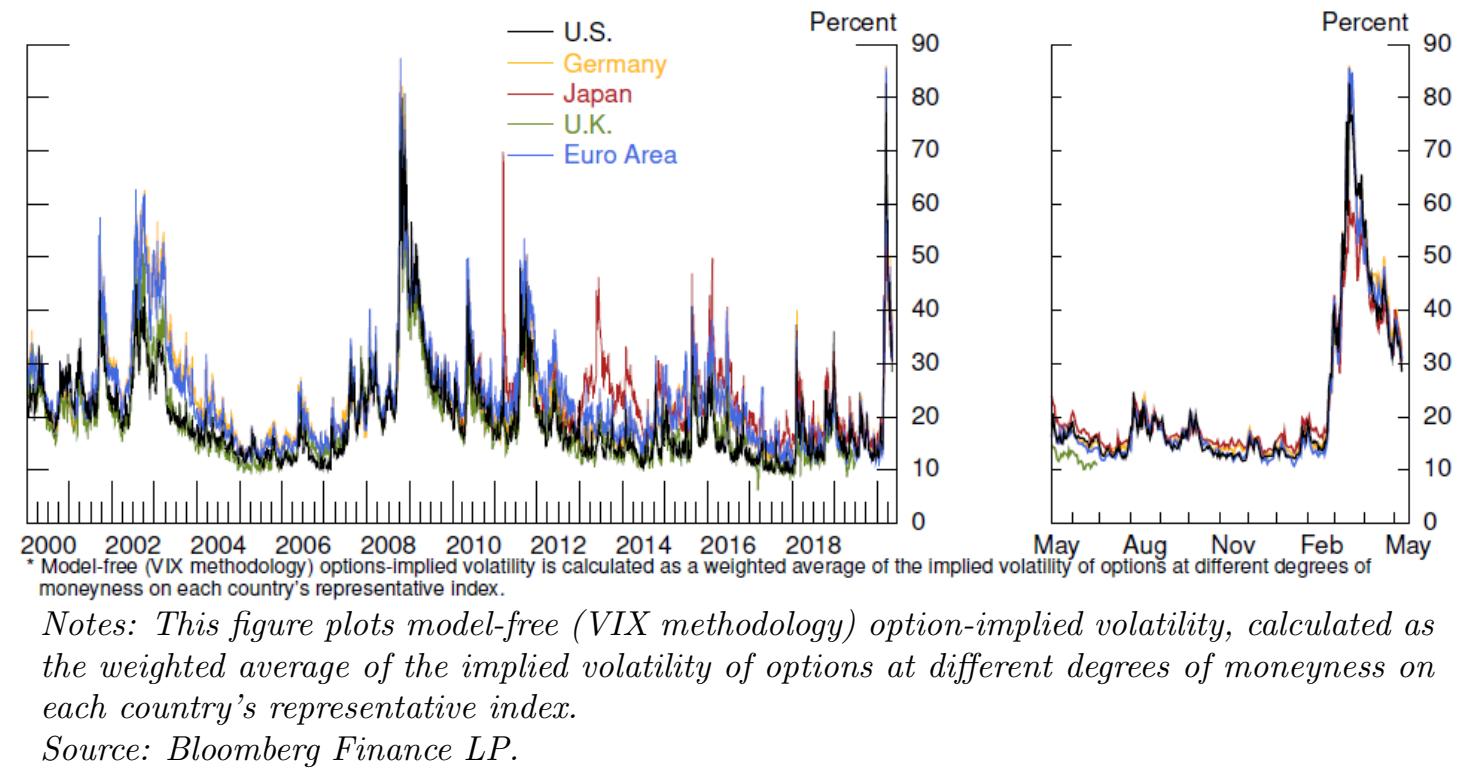

While analogous measures for longer horizons are also available, the 30-day measure is the most widely used because of the relatively high liquidity for the options around this horizon. This relatively short horizon implies that this index likely does not capture expected volatility beyond the 30-day horizon, and this short horizon could be one possible driver of the discrepancy between the low readings of the VIX observed in early 2017 and the higher perceived policy uncertainty at that time. Variance swap contracts with maturities ranging from one month to two years are traded as over-the-counter as- 
sets. ${ }^{11}$ Variance swap contracts allow us to examine the expectations of changes in market volatility beyond the 30 days captured by the VIX. In comparison with the VIX, variance swaps rose less during the global financial crisis; however, they did not return to their pre-crisis levels as rapidly. Variance swap levels seem to follow a pattern more similar to a macroeconomic uncertainty index, such as the EPU index. ${ }^{12}$

The informational content of option-implied volatilities, especially the VIX, has been extensively explored in the literature. In particular, the VIX has been shown to be a useful predictor of future RV (see, for example, Jiang and Tian, 2005). Additionally, as mentioned previously, the price of derivatives at different strikes contains information about the probability assigned to each possible market outcome as well as investor preferences (for example, having positive returns in one state of the economy). It can be difficult to disentangle how movements in the VIX reflect changes in expected volatility or changes in attitudes or preferences. However, under some assumptions (for example, the stationarity assumption), we can extract the component of the VIX related to investor attitudes or preferences toward volatility. This concept of the variance risk premium, which will be explained further below in section 3.4.3, is usually linked to risk aversion (see, for example, Bollerslev, Tauchen, and Zhou, 2009, and Bekaert, Hoerova, and Lo Duca, 2013) and has been documented to have predictive power for international equity index returns (Londono, 2013 and Bollerslev, Marrone, Xu, and Zhou, 2014).

\subsubsection{Variance Risk Premium and Its Components}

The variance risk premium is a measure of the compensation that investors demand for bearing volatility risk or, in other words, a measure of investors' preference for volatility. Formally, the variance risk premium is defined as the difference between a risk-neutral measure of expected variance (for example, the squared value of VIX; see section 3.4.2) and a physical measure of expected realized variance (see, for instance, Bollerslev et al.,

\footnotetext{
${ }^{11}$ Variance swaps are contracts in which one party pays a fixed amount at maturity, which we refer to as the price of the variance swap, in exchange for a payment equal to the sum of squared daily log returns of the underlying asset (in this case, S\&P 500 returns) occurring until maturity.

${ }^{12}$ For examples of use of these contracts in research see Dew-Becker, Giglio, Le, and Rodriguez (2017), Amengual and Xiu (2018), and Ait-Sahalia, Karaman, and Mancini (2018), among others.
} 
2009). The variance risk premium is often used as a time-varying and state-dependent measure of risk aversion (Rosenberg and Engle, 2002). This measure is also used as a gauge of macroeconomic risk compensation (Bollerslev et al., 2009; Drechsler and Yaron, 2011). Empirically, it has been shown that the variance risk premium is one of the most successful short-term (between one month and one-quarter ahead) predictors of returns across a broad range of U.S. and international financial assets (Bollerslev et al., 2009; Bollerslev, Gibson, and Zhou, 2011; Dew-Becker et al., 2017; Feunou, Jahan-Parvar, and Okou, 2018; Londono and Zhou, 2017, and Londono, 2013).

Figure 23 shows the time series of the variance risk premium for the United States, Germany, Japan, the United Kingdom, and the euro area between January 2000 and May 2020. As can be seen in the figure, the magnitude of this premium increases around key episodes generally associated with high macroeconomic uncertainty: The variance risk premium rose significantly after the COVID-19 pandemic, the collapse of Lehman Brothers, during the European debt crisis, and during the debt ceiling negotiations in the United States. However, similar to both the VIX and RV, the variance risk premium declined after the 2016 U.S. presidential election. Unlike VIX, the variance risk premium remained low after the onset of the trade uncertainty period in 2018, and only rose with the onset of the COVID-19 outbreak. Interestingly, the variance risk premium is highly correlated across countries, which suggests that there is a common or global component in variance risk premiums (see Londono, 2013; and Bollerslev et al., 2014).

A number of studies have investigated the historically low levels of volatility and the variance risk premium that followed the Great Recession. In particular, Feunou et al. (2018) attribute the low levels of variance risk premium to the additive nature of the variance risk premium and specifically to the fact that volatility-based measures treat market movements due to negative and positive realizations the same. However, market participants view positive and negative market movements differently. Feunou et al. (2018) and Kilic and Shaliastovich (2019) decompose the variance risk premium into upside and downside variance risk premiums. In practice, upside and downside variance risk premiums have different properties. The former represents market participants' interest 
in being exposed to upside risk and the higher gains it generates, while the latter represents the premium that market participants demand as compensation to bear downside risk and the possible losses it may generate. Upside and downside variance risk premiums may even have different signs. A low variance risk premium may mean calm markets or uncertainty in both positive and negative directions of similar magnitudes, because the variance risk premium is, by construction, the sum of these two risk premiums.

Figure 23 Variance Risk Premiums for Headline Equity Indexes

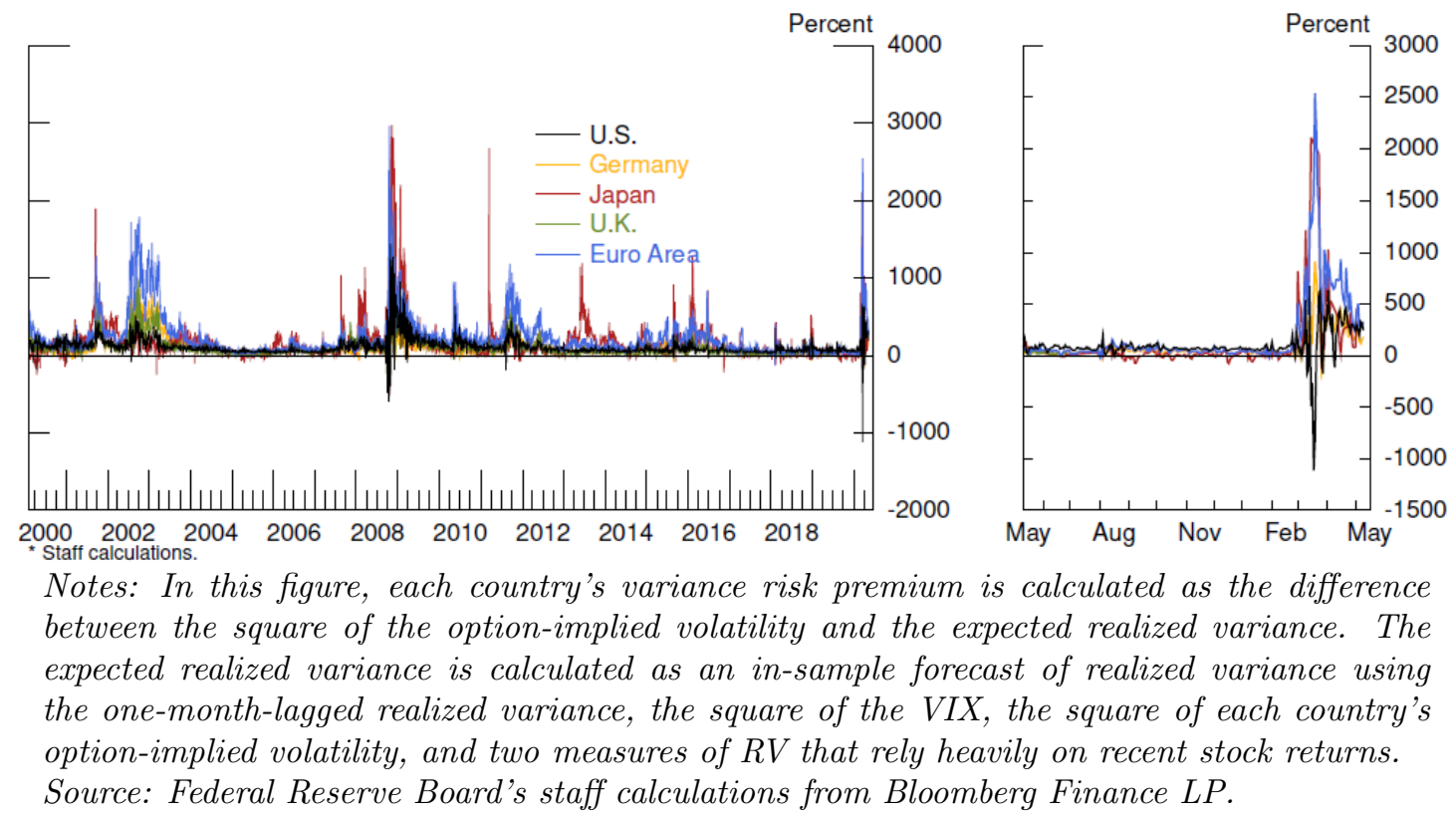

In addition, using earlier work by Kim and White (2004) as well as more recent studies by Feunou, Jahan-Parvar, and Tédongap (2013) Feunou, Jahan-Parvar, and Tédongap (2016) and Patton and Sheppard (2015), Feunou et al. (2018) show that the difference between upside and downside variance risk premiums, also known as the signed-jump premium, is a measure of the skewness risk premium. This measure, shown in figure 24, which shares many similarities with the Bollerslev and Todorov (2011) "fear index," is a better reflection of the direction of uncertainty and market participant concerns about tail risks.

Londono and $\mathrm{Xu}$ (2019) find that the U.S. downside and upside variance risk premiums are a good predictor of international stock returns. Moreover, they find that the economic interpretation and transmission channels of these asymmetric global risk variables are different. While the downside component is mostly driven by risk aversion and 


\section{Figure 24 The Skewness Risk Premium for S\&P 500 Returns}

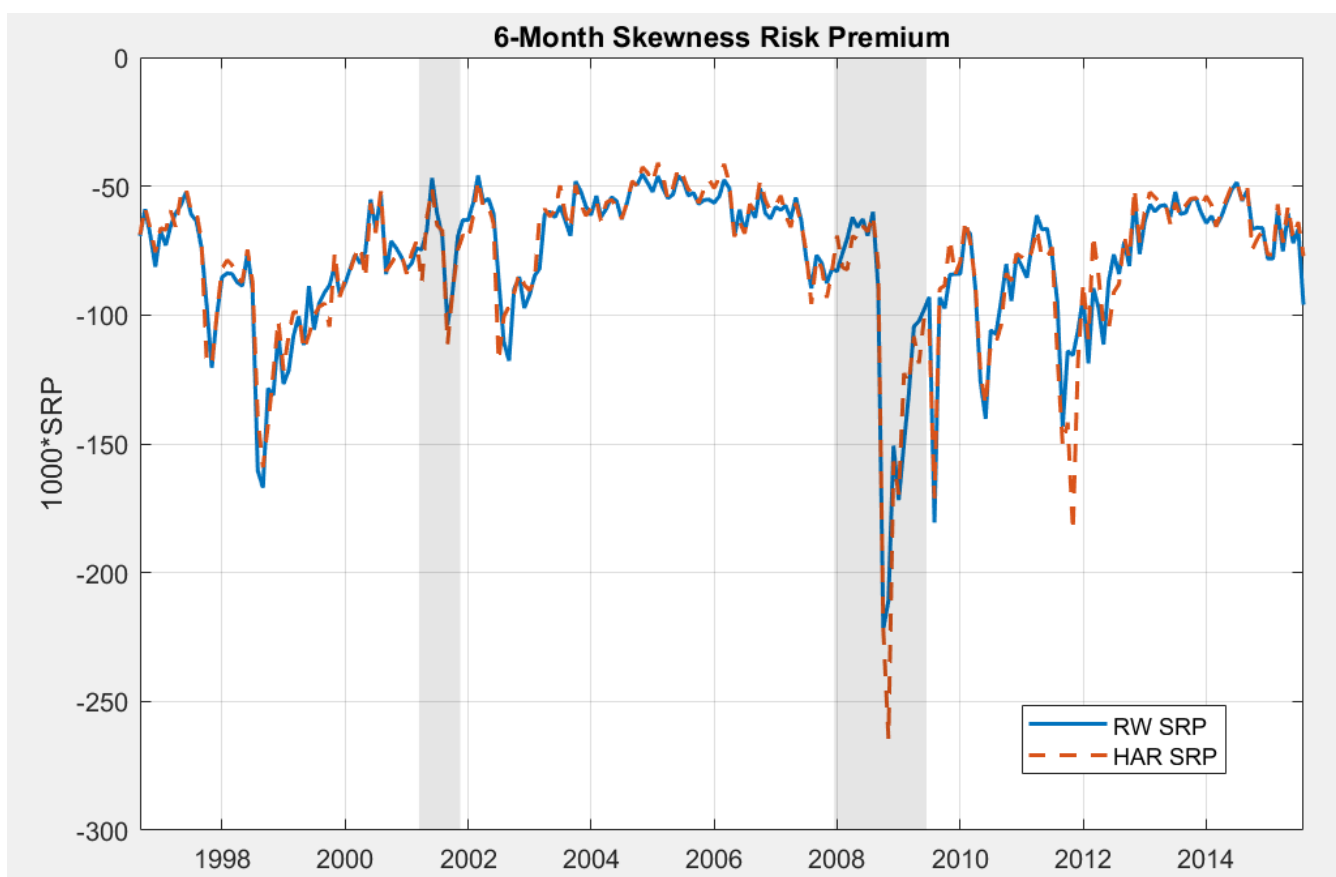

Notes: This figure plots the skewness risk premium as the difference between the upside and downside variance risk premiums, also known as signed jumps. The blue lines are based on random walk forecasts of the realized volatility and the red dotted lines are based on heteroskedastic autoregressive forecasts of the realized volatility as in Corsi (2009). Shaded areas represent NBER recessions. Source: Feunou et al. (2018).

transmitted to international markets through financial integration, the upside component is mostly driven by economic uncertainty and transmitted though economic/trade integration.

\subsubsection{Option-Implied Probability Distribution for Equity Indexes}

Options on equity indexes, unlike those on individual stocks, are fairly liquid and available for a wide range of strikes and time horizons, which facilitates the computation of optionimplied probability distributions. This section explains a semiparametric method used to calculate option-implied probability distributions for headline equity indexes.

Breeden and Litzenberger (1978) provide a direct mapping between observed option prices and the option-implied probability distribution, which can be applied to calculate option-implied equity index distributions. In particular, Breeden and Litzenberger (1978) show that the second difference of the price of a European call with respect to the strike price is equivalent to the risk-free rate discounted probability distribution function. 
However, because option prices are observed for a discrete set of strike prices and the strike prices do not extend to all possible values of the underlying asset, implementing this method requires the interpolation across observed option prices and making some assumptions about the distribution above and below the range of observed strikes. Also, as with the calculation of option-implied volatilities discussed in section 3.4.2, to make option-based distributions comparable across dates, a reference horizon, for example, 30 days or 1 year, must be fixed. Because most options have a fixed expiration date and not a fixed horizon, to calculate fixed-horizon distributions, we also need to interpolate across expiration dates.

This semiparametric method usually yields smooth option-implied distributions that are easy to interpret and are, therefore, suitable as a policy tool to monitor equity markets. However, this method does involve several choices that can influence the shape of the estimated distribution. First, instead of interpolating option prices directly, we interpolate in the space of Black-Scholes option-implied volatilities to reduce the sensitivity of the results to options with strike prices that are very distant from the current price of the equity index (away-from-the-money options). Second, because strike prices are often far from each other, we use a smoothing spline to interpolate volatilities. ${ }^{13}$ This method tends to produce smooth probability distributions with moderately low pricing errors (Datta, Londono, and Ross, 2017). Finally, we assume that option-implied volatilities remain constant beyond the region of strikes for which no options are traded, and we estimate the tails of the distribution under this assumption.

Figure 25 shows the time series for the cost of insurance against a $10 \%$ increase or decrease in the S\&P 500 index over the next 30 (panel A) and 90 days (panel B). The cost of insurance against large changes in the price is one of the outcomes of the optionimplied distributions and allows us to assess how much investors are willing to pay to hedge against these extreme events. Although the dynamics of the cost of insurance share some similarities with those of the VIX reported in figure 22, analyzing the tails yields

\footnotetext{
${ }^{13}$ The method used to interpolate across implied volatilities presents important challenges, especially because, in most cases, option prices obtained from interpolated option-implied volatilities ignore the law of one price.
} 
additional information. For instance, there are asymmetric hedge costs, with the cost of insurance against large drops usually above that against large increases, at least for short horizons. Also, while the dynamics of overall option-implied volatility are driven by the downside component in "normal" episodes, when the cost of insurance against a large increase is almost negligible, both the left and right tail insurance costs increase in episodes of "crisis". An interesting example of this behavior is the COVID-19 pandemic at the end of our sample. During this episode, the cost of insurance against both an increase and a decrease in equity prices increased notably to levels even higher than those observed during 2008. Interestingly, the cost of insurance against a price increase has been slightly higher than that against a decrease.

\subsubsection{Option-Implied Probability Distribution for Individual Stocks}

There is increasing interest in measuring the probability of large negative movements in individual companies' equity prices, especially as a large drop in price may induce default or even bankruptcy. For large, systemically important firms, such events are materially important for both investors and policy makers. There is an active market for options written on stock prices of publicly traded, and typically large, companies. These options are not as frequently traded as index options, most of them are American options (they can be exercised before the expiration date of the option), and they tend to have strike prices close to the underlying stock price. In other words, in sharp contrast to index options, individual company option prices do not span potentially large and negative drops in the underlying stock price. As a result, compared to index options of comparable maturity, individual stock options do not provide the level of comprehensive protection against large negative underlying price moves or convey extensive information about market participants' expected probability of such moves.

Since many single-firm options are relatively thinly traded and concentrated around strikes close to the underlying stock price, it is not advisable to apply the same methods used for index options to extract risk-neutral distributions for individual company option prices. In order to overcome this issue, Aramonte, Schindler, Jahan-Parvar, and Rosen 
Figure 25 Cost of Insurance against a 10 Percent Change in the S\&P 500 Index

Cost of Insurance, Next Thirty Days

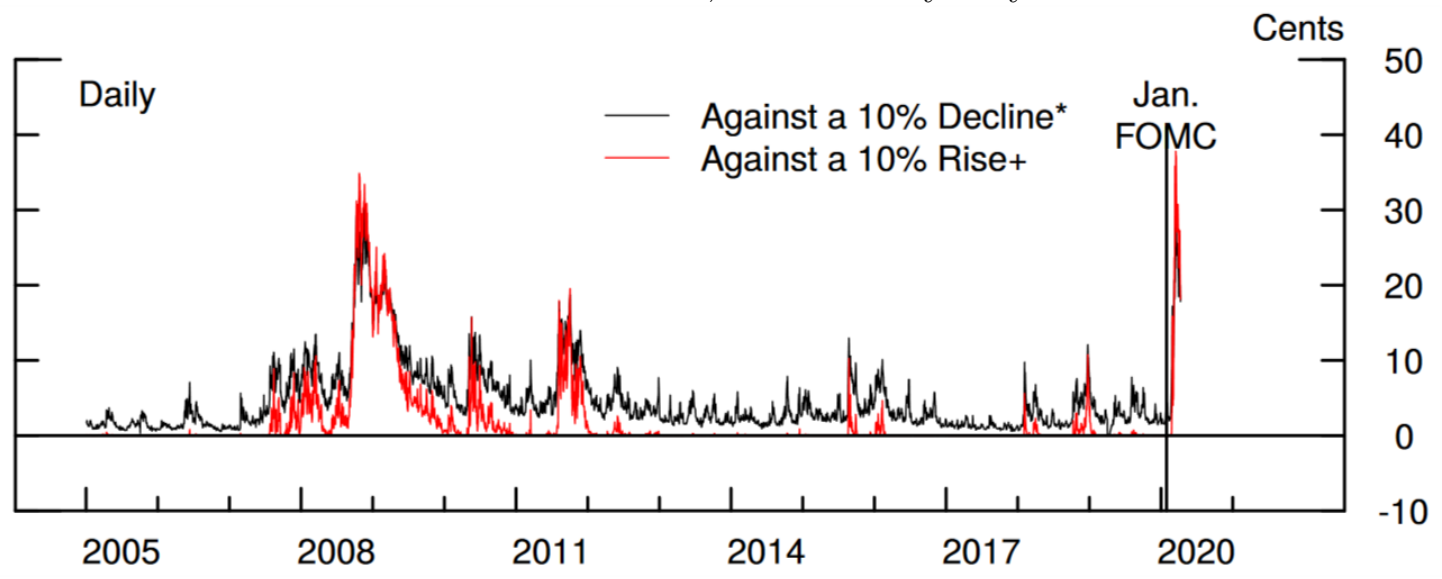

Cost of Insurance, Next Three Months

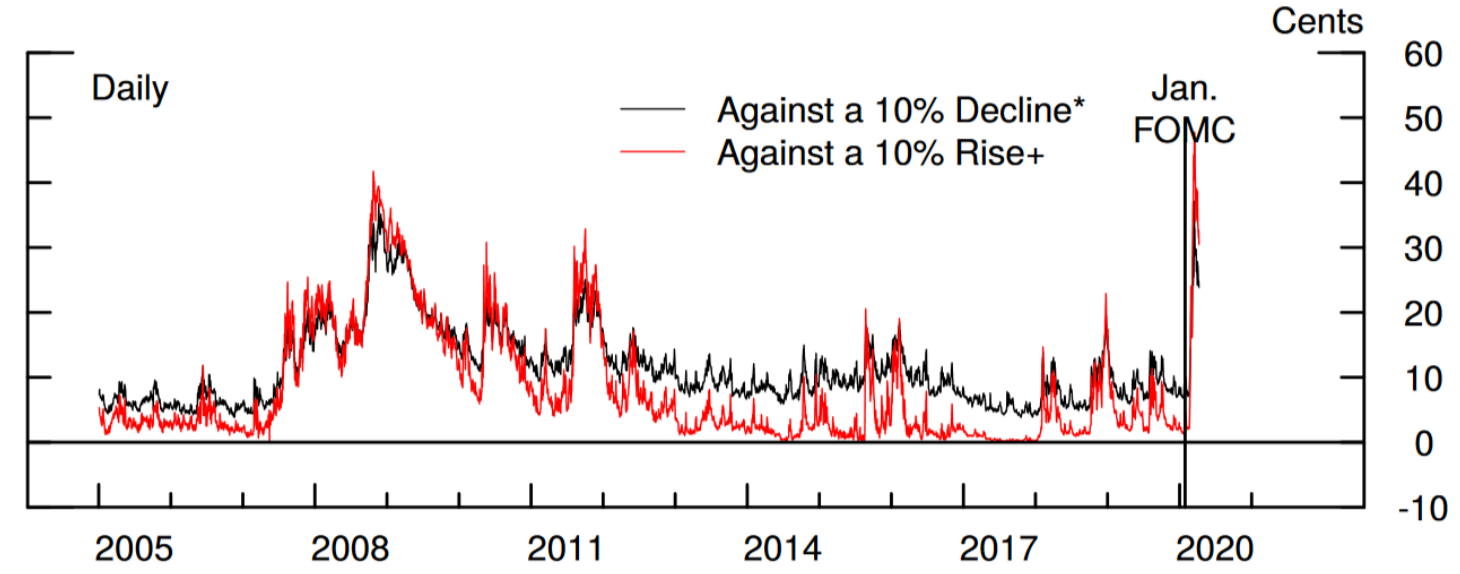

Notes: This figure shows the cost of insurance against a 10\% change in the price of the SEP 500 index. The cost of insurance against a decline (increase) is calculated as the price of a binary option that pays $\$ 1$ if the S\&P 500 declines (increases) $10 \%$ or more over the next thirty days (top panel) or 3 months (bottom panel).

Source: Federal Reserve Board's staff calculations using OptionMetrics Ivy DB US data. 
(2019) exploit the link between credit default swaps (CDS) and options documented by Carr and $\mathrm{Wu}(2010)$ to provide a method to extract a derivative-implied distribution for individual stocks by blending option prices and CDS spreads (with the former providing information about the central part of the distribution and the latter determining the left tail) and interpolating the remaining part of the risk-neutral distribution.

\subsubsection{Interest Rate Uncertainty Measures}

An interest rate swaption is an option to enter into a swap contract at a future date with a predetermined swap rate and given maturity. Market quotes of the interest rate swaptions provide a rich source of information about market participants' uncertainty regarding future interest rates.

Swaption prices vary along three dimensions: maturity of the underlying swap contract (tenor), the option expiries, and the option strikes. For example, a swaption with the oneyear expiry and the ten-year swap tenor is an option to enter into a 10-year interest-rate forward swap contract starting one-year from today. The swap rate (also called the strike rate) is agreed upon by the counterparties and defines the moneyness of the swaption contracts. The most liquid swaptions are at-the-money (ATM) swaptions, which are the swaptions with a strike rate that is equal to the forward swap rate that corresponds to the maturity of the swap specified in the swaption. For example, the strike rate for an ATM swaption with one-year expiry and ten-year tenor is equal to the current one-year ahead ten-year forward swap rate. In the remainder of this section, we focus on the ATM swaptions.

One approach commonly used by market participants to measure the uncertainty surrounding future movements in forward yields is the basis-point volatility implied by option prices. Basis-point volatility, defined as the standard deviation of the changes in the forward yields, allows for a more direct comparison of market participants' uncertainty about future yield movements across different interest rate environments. We focus on the basis-point volatility. ${ }^{14}$

\footnotetext{
${ }^{14}$ An alternative implied volatility unit refers to Black volatility (or percentage volatility). A key underlying assumption in calculating Black volatility is the log-normal distribution of the underlying
} 
Figure 26 shows the time series of annualized swaption-implied volatilities for 6-month option expiry on 2-year (red line) and 10-year (black line) interest rate swaps. Implied volatilities for both short- and long-term rates increased notably following the large declines in interest rates ahead of the June 2019 FOMC meeting. Although the near-term interest rate swaption-implied volatility increased across the maturities, volatility of the shorter-term interest rates increased more than that of the longer-term interest rates, likely reflecting market participants' concerns about uncertainty of the near-term monetary policy. In particular, annualized implied volatility on the two-year rate reached a nine-year high around the June FOMC. Moreover, the implied volatility of the two-year rate rose above the implied volatility of the ten-year rate at the beginning of May 2019, but dropped later on to the levels comparable with the ten-year volatility. Moreover, following the COVID-19 outbreak, implied volatility of 10-year swap rate rose sharply in March 2020, but partially retraced afterwards, amid the improved liquidity conditions along with Fed's monetary policy actions.

Figure 26 Near-Term Implied Volatilities for Swap Rates
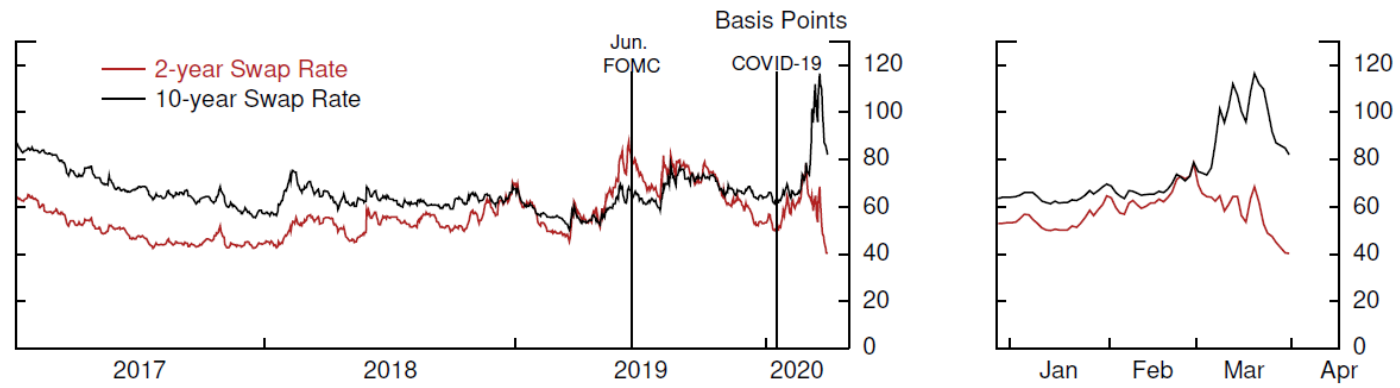

Notes: This figure plots near-term (6-month) swaption-implied volatilities of the 2-year and the 10-year swap rates.

Source: ICAP.

Figure 27 shows the time series of the near-term (6-month, blue line) and medium-term (2-year, black line) swaption-implied volatilities on the ten-year swap rates. Following the escalation in trade tensions between the United States and China in early August 2019, both near-term and medium-term implied volatilities on the long-term rates increased somewhat. Following the COVID-19 outbreak, both near-term and medium term implied volatilities increased significantly, with near-term implied volatility reaching the highest rates. Unlike basis-point volatility, Black volatility does not allow the distribution of interest rates to include negative rates. 
levels since 2014. Moreover, the near-term implied volatility rose more than the mediumterm volatility of the long-term rates and remained at those elevated levels likely reflecting increased uncertainty over the near-term economic outlook.

Figure 27 Implied Volatility on 10-year Rate
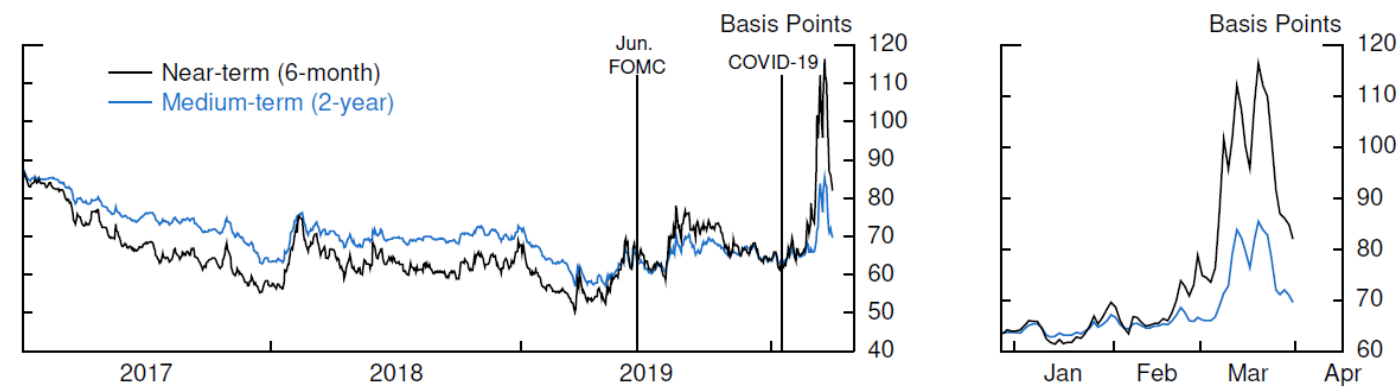

Notes: This figure plots the near-term (6-month) and medium-term (2-year) swaption-implied volatilities of the ten-year swap rates.

Source: ICAP.

\subsubsection{Currency Option-Implied Distributions and Risk Premiums}

The foreign exchange (FX) derivative market is one of the largest and most liquid in the world. However, while a drop in prices is usually considered an unfavorable event for stocks, for currencies, whether the appreciation or depreciation of a currency with respect to another is an unfavorable outcome depends on several factors, especially investor location. Therefore, unlike the options written on equity markets described in section 3.4.4, most exchange rate derivatives are written as a combination of put and call options with the same deltas (the sensitivity of the option price to changes in the price of the underlying asset). Therefore, we can still use these combination derivatives, or "strategies," to derive the risk-neutral distribution of currencies.

The most common strategies are risk reversals and strangles. Risk reversals provide information about the cost of insurance against the depreciation of a currency relative to the cost of insurance against the appreciation of such currency. Specifically, a long position in a risk reversal is equivalent to purchasing a call option and selling a put option on a single bilateral exchange rate. Thus, this strategy protects the investor against an unfavorable drop in the exchange rate (for example, a drop in the dollar with respect to another currency for an exporter located in the United States) but limits investor gains 
if there is a favorable increase in the exchange rate. In a strangle, the investor buys out-of-the-money calls and puts that have the same maturities and deltas. With this strategy, the investor can profit when a currency appreciates or depreciates significantly.

The prices of call and put options at different strikes can be extracted from the prices of the different FX strategies. Consequently, all the methods to calculate option-implied distributions for equities described previously can be used for currencies once the options prices are extracted. In addition, the strategies also give us direct readings of the cost of insurance against a currency depreciation. Figure 28 shows an example relating the cost of insurance derived from risk reversals to the uncertainty of some economic events. The figure shows the time series for euro-dollar risk reversals for the three-month horizon between January 2016 and May 2020. As is clear from the figure, concerns about the outcome of the Brexit vote and the French presidential elections contributed a notable increase in the cost of insuring against a euro depreciation relative to a euro appreciation. Morever, following the COVID-19 outbreak, risk reversals on eur-usd pair rose sharply in March 2020, indicating increased demand for protection against euro appreciation with respect to the U.S. dollar. This move reverted quickly and the cost of protection against a euro depreciation increased dramatically towards the end of March 2020, along with increased safe-haven demands for the U.S. dollar and aggressive monetary policy actions.

As with equities (see section 3.4.2), we can also calculate the currency variance risk premium and its components for all currency pairs with option data available. Londono and Zhou (2017) show that the global currency variance risk premium, which is an average of currency-specific variance risk premiums, is a useful predictor for future appreciation rates. In particular, an increase in the global currency variance risk premium is followed by an appreciation of the USD with respect to other currencies. Interestingly, the currency variance risk premium contains additional information relative to the equity variance risk premium. The additional informational content of the global variance risk premium can be empirically and theoretically related to global inflation uncertainty. 


\section{Figure 28 Euro-USD Risk Reversals}

\section{Euro-USD Risk Reversals}

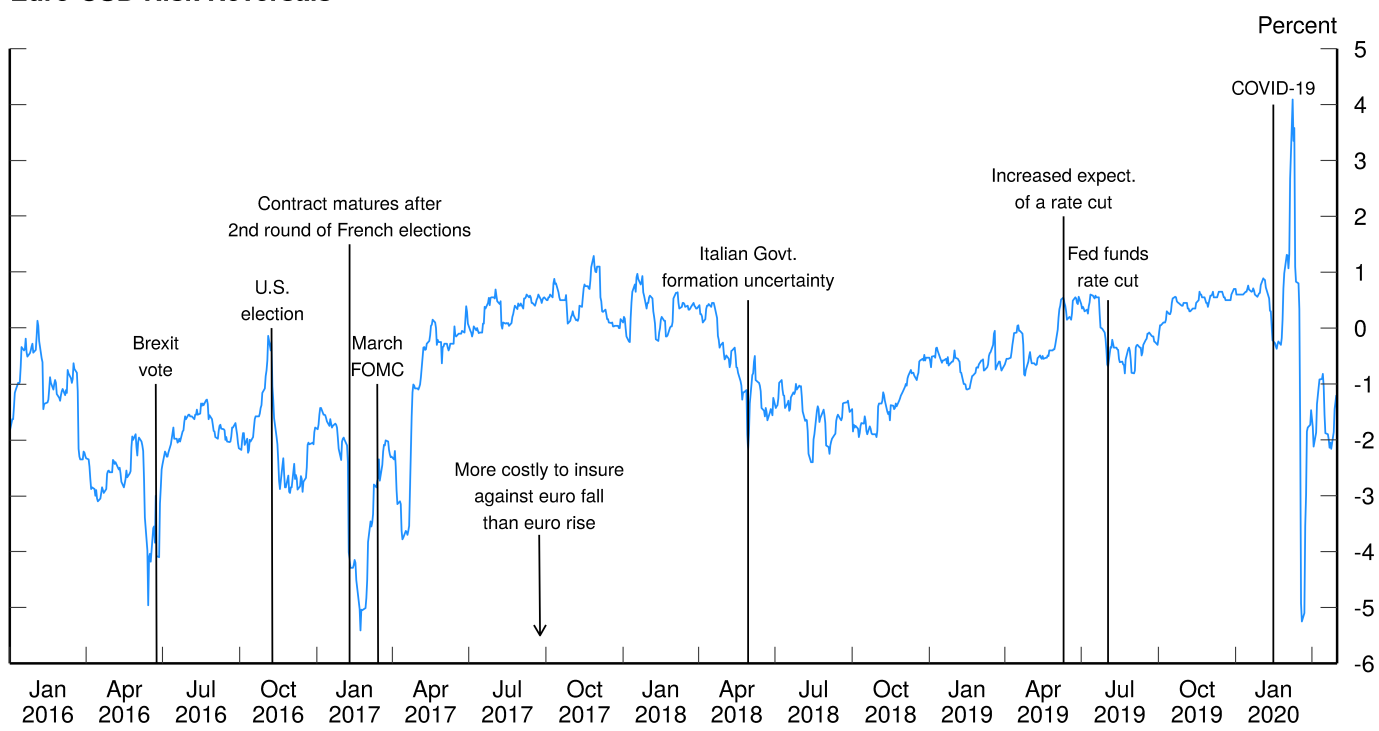

Notes: This figure plots a time series derived from the prices of risk reversals for the cost of insurance against a euro depreciation against the U.S. dollar. These are over-the-counter derivatives with a 10-delta strike and 3-month maturity.

Source: Bloomberg Finance LP.

\subsubsection{Oil Price Option-Implied Probability Distributions and Risk Measures}

Options on oil futures contracts for West Texas Intermediate (WTI) crude oil are available on the New York Mercantile Exchange (NYMEX). As with other assets, the prices of options with different strikes and different horizons to maturity contain information about the probability assigned to each possible market outcome for crude oil prices as well as investor preferences. These option prices can be used to generate option-implied distributions, which, in turn, can be used to calculate option-implied moments, such as implied volatility or the cost of insurance against particular market outcomes. The bottom panel of figure 29 depicts the implied volatility calculated from option-implied distributions as well as the Chicago Board Options Exchange (CBOE) oil VIX, which is an alternative summary measure of implied volatility for the WTI price of crude oil that is analogous to the S\&P 500 VIX.

Datta et al. (2017) apply the semiparametric method developed by Breeden and Litzenberger (1978) to map between observed option prices and the option-implied probability distribution, analogous to the method used for equity distributions discussed previ- 
ously. This method generally produces smooth probability distributions with low pricing errors. To reduce the sensitivity of the results to options with strike prices that are very distant from the current oil price, the authors use a smoothing spline and interpolate across the volatilities implied by the observed strike prices. Then, to generate the distribution above and below the range of observed strikes, the authors assume that option-implied volatilities remain constant beyond the region of strikes for which no options are traded. Lastly, to make option-implied distributions comparable across dates, the authors fix a reference horizon (for example, 30 days or 1 year). As with options on equity indexes, these options are available for fixed expiration dates that coincide with futures contract availability, which have a monthly frequency. Datta et al. (2017) find that a fixed horizon of 90 days generally has enough liquidity to support estimation of informative option-implied distributions. Distributions with fixed December expiration dates (for example, December 2017) are also informative.

The top two panels of Figure 29 illustrate the additional information provided by the entire WTI option-implied probability density function (PDF) compared to summary moments, such as the volatility. The top left panel shows the shift in the 90-day distribution that occurred after the September 14, 2019 attack on Saudi oil facilities. While the attacks led to only a small increase in the mean of the distribution, the shape of the distribution changed more significantly. In particular, as shown by the distribution in red, there is a noticeable increase in the probability of the oil price falling in the $\$ 70$ to $\$ 90$ range after the attacks. Additionally, the resulting distribution has much higher volatility and an increase in right skewness. Turning to the top right panel, the distribution of prices for December 2020, shows that the slight bimodality of the distribution before the attacks (in black) was amplified (in red) in the days following the attacks, likely indicating two possible scenarios: either the Saudi facilities would recover quickly, contributing to continued oversupply in the market and contributing to the mass in the $\$ 40$ to $\$ 50$ per barrel range, or the higher risk premium in the market would remain, keeping prices in the $\$ 60$ to $\$ 70$ range. In April 2020, following the collapse in oil demand precipitated by the outbreak of the COVID-19, the distribution (shown in blue) showed a significant 
probability that oil prices would remain as low as $\$ 5$ to $\$ 20$ per barrel through the end of the year.

While we show here the distribution of the expected price level, we can also express these results as a distribution of expected returns (that is, changes in future oil prices with respect to the current price). Using the distribution of returns, we calculate summary measures, which can be plotted over time. In particular, the middle panel shows the weekly frequency series for the cost of insurance against 15 percent changes in the price of oil in the next 90 days. Lastly, the bottom panel shows the CBOE Oil VIX along with option-implied quantile volatility. ${ }^{15}$ All of these alternative measures of oil market uncertainty show a steep increase in March 2020, driven by the collapse in oil demand and the uncertain outlook for supply precipitated by the COVID-19 outbreak.

\section{Knightian Uncertainty and Ambiguity Aversion}

So far, we have treated risk and uncertainty interchangeably. In this section, we explain the concept of "Knightian uncertainty," first introduced by Knight (1921), that separates risk from uncertainty. Models based on the notion of Knightian uncertianty depart from the rational expectations paradigm that dominates modern macro and financial economics. These rational expectations models have difficulty explaining several salient features of financial asset prices jointly. In particular, reconciling several riskrelated puzzles, such as the low volatility of interest rates, long episodes of low realized and option-implied volatility (See sections 3.2 and 3.4.4), and equity total, upside, and downside variance risk premiums (see section 3.4.3), in a unified model requires imposing structures on the state variables that are hard to justify based on statistical evidence.

\footnotetext{
${ }^{15}$ Datta et al. (2017) show that relative to the usual calculations for volatility, skewness, and kurtosis, quantile moments are more likely to reflect meaningful underlying daily market movements than data anomalies. As quantile moments do not use the most extreme tails of the distribution, they are less reliant on the distribution assumptions above and below the range of observed strike prices. Quantile volatility is the difference between the returns at the $75^{\text {th }}$ and $25^{\text {th }}$ percentiles of the option-implied probability density functions. Quantile skewness is the difference between the returns at the $75^{\text {th }}$ and $50^{\text {th }}$ percentiles minus the difference between the returns at the $50^{\text {th }}$ and $25^{\text {th }}$ percentiles, with this difference then divided by the difference between the returns at the $75^{\text {th }}$ and $25^{\text {th }}$ percentiles. Finally, quantile kurtosis is the difference between the returns at the $95^{\text {th }}$ and $5^{\text {th }}$ percentiles divided by the difference between the returns at the $75^{\text {th }}$ and $25^{\text {th }}$ percentiles minus a coefficient adjustment.
} 
Figure 29 Option-Implied Measures for WTI Crude Oil

PDFs, 90-Day Futures

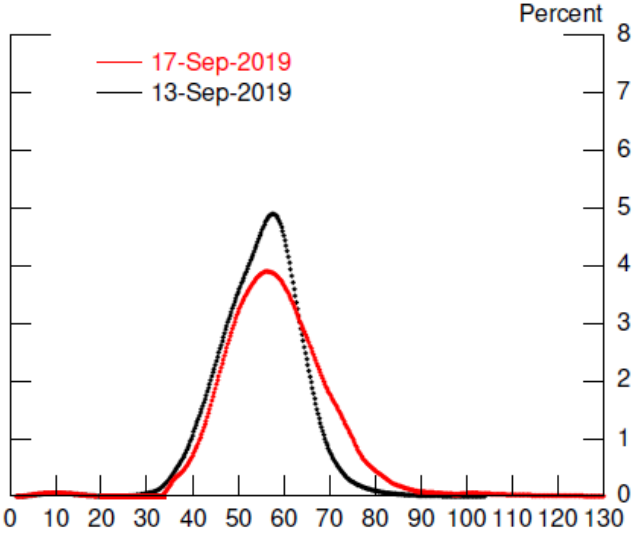

PDFs, December 2020 Futures

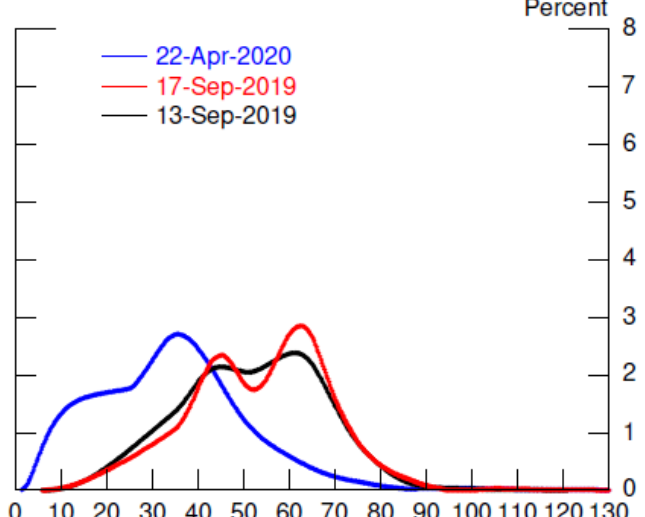

Cost of Insurance*

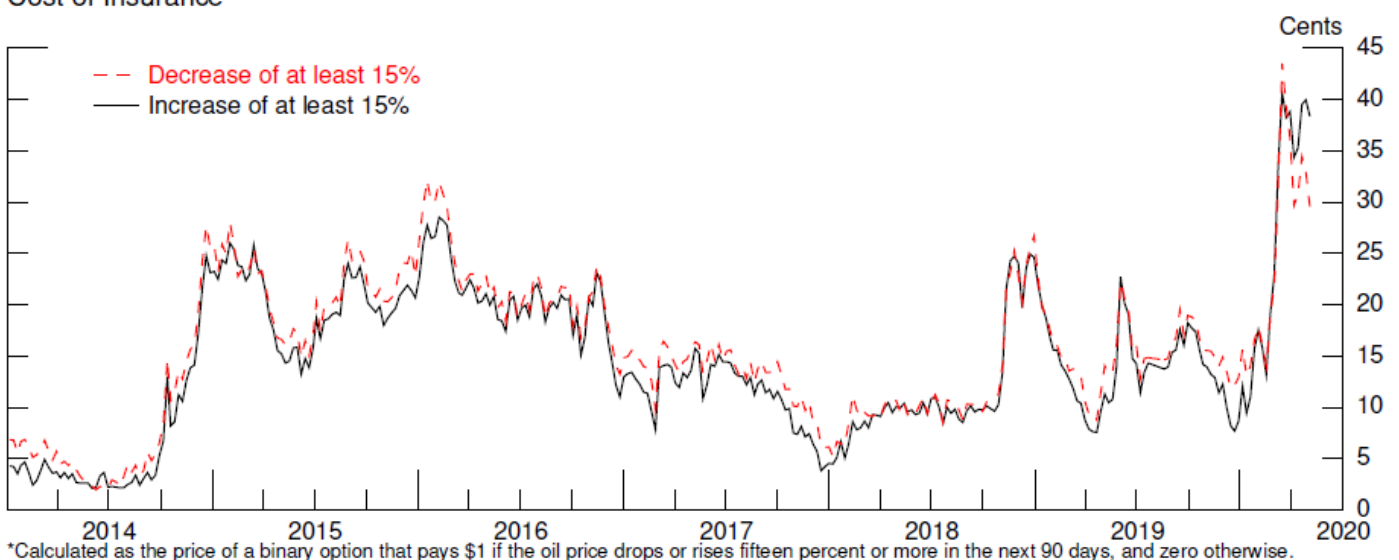

Options-Implied Volatility

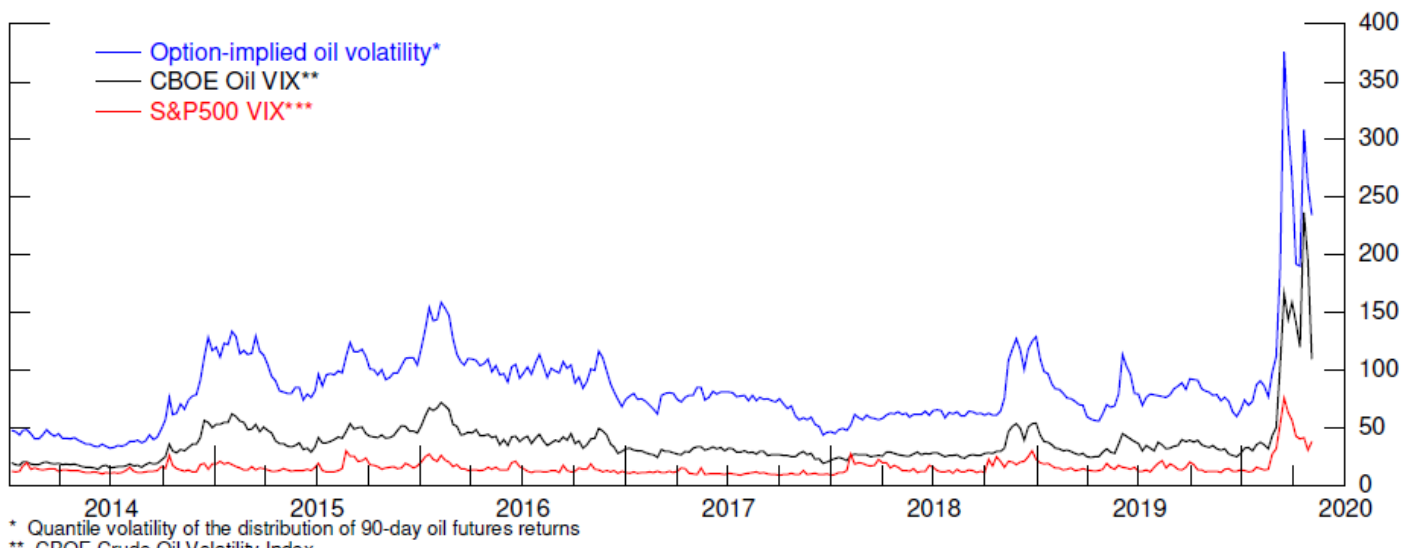

* Quantile volatility of the distribution

*** S\&P500 VIX; Stock Implied Volatility Index (1 to 2 Months)

Notes: Top charts illustrate the probability distributions for the price of WTI crude oil 90days ahead (left chart) and for December 2020 (right chart). Blue line uses options data from April 22, 2020, red lines use data from September 17, 2019, and black lines use data from September 13, 2019. Center chart illustrates the cost of insurance against a 15 percent increase (in black) or decrease (in dashed red) over the next 90 days. Bottom chart illustrates option-implied volatility for oil future returns over a 90-day horizon in blue and a 30-day horizon in black (CBOE Oil VIX), compared to the SEPP 500 VIX.

Source: Federal Reserve Board's staff calculations using NYMEX data, and FRED for CBOE Oil VIX and SEP 500 VIX. 
For example, both Bekaert and Engstrom (2017) and Feunou et al. (2018) assume distinct dynamics for positive- and negative-valued movements in consumption growth. In response to these limitations, a number of modifications to the standard rational expectations asset pricing models have been developed. Among these modifications, ambiguity aversion has emerged as a powerful contender for rational expectations explanations of financial market behavior.

We use Knightian uncertainty and ambiguity about the dynamics of state variables as synonyms. Roughly speaking, risk refers to the situation where there is a probability measure to guide a choice, while ambiguity refers to the situation where the decision maker is uncertain about this probability measure due to cognitive or informational constraints. Alternatively, think about ambiguity as uncertainty about the "true" probability distribution governing future paths of state variables. The decision makers' ambiguity attitude determines how and to what extent such uncertainty affects their choices. As a result, compared with a solely risk-averse agent, the ambiguity-averse agent effectively assigns more probability weight to "bad" states that are associated with lower levels of the continuation values. Alternatively, one may characterize ambiguity averse agents as lacking the confidence to assign probabilities to all relevant events. Instead, they act as if they evaluate plans using a worst-case probability drawn from a set of multiple plausible probability distributions.

A crucial assumption in many rational-expectation-based asset pricing models is that decision makers (households, investors, firms, intermediaries, policy makers, and the economist/econometrician observing them) have the same information about the dynamics of all state variables in the economy. Therefore, these agents base their conditional expectations of state variables on the same (joint) probability law. In such an environment, given a (conditional) probability distribution for the state variables, with defined and finite first and second moments, risk assessment is merely an exercise of estimating the (conditional) second moment of these state variables, which governs the dispersion of outcomes. Ambiguity aversion models assume that there is a wedge between the decision maker's subjective probabilities and expectations compared to rational expectations mod- 
els. These wedges are modeled by modifying the agent's preferences. There are several methods for modeling the preferences of ambiguity averse decision makers. Among them, the multiple prior utility of Gilboa and Schmeidler (1989), Epstein and Wang (1994), Epstein and Schneider (2003), and Chen and Epstein (2002); smooth ambiguity aversion of Klibanoff, Marinacci, and Mukerji (2005), Klibanoff, Marinacci, and Mukerji (2009), Hayashi and Miao (2011); and uncertain probability expected utility of Izhakian (2017) feature more prominently in the literature. Bachmann, Carstensen, Lautenbacher, and Schneider (2020) survey firms directly to investigate whether decision-makers think about the future in terms of probabilities.

As mentioned above, all these preferences tilt the decision maker's subjective view of the world toward "bad" outcomes. Figure 30 shows two examples based on the smooth ambiguity preferences of Klibanoff et al. (2009). On the left, we report the plot of simulated paths for Bayesian and ambiguity-distorted probabilities of transitioning from a good to the next good state in a Markov switching model (from Jahan-Parvar and Liu, 2014 and similar to findings of Ju and Miao, 2012). It is clear that the ambiguity-averse decision maker is less confident about the continuation of the good state, evidenced by the consistently lower values assigned to this probability. On the left, we plot the Bayesian and ambiguity-distorted distribution of Bansal and Yaron (2004) long-run component of consumption growth (from Gallant, Jahan-Parvar, and Liu, 2019 and in the same spirit as in Bidder and Dew-Becker, 2016). Similar to the left panel, the ambiguity averse agent is more pessimistic and assigns lower values to the probability of positive long-run component realizations.

In recent years, financial economic models based on ambiguity aversion have become increasingly popular. Applications to risky financial assets include equity risk premium (Ju and Miao, 2012; Jahan-Parvar and Liu, 2014; and Jeong, Kim, and Park, 2015), portfolio choice (Maccheroni, Marinacci, and Ruffino, 2013), term structure of interest rates (Gagliardini, Porchia, and Trojani, 2009 and Zhao, 2019), variance risk premium (Drechsler, 2013; Miao, Wei, and Zhou, 2019; and Gallant et al., 2019), and CDS spreads (Augustin and Izhakian, 2019), among other applications. 
Figure 30 Effect of Ambiguity Aversion
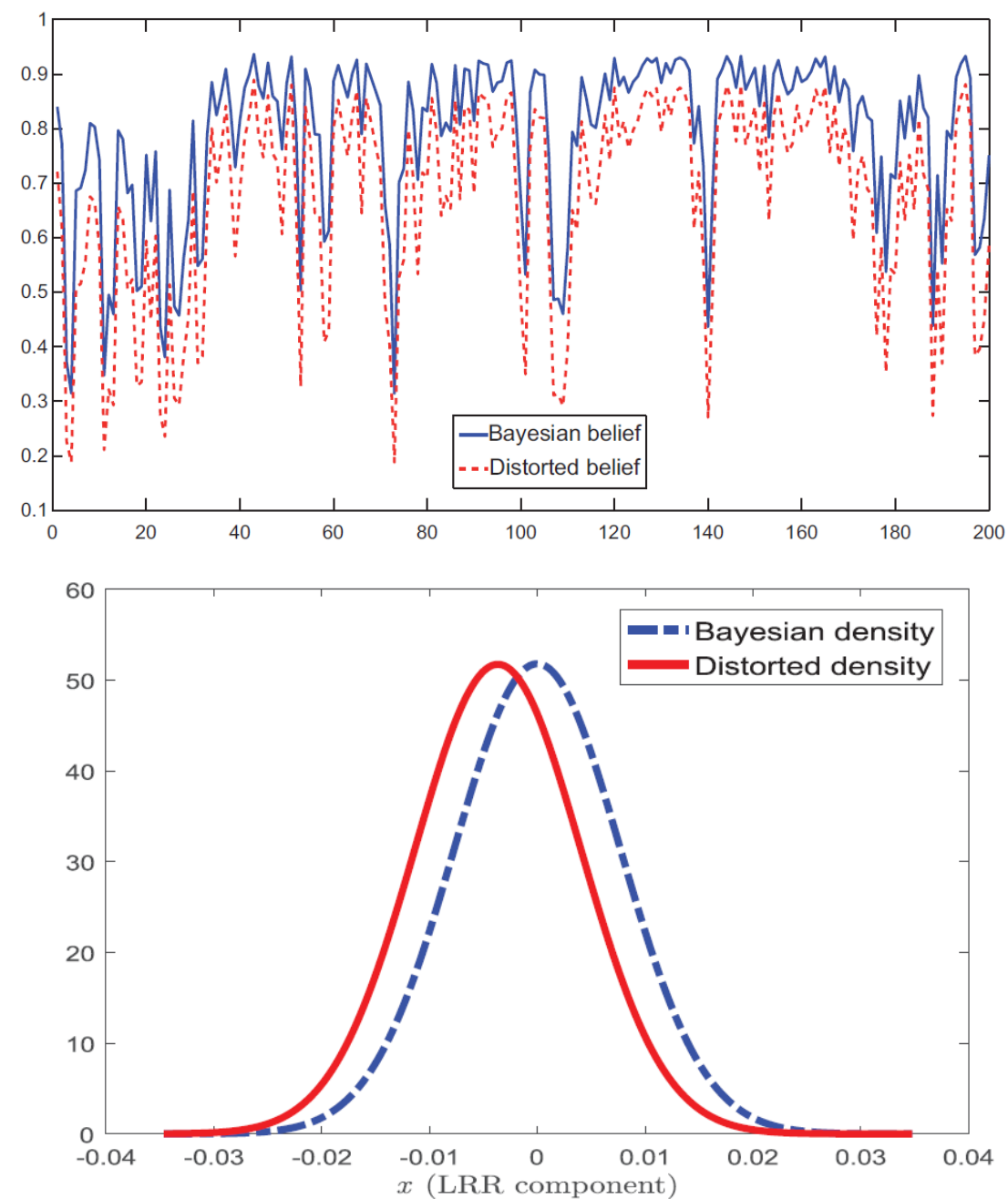

Notes: In both figures, the blue lines show the Bayesian probability of the transition from good to the next good state in a Markov switching model (top) and the posterior distribution of the long-run component of consumption growth as in Bansal and Yaron (2004) (bottom). The red lines show the same for the decision maker's ambiguity-distorted probabilities. The ambiguity averse agent is more pessimistic than the purely Bayesian agent.

Brenner and Izhakian (2018) document an interesting application of ambiguity aversion. They develop a measure of monthly realized market ambiguity based on 5-minute returns of S\&P 500 index exchange traded funds. They decompose the uncertainty premium into a risk premium (proportional to risk tolerance of the agent and the variance of returns) and an ambiguity premium (proportional to tolerance for ambiguity and perceptions of the magnitude of ambiguity). Ambiguity tolerance stems from the functional form of the agent's preferences. The ambiguity index is a measure of the agent's perception of ambiguity. Brenner and Izhakian (2018) define the degree of ambiguity as the expected product of the conditional expected value of the distribution of returns and the 
conditional variance of the distribution of returns. To build this measure, the authors divide the daily range of intraday returns into 60 intervals (bins) between -6 and +6 percent. They sort intraday 5-minute returns into these bins and compute the probability of returns that occur outside the \pm 6 percent interval. Then, they compute the mean and variance for each of these 62 bins. The monthly realized ambiguity index is the scaled sum of the product of each bin's mean and variance, conditioned on the bin's computed mean and variance values.

The ambiguity index differs from realized volatility (see section 3.1) in that Brenner and Izhakian (2018) build a histogram of intraday returns first, then compute the ambiguity measure of realized returns across trading days for each bin in the histogram before forming the index. In constructing the realized volatility, we average the squared intraday returns, without separating the returns across trading days based on their magnitude. This measure reveals an interesting pattern. For instance, many observers are puzzled by the relatively low values of market volatility measures, such as realized and option-implied volatilities, in the post-2016 U.S. presidential election period. While overall uncertainty about the economy has increased, financial market volatility measures are much lower than, for example, their recent highs during the European debt crisis in 2011 or during the late 1990s emerging market debt crises. They are also lower than economic policy uncertainty measures. This puzzle is clear in the bottom panel of figure 31, which plots VIX values for 2000-2019 period. On the other hand, Brenner and Izhakian's realized ambiguity measure, plotted in the top panel in the same figure, implies that market ambiguity has increased significantly since late 2016. That is, investors are more uncertain about the state of the economy or the market (and the path that they may take in the future), rather than the realized or implied volatility of index returns.

\section{Conclusion}

As uncertainty episodes, such as the COVID-19 pandemic, weigh heavily on economic projections of researchers and policymakers, it is important to know how well suited 


\section{Figure 31 Ambiguity Index}
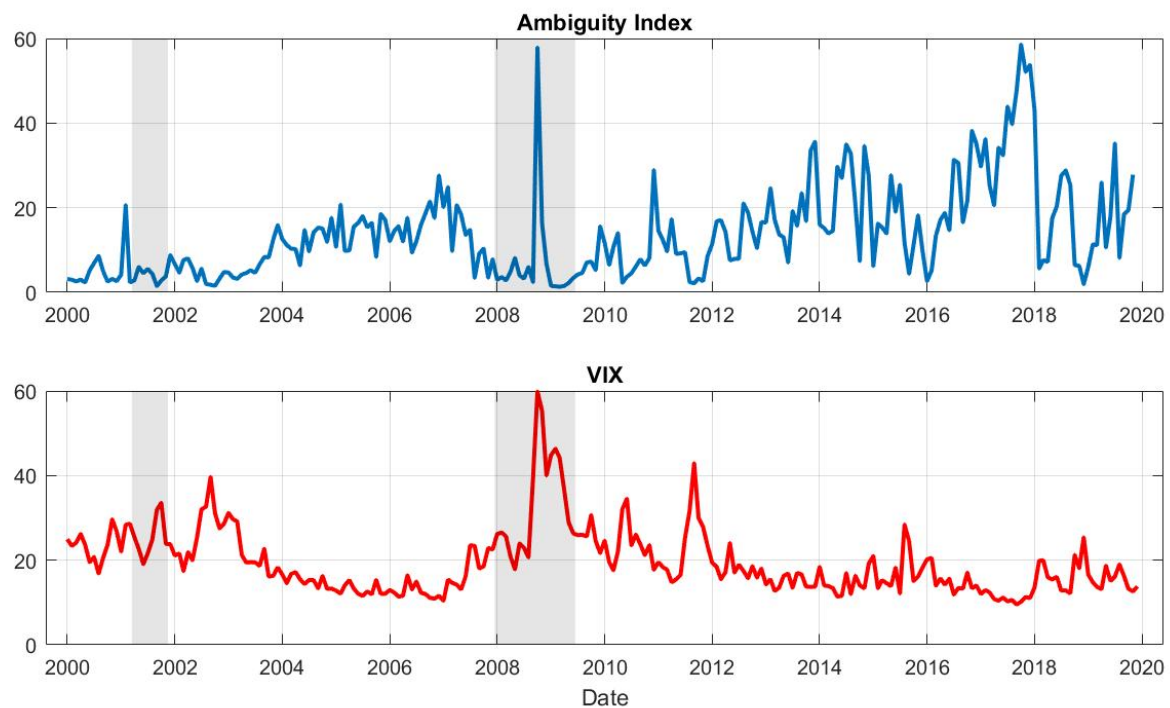

Notes: This figure plots Brenner and Izhakian (2018) measure of monthly market ambiguity level for the SPDR ETF (top) and VIX values, reflecting option-implied volatilities for the $S \mathscr{S P} 500$ index (bottom). The ambiguity index is rescaled (multiplied by 10) so that its magnitude is comparable to VIX values. Shaded areas represent NBER recessions.

standard measures of risk and uncertainty are for understanding its various economic and financial outcomes. In this paper, we review a broad set of measures of risk, uncertainty, and volatility to help researchers, market participants, and policymakers broaden their knowledge about the calculation and usefulness of these measures. We use a unified structure to review all measures, which allows us to highlight their differences and comparative advantages. In particular, we explain in detail their calculation methods to facilitate the replicability of existing evidence and the use of these measures in other applications. We also plot the time series of all measures to show their dynamics around key events, such as the 2008 global financial crisis, the recent trade disputes between China and the United States, and the outbreak of the COVID-19 in 2020. We also provide a summary of all measures reviewed in this survey in table A.1. Finally, we do a comprehensive review of the literature to understand the domestic and spillover effects of different sources of risk, uncertainty, and volatility on macroeconomic and financial outcomes.

Although we believe the list of measures presented in this paper is exhaustive, we plan to add new measures and update the reviewed measures as future developments 
warrant. We also hope our review and "taxonomy" paves the way for future research related to risk, uncertainty, and volatility. Several research topics remain somewhat thinly explored, including the exploration of the channels through which uncertainty affects real and financial outcomes; a more structured understanding of the interconnection among uncertainty measures; the endogeneity and causality between macroeconomic and financial uncertainty; the spillover effects of uncertainty across countries; and whether uncertainty modifies how other economic shocks are transmitted. 


\section{References}

Aastveit, K. A., Natvik, G. J., and Sola, S. (2013). Economic uncertainty and the effectiveness of monetary policy. Working Paper 2013/17, Norges Bank.

Adrian, T., Boyarchenko, N., and Giannone, D. (2019). Vulnerable Growth. American Economic Review, $109(4), 1263-1289$.

Adrian, T., Grinberg, F., Liang, N., and Malik, S. (2018). The Term Structure of Growthat-Risk. IMF Working Papers 18/180, International Monetary Fund.

Ahir, H., Bloom, N., and Furceri, D. (2018). The World Uncertainty Index. Mimeo.

Ait-Sahalia, Y., Karaman, M., and Mancini, L. (2018). The Term Structure of Variance Swaps and Risk Premia. Swiss Finance Institute Research Paper Series 18-37, Swiss Finance Institute.

Alessandri, P., and Mumtaz, H. (2014). Financial regimes and uncertainty shocks. BCAM Working Papers, 1404.

Alizadeh, S., Brandt, M. W., and Diebold, F. X. (2002). Range-based estimation of stochastic volatility models. The Journal of Finance, 57(3), 1047-1091.

Altig, D., Barrero, J. M., Bloom, N., Davis, S. J., Meyer, B. H., and Parker, N. (2020). Surveying business uncertainty. Journal of Econometrics (forthcoming).

Amengual, D., and Xiu, D. (2018). Resolution of policy uncertainty and sudden declines in volatility. Journal of Econometrics, 203(2), 297-315.

Andersen, T. G., Bollerslev, T., Diebold, F. X., and Labys, P. (2001). The Distribution of Realized Exchange Rate Volatility. Journal of the American Statistical Association, $96,42-55$.

Andersen, T. G., Bollerslev, T., Diebold, F. X., and Labys, P. (2003). Modeling and forecasting realized volatility. Econometrica, 71(2), 579-625. 
Aramonte, S., Schindler, J. W., Jahan-Parvar, M., and Rosen, S. (2019). Firm-specific risk-neutral distributions with options and CDS. International Finance Discussion Papers 1212, Board of Governors of the Federal Reserve System (U.S.).

Arbatli, E. C., Davis, S. J., Ito, A., Miake, N., and Saito, I. (2017). Policy Uncertainty in Japan. IMF Working Papers 17/128, International Monetary Fund.

Arslan, Y., Atabek, A., Hulagu, T., and Şahinöz, S. (2015). Expectation errors, uncertainty, and economic activity. Oxford Economic Papers, 67(3), 634-660.

Augustin, P., and Izhakian, Y. (2019). Ambiguity, Volatility, and Credit Risk. Review of Financial Studies (forthcoming).

Bachmann, R., and Bayer, C. (2014). Investment dispersion and the business cycle. American Economic Review, 104(4), 1392-1416.

Bachmann, R., Carstensen, K., Lautenbacher, S., and Schneider, M. (2018). Uncertainty and change: Survey evidence of firms' subjective beliefs. Tech. rep., working paper.

Bachmann, R., Carstensen, K., Lautenbacher, S., and Schneider, M. (2020). Uncertainty is more than risk-survey evidence on knightian and bayesian firms. Tech. rep., working paper.

Bachmann, R., Elstner, S., and Hristov, A. (2017). Surprise, surprise-measuring firm-level investment innovations. Journal of Economic Dynamics and Control, 83, 107-148.

Bachmann, R., Elstner, S., and Sims, E. R. (2013). Uncertainty and Economic Activity: Evidence from Business Survey Data. American Economic Journal: Macroeconomics, $5(2), 217-249$.

Baker, S. R., Bloom, N., and Davis, S. J. (2016). Measuring Economic Policy Uncertainty. The Quarterly Journal of Economics, 131(4), 1593-1636.

Baker, S. R., Bloom, N., Davis, S. J., and Kost, K. J. (2019a). Policy news and stock market volatility. Tech. rep., National Bureau of Economic Research. 
Baker, S. R., Bloom, N., Davis, S. J., Kost, K. J., Sammon, M., and Viratyosin, T. (2020). The Unprecedented Stock Market Reaction to COVID-19. COVID Economics: Vetted and Real-Time Papers, 1(1).

Baker, S. R., Bloom, N., Davis, S. J., and Sammon, M. (2019b). What Triggers Stock Market Jumps? Tech. rep., Mimeo.

Bansal, R., and Yaron, A. (2004). Risks for the long run: A potential resolution of asset pricing puzzles. The Journal of Finance, 59(4), 1481-1509.

Bauer, M., Lakdawala, A., and Mueller, P. (2019). Market-based monetary policy uncertainty. Federal Reserve Bank of San Francisco Working Series.

Bekaert, G., and Engstrom, E. (2017). Asset Return Dynamics under Habits and Bad Environment-Good Environment Fundamentals. Journal of Political Economy, 125(3), $713-760$.

Bekaert, G., Hoerova, M., and Lo Duca, M. (2013). Risk, uncertainty and monetary policy. Journal of Monetary Economics, 60(7), 771-788.

Bidder, R., and Dew-Becker, I. (2016). Long-run risk is the worst-case scenario. American Economic Review, 106(9), 2494-2527.

Binder, C. C. (2017). Measuring uncertainty based on rounding: New method and application to inflation expectations. Journal of Monetary Economics, 90, 1-12.

Bloom, N. (2009). The Impact of Uncertainty Shocks. Econometrica, 77(3), 623-685.

Bloom, N. (2014). Fluctuations in uncertainty. Journal of Economic Perspectives, 28(2), $153-76$.

Bollerslev, T., Gibson, M., and Zhou, H. (2011). Dynamic estimation of volatility risk premia and investor risk aversion from option-implied and realized volatilities. Journal of Econometrics, $160(1), 235-245$. 
Bollerslev, T., Marrone, J., Xu, L., and Zhou, H. (2014). Stock Return Predictability and Variance Risk Premia: Statistical Inference and International Evidence. Journal of Financial and Quantitative Analysis, 49(3), 633-661.

Bollerslev, T., Tauchen, G., and Zhou, H. (2009). Expected Stock Returns and Variance Risk Premia. Review of Financial Studies, 22(11), 4463-4492.

Bollerslev, T., and Todorov, V. (2011). Tails, Fears, and Risk Premia. Journal of Finance, $66(6), 2165-2211$.

Bollerslev, T., and Zhou, H. (2006). Volatility puzzles: a simple framework for gauging return-volatility regressions. Journal of Econometrics, 131(1-2), 123-150.

Breeden, D. T., and Litzenberger, R. H. (1978). Prices of State-contingent Claims Implicit in Option Prices. The Journal of Business, 51(4), 621-651.

Brenner, M., and Izhakian, Y. (2018). Asset pricing and ambiguity: Empirical evidence. Journal of Financial Economics, $130(3), 503$ - 531.

Britten-Jones, M., and Neuberger, A. (2000). Option prices, implied price processes, and stochastic volatility. The Journal of Finance, 55(2), 839-866.

Brogaard, J., and Detzel, A. (2015). The Asset-Pricing Implications of Government Economic Policy Uncertainty. Management Science, 61(1), 3-18.

Bundick, B., Herriford, T., and Smith, A. L. (2017). Forward guidance, monetary pplicy uncertainty, and the term premium. Federal Reserve Bank of Kansas City Working Paper.

Caldara, D., Cascaldi-Garcia, D., Cuba-Borda, P., and Loria, F. (2020). Real-Time Growth-at-Risk. Tech. rep., Mimeo.

Caldara, D., and Iacoviello, M. (2018). Measuring Geopolitical Risk. International Finance Discussion Papers 1222, Board of Governors of the Federal Reserve System (U.S.). 
Caldara, D., Iacoviello, M., Molligo, P., Prestipino, A., and Raffo, A. (2019a). The Economic Effects of Trade Policy Uncertainty. Journal of Monetary Economics (forthcoming).

Caldara, D., Scotti, C., and Zhong, M. (2019b). Macroeconomic and Financial Risks: A Tale of Volatility. Mimeo.

Carr, P., and Wu, L. (2010). Stock Options and Credit Default Swaps: A Joint Framework for Valuation and Estimation. Journal of Financial Econometrics, 8(4), 409-449.

Carriero, A., Clark, T. E., and Marcellino, M. (2018). Measuring Uncertainty and Its Impact on the Economy. The Review of Economics and Statistics, 100(5), 799-815.

Cascaldi-Garcia, D. (2019). Dynamic Effects of News Shocks Under Uncertainty. Tech. rep., Mimeo.

Cascaldi-Garcia, D., and Galvao, A. B. (2019). News and Uncertainty Shocks. Journal of Money, Credit and Banking (forthcoming).

Chan, J. C. (2017). The stochastic volatility in mean model with time-varying parameters: An application to inflation modeling. Journal of Business $\&$ Economic Statistics, $35(1)$, $17-28$.

Chen, Z., and Epstein, L. (2002). Ambiguity, risk, and asset returns in continuous time. Econometrica, 70(4), 1403-1443.

Christiano, L. J., Motto, R., and Rostagno, M. (2014). Risk Shocks. American Economic Review, $104(1), 27-65$.

Corsi, F. (2009). A Simple Approximate Long-Memory Model of Realized Volatility. Journal of Financial Econometrics, 7(2), 174-196.

Dahlhaus, T., and Sekhposyan, T. (2020). Survey-based monetary policy uncertainty and its asymmetric effects. Tech. rep., working paper. 
Danielsson, J., Valenzuela, M., and Zer, I. (2018). Learning from History: Volatility and Financial Crises. The Review of Financial Studies, 31, 2774-2805.

Datta, D. D., Londono, J. M., and Ross, L. J. (2017). Generating options-implied probability densities to understand oil market events. Energy Economics, 64 (C), 440-457.

De Pooter, M. and Favara, G. and Modugno, M. and Wu, J. (2020). Monetary policy uncertainty and monetary policy surprises. Journal of International Money and Finance (forthcoming).

Dew-Becker, I., Giglio, S., Le, A., and Rodriguez, M. (2017). The price of variance risk. Journal of Financial Economics, 123(2), 225-250.

Drechsler, I. (2013). Uncertainty, Time-Varying Fear, and Asset Prices. Journal of Finance, 68(5), 1843-1889.

Drechsler, I., and Yaron, A. (2011). What's vol got to do with it. Review of Financial Studies, 24(1), 1-45.

Epstein, L. G., and Schneider, M. (2003). Recursive multiple-priors. Journal of Economic Theory, $113(1), 1-31$.

Epstein, L. G., and Wang, T. (1994). Intertemporal asset pricing under knightian uncertainty. Econometrica, 62(2), 283-322.

Fernández-Villaverde, J., Guerrón-Quintana, P., Kuester, K., and Rubio-Ramírez, J. (2015). Fiscal volatility shocks and economic activity. American Economic Review, $105(11), 3352-84$.

Fernández-Villaverde, J., Guerrón-Quintana, P., Rubio-Ramírez, J. F., and Uribe, M. (2011). Risk matters: The real effects of volatility shocks. American Economic Review, $101(6), 2530-61$.

Fernández-Villaverde, J., and Guerrón-Quintana, P. A. (2020). Uncertainty Shocks and Business Cycle Research. NBER Working Papers 26768, National Bureau of Economic Research, Inc. 
Ferreira, T. R. T. (2018). Stock Market Cross-Sectional Skewness and Business Cycle Fluctuations. International Finance Discussion Papers 1223, Board of Governors of the Federal Reserve System (U.S.).

Feunou, B., Jahan-Parvar, M., and Tédongap, R. (2013). Modeling market downside volatility. Review of Finance, 17(1), 443-481.

Feunou, B., Jahan-Parvar, M. R., and Okou, C. (2018). Downside Variance Risk Premium. Journal of Financial Econometrics, 16(3), 341-383.

Feunou, B., Jahan-Parvar, M. R., and Tédongap, R. (2016). Which parametric model for conditional skewness? The European Journal of Finance, 22(13), 1237-1271.

Francis, B. B., Hasan, I., and Zhu, Y. (2014). Political uncertainty and bank loan contracting. Journal of Empirical Finance, 29(C), 281-286.

Gagliardini, P., Porchia, P., and Trojani, F. (2009). Ambiguity Aversion and the Term Structure of Interest Rates. Review of Financial Studies, 22(10), 4157-4188.

Gallant, A. R., Jahan-Parvar, M. R., and Liu, H. (2019). Does Smooth Ambiguity Matter for Asset Pricing? Review of Financial Studies, 32(9), 3617-3666.

Gilboa, I., and Schmeidler, D. (1989). Maxmin expected utility with non-unique prior. Journal of Mathematical Economics, 18(2), 141-153.

Gilchrist, S., and Zakrajsek, E. (2012). Credit Spreads and Business Cycle Fluctuations. American Economic Review, 102(4), 1692-1720.

Giordani, P., and Söderlind, P. (2003). Inflation forecast uncertainty. European Economic Review, 47(6), 1037-1059.

Grishchenko, O., Mouabbi, S., and Renne, J. (2019). Measuring Inflation Anchoring and Uncertainty: A U.S. and Euro Area Comparison. Journal of Money, Credit and Banking, 51(5), 1053-1096. 
Gulen, H., and Ion, M. (2016). Policy uncertainty and corporate investment. Review of Financial Studies, 29(3), 523-564.

Guvenen, F., Ozkan, S., and Song, J. (2014). The Nature of Countercyclical Income Risk. Journal of Political Economy, 122(3), 621-660.

Hardouvelis, G. A., Karalas, G., Karanastasis, D., and Samartzis, P. (2018). Economic policy uncertainty, political uncertainty and the greek economic crisis. Political Uncertainty and the Greek Economic Crisis (April 3, 2018).

Hayashi, T., and Miao, J. (2011). Intertemporal substitution and recursive smooth ambiguity preferences. Theoretical Economics, 6(3), 423-472.

Hodrick, J., R., and Prescott, C., E. (1997). Postwar US business cycles: an empirical investigation. Journal of Money Credit and Banking, 29, 1-16.

Husted, L., Rogers, J. H., and Sun, B. (2020). Monetary policy uncertainty. Journal of Monetary Economics (forthcoming).

Husted, L. F., Rogers, J. H., and Sun, B. (2016). Measuring Cross Country Monetary Policy Uncertainty. IFDP Notes 2016-11-23, Board of Governors of the Federal Reserve System (U.S.).

Istrefi, K., and Mouabbi, S. (2018). Subjective interest rate uncertainty and the macroeconomy: Cross-country analysis. Journal of International Money and Finance, 88, $296-313$.

Izhakian, Y. (2017). Expected utility with uncertain probabilities theory. Journal of Mathematical Economics, 69(C), 91-103.

Jahan-Parvar, M. R., and Liu, H. (2014). Ambiguity Aversion and Asset Prices in Production Economies. Review of Financial Studies, 27(10), 3060-3097.

Jeong, D., Kim, H., and Park, J. Y. (2015). Does ambiguity matter? estimating asset pricing models with a multiple-priors recursive utility. Journal of Financial Economics, $115(2), 361$ - 382 . 
Jiang, G. J., and Tian, Y. S. (2005). The Model-Free Implied Volatility and Its Information Content. Review of Financial Studies, 18(4), 1305-1342.

Jo, S., and Sekkel, R. (2019). Macroeconomic Uncertainty Through the Lens of Professional Forecasters. Journal of Business 63 Economic Statistics, 37(3), 436-446.

Ju, N., and Miao, J. (2012). Ambiguity, learning, and asset returns. Econometrica, 80(2), $559-591$.

Jurado, K., Ludvigson, S. C., and Ng, S. (2015). Measuring uncertainty. American Economic Review, 105(3), 1177-1216.

Kalamara, E., Turrell, A., Redl, C., Kapetanios, G., and Kapadia, S. (2020). Making text count: economic forecasting using newspaper text. Bank of England working papers 865, Bank of England.

Keynes, J. M. (1936). The General Theory of Interest, Employment and Money. London: Macmillan.

Kilic, M., and Shaliastovich, I. (2019). Good and bad variance premia aned expected returns. Management Science, 65, 2445-2995.

Kim, T.-H., and White, H. (2004). On more robust estimation of skewness and kurtosis. Finance Research Letters, 1(1), 56-73.

Klibanoff, P., Marinacci, M., and Mukerji, S. (2005). A smooth model of decision making under ambiguity. Econometrica, 73(6), 1849-1892.

Klibanoff, P., Marinacci, M., and Mukerji, S. (2009). Recursive smooth ambiguity preferences. Journal of Economic Theory, 144(3), 930-976.

Knight, F. (1921). Risk Uncertainty and Profit. Houghton Mifflin.

Larsen, V. H. (2017). Components of Uncertainty. Working Papers No 4/2017, Centre for Applied Macro- and Petroleum economics (CAMP), BI Norwegian Business School. 
Londono, J. M. (2013). The Variance Risk Premium around the World. International Finance Discussion Papers 1035, Board of Governors of the Federal Reserve System (U.S.).

Londono, J. M., Ma, S., and Wilson, B. A. (2019). Quantifying the Impact of Foreign Economic Uncertainty on the U.S. Economy. FEDS Notes 2019-10-08, Board of Governors of the Federal Reserve System (U.S.).

Londono, J. M., and Wilson, B. A. (2018). Understanding global volatility. Ifdp notes, Board of Governors of the Federal Reserve System (U.S.).

Londono, J. M., and Xu, N. (2019). Variance risk premium components and international stock return predictability. International Finance Discussion Papers.

Londono, J. M., and Zhou, H. (2017). Variance risk premiums and the forward premium puzzle. Journal of Financial Economics, 124(2), 415-440.

Lopez-Salido, J., and Loria, F. (2019). Inflation at Risk. Tech. Rep. DP14074, Centre for Economic Policy Research.

Ludvigson, S. C., Ma, S., and Ng, S. (2019). Uncertainty and Business Cycles: Exogenous Impulse or Endogenous Response? American Economic Journal: Macroeconomics (forthcoming).

Luo, S., and Vallenas, D. V. (2017). The Skewness of the Price Change Distribution : A New Touchstone for Sticky Price Models. Finance and Economics Discussion Series 2017-028, Board of Governors of the Federal Reserve System (U.S.).

Maccheroni, F., Marinacci, M., and Ruffino, D. (2013). Alpha as ambiguity: Robust mean-variance portfolio analysis. Econometrica, 81(3), 1075-1113.

Manzo, G. (2013). Political Uncertainty, Credit Risk Premium and Default Risk. Working paper, University of Chicago Booth School of Business. 
Masayuki, M. (2016). Business Uncertainty and Investment: Evidence from Japanese companies. Discussion papers 16014, Research Institute of Economy, Trade and Industry (RIETI).

Miao, J., Wei, B., and Zhou, H. (2019). Ambiguity Aversion and the Variance Premium. Quarterly Journal of Finance (QJF), 9(02), 1-36.

Minsky, H. (1977). The financial instability hypothesis: An interpretation of Keynes and an alternative to "standard" theory. Nebraska Journal of Economics and Business, $16,5-16$.

Mumtaz, H., and Musso, A. (2019). The evolving impact of global, region-specific, and country-specific uncertainty. Journal of Business \& Economic Statistics, 0(0), 1-16.

Patton, A. J., and Sheppard, K. (2015). Good Volatility, Bad Volatility: Signed Jumps and The Persistence of Volatility. The Review of Economics and Statistics, 97(3), $683-697$.

Poon, S.-H., and Granger, C. W. (2003). Forecasting volatility in financial markets: A review. Journal of Economic Literature, 41(2), 478-539.

Pástor, L., and Veronesi, P. (2012). Uncertainty about Government Policy and Stock Prices. Journal of Finance, 67(4), 1219-1264.

Pástor, L., and Veronesi, P. (2013). Political uncertainty and risk premia. Journal of Financial Economics, 110(3), 520-545.

Redl, C. (2018). Uncertainty matters: evidence from close elections. Bank of England working papers 722, Bank of England.

Rogers, J. H., and Xu, J. (2019). How Well Does Economic Uncertainty Forecast Economic Activity? Finance and Economics Discussion Series 2019-085, Board of Governors of the Federal Reserve System (U.S.).

Rosenberg, J., and Engle, R. (2002). Empirical pricing kernels. Journal of Financial Economics, 64(3), 341-372. 
Rossi, B., and Sekhposyan, T. (2015). Macroeconomic Uncertainty Indices Based on Nowcast and Forecast Error Distributions. American Economic Review, 105(5), 650655.

Salgado, S., Guvenen, F., and Bloom, N. (2019). Skewed Business Cycles. NBER Working Papers 26565, National Bureau of Economic Research, Inc.

Scotti, C. (2016). Surprise and uncertainty indexes: Real-time aggregation of real-activity macro-surprises. Journal of Monetary Economics, 82(C), 1-19.

Shin, M., and Zhong, M. (2018). A new approach to identifying the real effects of uncertainty shocks. Journal of Business and Economic Statistics (forthcoming).

Swanson, E. T. (2006). Have increases in federal reserve transparency improved private sector interest rate forecasts? Journal of Money, Credit, and Banking, 38(3), 791-819.

Tillmann, P. (2020). Monetary policy uncertainty and the response of the yield curve to policy shocks. Journal of Money, Credit and Banking (forthcoming).

Whaley, R. E. (2000). The investor fear gauge. The Journal of Portfolio Management, $26(3), 12-17$.

Zhao, G. (2019). Ambiguity, nominal bond yields, and real bond yields. American Economic Review: Insights (forthcoming). 


\section{Appendix}

\section{Table A.1 Summary of Measures}

\begin{tabular}{|c|c|c|c|c|c|}
\hline Measure & Outcome & Type & Methodology & Source & Figures \\
\hline $\begin{array}{l}\text { Economic policy uncer- } \\
\text { tainty (EPU) }\end{array}$ & Economic policy & News-based & $\begin{array}{l}\text { Proportion of economic policy } \\
\text { words used in news coverage }\end{array}$ & Website & $\begin{array}{c}1,2 \text { and } \\
9\end{array}$ \\
\hline $\begin{array}{l}\text { Macroeconomic uncertainty } \\
(\mathrm{JLN})\end{array}$ & $\begin{array}{l}\text { Overall macroe- } \\
\text { conomic }\end{array}$ & Econometric & $\begin{array}{l}\text { Aggregate of the conditional } \\
\text { volatility of the unforecastable } \\
\text { component of a set of economic } \\
\text { variables }\end{array}$ & Website & 1 and 9 \\
\hline $\begin{array}{l}\text { Trade policy uncertainty } \\
(\mathrm{TPU})\end{array}$ & Trade policy & News-based & $\begin{array}{l}\text { Trade policy words used in news } \\
\text { coverage }\end{array}$ & Website & 1 and 4 \\
\hline $\begin{array}{l}\text { Monetary policy uncer- } \\
\text { tainty (MPU) }\end{array}$ & Monetary policy & News-based & $\begin{array}{l}\text { Monetary policy words used in } \\
\text { news coverage }\end{array}$ & Website & 3 \\
\hline World uncertainty (WUI) & $\begin{array}{l}\text { Overall macroe- } \\
\text { conomic }\end{array}$ & Report-based & $\begin{array}{l}\text { Frequency counts in the quar- } \\
\text { terly Economist Intelligence Unit } \\
\text { (EIU) country reports }\end{array}$ & Website & 5 \\
\hline Geopolitical risk (GPR) & $\begin{array}{l}\text { Geopolitical ten- } \\
\text { sions }\end{array}$ & News-based & $\begin{array}{l}\text { Geopolitical risk words used in } \\
\text { news coverage }\end{array}$ & Website & 6 \\
\hline $\begin{array}{l}\text { Scotti's macroeconomic un- } \\
\text { certainty }\end{array}$ & Real activity & Survey-based & $\begin{array}{l}\text { Weighted average of economic } \\
\text { data surprises }\end{array}$ & Website & 7 \\
\hline Inflation uncertainty & Inflation & Econometric & $\begin{array}{l}\text { Conditional variance of expected } \\
\text { inflation rate and term structure } \\
\text { of model-implied conditional vari- } \\
\text { ance up to } 10 \text { years }\end{array}$ & Website & 8 \\
\hline $\begin{array}{l}\text { Real time and ex-post } \\
\text { macro uncertainty }\end{array}$ & $\begin{array}{l}\text { Overall macroe- } \\
\text { conomic }\end{array}$ & Econometric & $\begin{array}{l}\text { Aggregate of the conditional } \\
\text { volatility of the unforecastable } \\
\text { component of a set of economic } \\
\text { variables }\end{array}$ & $\begin{array}{l}\text { Rogers } \\
\text { and Xu } \\
(2019)\end{array}$ & 10 \\
\hline $\begin{array}{l}\text { Foreign real economic un- } \\
\text { certainty }\end{array}$ & $\begin{array}{l}\text { Overall macroe- } \\
\text { conomic }\end{array}$ & Econometric & $\begin{array}{l}\text { Aggregate of the conditional } \\
\text { volatility of the unforecastable } \\
\text { component of a set of economic } \\
\text { variables }\end{array}$ & $\begin{array}{l}\text { Londono } \\
\text { et al. } \\
(2019)\end{array}$ & 11 \\
\hline $\begin{array}{l}\text { Macroeconomic and finan- } \\
\text { cial uncertainties }\end{array}$ & $\begin{array}{l}\text { Overall macroe- } \\
\text { conomic and fi- } \\
\text { nancial }\end{array}$ & Econometric & $\begin{array}{l}\text { Latent stochastic volatility fac- } \\
\text { tors of a set of economic variables }\end{array}$ & Website & 12 \\
\hline $\begin{array}{l}\text { Conditional quantiles - } \\
\text { GDP growth }\end{array}$ & Real activity & Econometric & $\begin{array}{l}\text { Conditional quantiles estimated } \\
\text { from quantile regressions }\end{array}$ & $\begin{array}{l}\text { Caldara } \\
\text { et al. } \\
(2020)\end{array}$ & 14 \\
\hline $\begin{array}{l}\text { Conditional quantiles - core } \\
\text { CPI }\end{array}$ & Inflation & Econometric & $\begin{array}{l}\text { Conditional quantiles estimated } \\
\text { from quantile regressions }\end{array}$ & $\begin{array}{l}\text { Lopez- } \\
\text { Salido } \\
\text { and } \\
\text { Loria } \\
(2019)\end{array}$ & 16 \\
\hline
\end{tabular}


Table A.1 Summary of Measures, Continued

\begin{tabular}{|c|c|c|c|c|c|}
\hline Measure & O Outcome & Type & Methodology & Source & Figures \\
\hline Realized volatility & Stocks & Asset markets & $\begin{array}{l}\text { Scaled sum of squared daily / in- } \\
\text { tradaily returns }\end{array}$ & $\begin{array}{l}\text { Federal } \\
\text { Reserve } \\
\text { Board's } \\
\text { staff } \\
\text { calcula- } \\
\text { tions }\end{array}$ & 17 \\
\hline Low volatility & Stocks & Asset markets & $\begin{array}{l}\text { Deviation of realized volatility } \\
\text { from historical trend }\end{array}$ & $\begin{array}{l}\text { Global } \\
\text { Finan- } \\
\text { cial } \\
\text { Data, } \\
\text { Inc., } \\
\text { GF- } \\
\text { Database }\end{array}$ & 19 \\
\hline Financial skewness & Stocks & Asset markets & $\begin{array}{l}\text { Cross-sectional skewness of stock } \\
\text { returns }\end{array}$ & $\begin{array}{l}\text { Ferreira } \\
(2018)\end{array}$ & 20 \\
\hline $\begin{array}{l}\text { Market-based monetary } \\
\text { policy uncertainty }\end{array}$ & Monetary policy & Derivatives & $\begin{array}{l}90 \% \text { confidence interval of the } \\
\text { market-implied distribution for } \\
\text { the effective federal funds rate }\end{array}$ & $\begin{array}{l}\text { Federal } \\
\text { Reserve } \\
\text { Board's } \\
\text { staff } \\
\text { calcula- } \\
\text { tions }\end{array}$ & 21 \\
\hline $\begin{array}{l}\text { Option-implied volatilities } \\
\text { for headline equity indexes } \\
\text { (VIX and others) }\end{array}$ & Stocks & Derivatives & $\begin{array}{l}\text { Weighted-average of the price of } \\
\text { put and calls }\end{array}$ & $\begin{array}{l}\text { CBOE, } \\
\text { FRED } \\
\text { and } \\
\text { Bloomberg }\end{array}$ & g \\
\hline $\begin{array}{l}\text { Variance risk premiums for } \\
\text { headline equity indexes }\end{array}$ & Stocks & Derivatives & 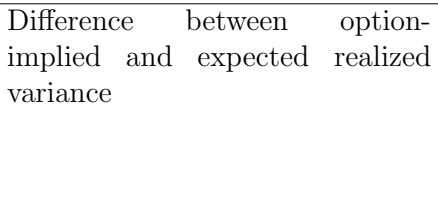 & $\begin{array}{l}\text { Federal } \\
\text { Reserve } \\
\text { Board's } \\
\text { staff } \\
\text { calcula- } \\
\text { tions }\end{array}$ & 23 \\
\hline $\begin{array}{l}\text { Skewness risk premium for } \\
\text { S\&P } 500 \text { returns }\end{array}$ & Stocks & Derivatives & 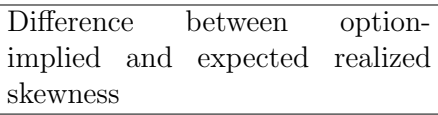 & $\begin{array}{l}\text { Feunou } \\
\text { et al. } \\
(2018)\end{array}$ & 24 \\
\hline $\begin{array}{l}\text { Option-implied probability } \\
\text { distribution for equity in- } \\
\text { dexes }\end{array}$ & Stocks & Derivatives & $\begin{array}{l}\text { Semiparametric method in Bree- } \\
\text { den and Litzenberger (1978) us- } \\
\text { ing equity options }\end{array}$ & $\begin{array}{l}\text { Federal } \\
\text { Reserve } \\
\text { Board's } \\
\text { staff } \\
\text { calcula- } \\
\text { tions }\end{array}$ & 25 \\
\hline $\begin{array}{l}\text { Implied volatilities for swap } \\
\text { rates }\end{array}$ & Interest rate & Derivatives & Swaption-implied volatilities & ICAP & $\begin{array}{l}26 \text { and } \\
27\end{array}$ \\
\hline Euro-USD risk reversals & Currencies & Derivatives & $\begin{array}{l}\text { Risk-neutral distribution calcu- } \\
\text { lated using currency options (and } \\
\text { currency option strategies) }\end{array}$ & Reuters & 28 \\
\hline $\begin{array}{l}\text { Option-implied } r \text { mea- } \\
\text { sures for WTI crude oil } \\
(\text { NYMEX) }\end{array}$ & Oil & Derivatives & $\begin{array}{l}\text { Semiparametric method in Bree- } \\
\text { den and Litzenberger (1978) us- } \\
\text { ing options on WTI futures with } \\
\text { different strikes and at different } \\
\text { maturities }\end{array}$ & $\begin{array}{l}\text { Federal } \\
\text { Reserve } \\
\text { Board's } \\
\text { staff } \\
\text { calcula- } \\
\text { tions }\end{array}$ & 29 \\
\hline Ambiguity index & Stocks & Asset markets & $\begin{array}{l}\text { Ambiguity measure of realized re- } \\
\text { turns across trading days for each } \\
\text { bin in the histogram of intraday } \\
\text { returns }\end{array}$ & $\begin{array}{l}\text { Brenner } \\
\text { and } \\
\text { Izhakian } \\
(2018)\end{array}$ & 31 \\
\hline
\end{tabular}

